\title{
QUANTIFYING MAMMALIAN INTERACTIONS AND DISTRIBUTIONS TO INFORM CONSERVATION PLANNING IN MOZAMBIQUE
}

\section{by}

Tara Easter

\author{
A thesis \\ submitted in partial fulfillment \\ of the requirements for the degree of \\ Master of Science in Biology \\ Boise State University
}

August 2018 
(C) 2018

Tara Easter

ALL RIGHTS RESERVED 


\title{
BOISE STATE UNIVERSITY GRADUATE COLLEGE
}

\section{DEFENSE COMMITTEE AND FINAL READING APPROVALS}

\author{
of the thesis submitted by
}

\section{Tara Easter}

Thesis Title: Quantifying Mammalian Interactions and Distributions to Inform Conservation Planning in Mozambique

Date of Final Oral Examination: $\quad 23$ May 2018

The following individuals read and discussed the thesis submitted by student Tara Easter, and they evaluated her presentation and response to questions during the final oral examination. They found that the student passed the final oral examination.

Neil Carter, Ph.D.

Amy C. Ulappa, Ph.D.

Jesse R. Barber, Ph.D.
Chair, Supervisory Committee

Member, Supervisory Committee

Member, Supervisory Committee

The final reading approval of the thesis was granted by Neil Carter, Ph.D., Chair of the Supervisory Committee. The thesis was approved by the Graduate College. 


\section{DEDICATION}

To my mom, Cyntha Ruth Crowe Easter. 


\section{ACKNOWLEDGMENTS}

I would first like to acknowledge the team of people in Mozambique who made this research possible: my technicians, Nelson Marrula and Joaquim Campira, my scouts, Domingos and Antonio, and the forestry concession's head scout, Elidio, and manager, Nils Von Sydow. I also want to thank Paola Bouley, Paulo Tonecas, Tonga Torcida and Dr. Marc Stalmans from the Gorongosa Lion Project and Gorongosa National Park for their ideas, assistance, and data collection toward the end of the season. I also want to thank several other national park staff for helping me with safety and logistics: Mike and Anne Marchington, Dr. Rui Branco, and my fellow Boise State researcher, Teague Scott, who was always monitoring our truck's maintenance and repairs. I also want to thank Greg Carr, founder of the Gorongosa Restoration Project for making all of this possible.

This research would not have been possible without the generous support provided by Boise State's Office of Research and the National Science Foundation's Graduate Research Fellowship. I also want to thank the Howard Hughes Medical Institute for providing the cameras used in this research.

I would also like to thank my committee, Dr. Amy Ulappa and Dr. Jesse Barber, and my advisor, Dr. Neil Carter, for their ideas, suggestions, and edits to this thesis. I especially want to thank Neil for his mentorship throughout this whole process, his patience as I struggled with my analyses, and his infectious enthusiasm for science and conservation. I also want to thank everyone in the Human-Environment Systems program for their research ideas, help with analyses, friendship and general support. Finally, I 
would not have been able to do this without the support and encouragement of my partner Jason, my family, and my friends. 


\begin{abstract}
Protected areas are a staple in conservation, but human activities outside of protected areas drive species interactions, compositions, and distributions. Research is especially needed in these multi-use landscapes to maintain habitat connectivity for entire wildlife communities between protected areas. Yet, such research is lacking in areas it is needed most, such as in sub-Saharan Africa, where human populations are expected to double by 2050 . My objectives were to quantify mammal distributions, interactions, community compositions, and their relationships with human and natural factors within a sustainable-use forestry concession outside of Gorongosa National Park. I used recently developed multispecies occupancy models to analyze presence/absence data from 75 motion-detecting camera traps.
\end{abstract}

First, I wanted to know if small, sympatric carnivores avoided each other in time or space in a human-modified landscape with few apex predators. I examined activity patterns, habitat preferences, tolerance to people and potential for intraguild competition among three common, but understudied African carnivores: African civets (Civettictis civetta), bushy-tailed mongoose (Bdeogale crassicauda), and large-spotted genets (Genetta maculata). I hypothesized that all three species would overlap in time, but in space, genets and mongoose would both avoid civets due to being smaller; and genets and mongoose, being roughly the same size, would not affect each other. I used the time stamps from each species' detections and found that these three species exhibited strong temporal overlap. I then used N-mixture models in a Bayesian framework to measure 
these species' spatial relationships. I found that civets and mongoose avoid each other, indicated by the strong negative relationship between their predicted abundances at each camera trap site. In contrast, genets and mongoose exhibited a positive relationship, and there was no significant relationship between genets and civets. Civets and mongoose may be further limited in space through the avoidance of human settlements if they are also competing with each other, while genets were unaffected by human presence. Such interspecific interactions are important to consider for multispecies conservation planning in multi-use landscapes, as these relationships may change as human populations grow.

Second, I investigated how natural and anthropogenic factors influence animal space use and richness in a multi-use area. We used hierarchical, multispecies models to quantify species and species groups, and community level spatial relationships with human and environmental variables for 30 detected mammals. We modelled species occupancies when separated into two different groups: 1) taxonomic/functional groups consisting of carnivores, ungulates, primates, other foragers, and insectivores, and 2) body size groups, consisting of small species $(<20 \mathrm{~kg})$ to extra-large species $(>200 \mathrm{~kg})$. We also quantified occupancy probabilities and richness for the entire community to determine where species richness was greatest and inform biodiversity conservation efforts. We predicted that carnivores and large mammals would be the most sensitive to anthropogenic features. In partial support of this hypothesis, increasing distance from settlements positively affected the occupancies of carnivores, as well as primates and other foragers, and large mammals, as well as all three of the other body size groups. However, active roads and human activity rates did not have a statistically significant relationship with any species' occupancies or detection rates, respectively. Overall, 
mammalian richness was highest far from human settlements in the concession and close to rivers. Our results have important implications for connectivity planning for multispecies conservation outside of Gorongosa National Park, and provide a starting point for prioritizing these efforts. 


\section{TABLE OF CONTENTS}

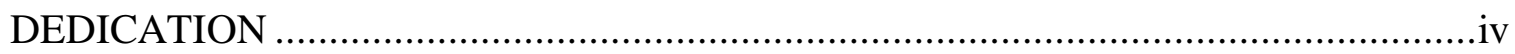

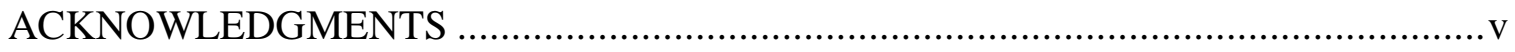

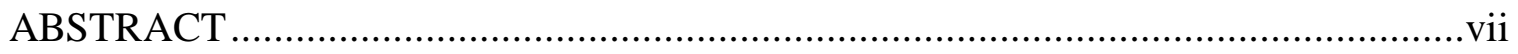

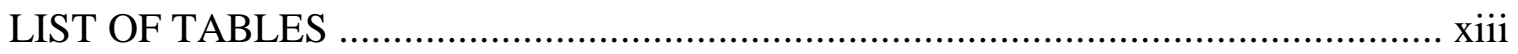

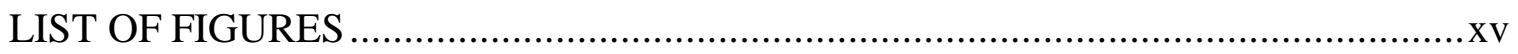

GENERAL INTRODUCTION ..........................................................................

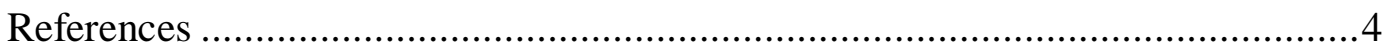

CHAPTER ONE: EVIDENCE FOR COMPETITION AND RESOURCE

PARTITIONING AMONG AFRICA'S INCONSPICUOUS CARNIVORES...................8

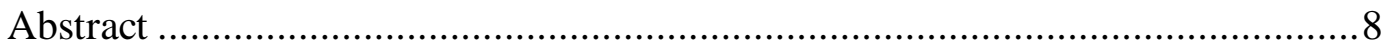

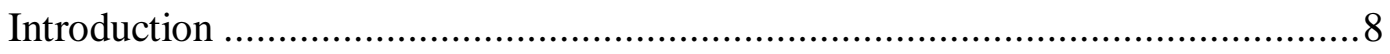

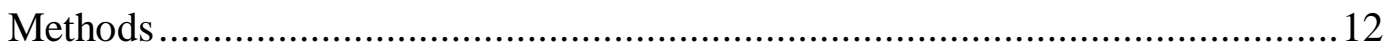

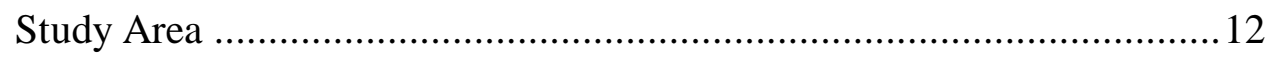

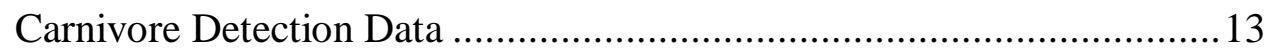

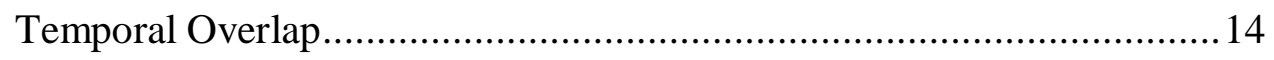

Co-Abundance

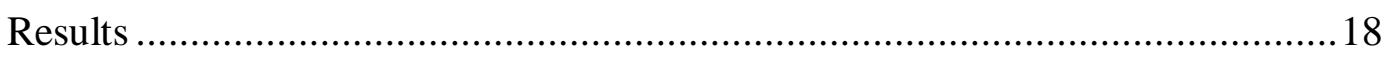

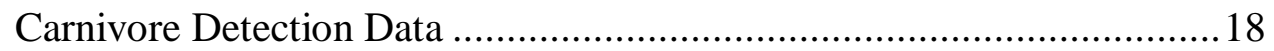




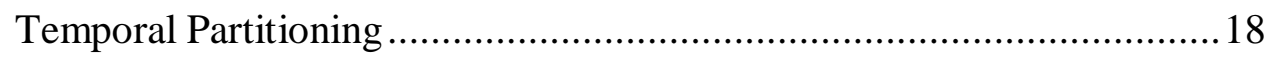

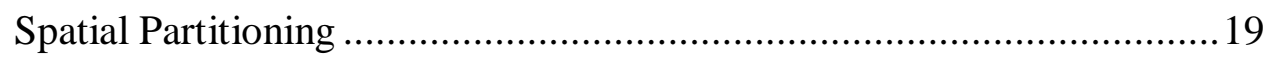

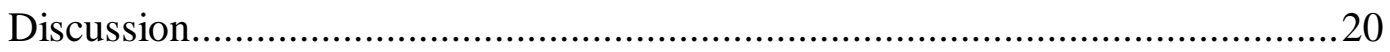

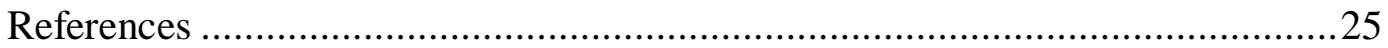

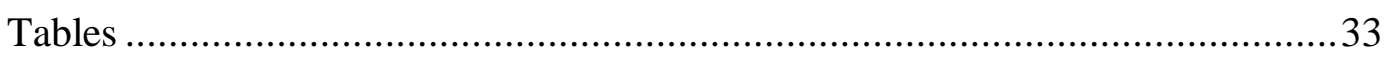

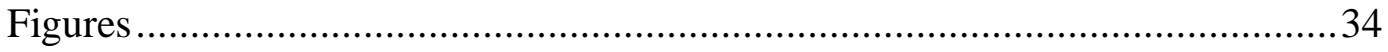

CHAPTER TWO: SPATIAL PREDICTION OF MAMMAL RICHNESS OUTSIDE MOZAMBIQUE'S GORONGOSA NATIONAL PARK FOR LANDSCAPE

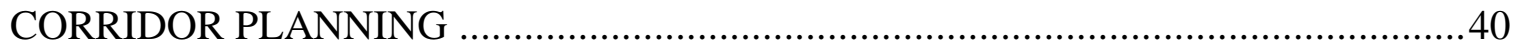

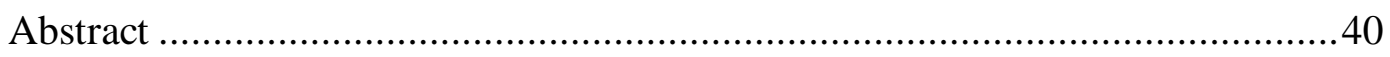

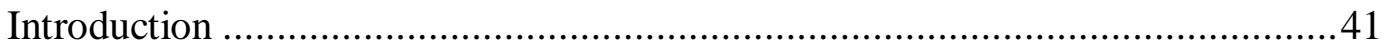

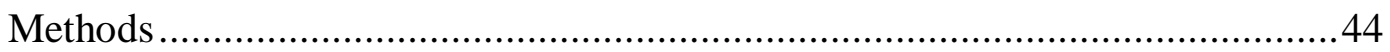

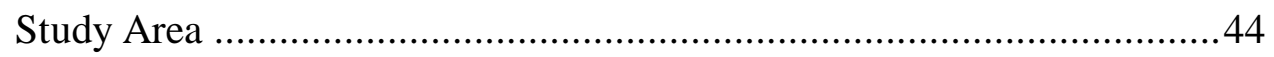

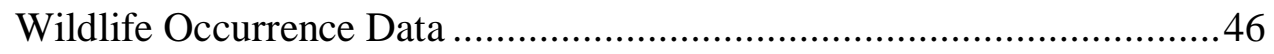

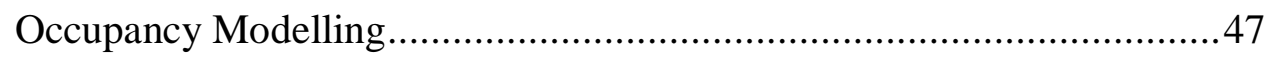

Predictors of Animal Occupancy ………...............................................48

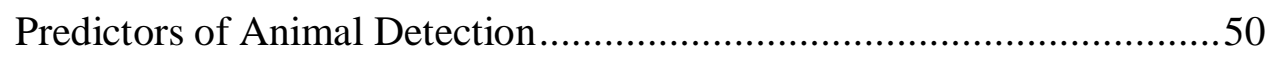

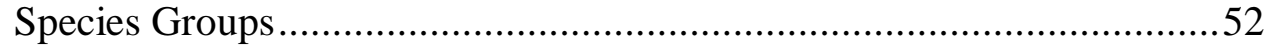

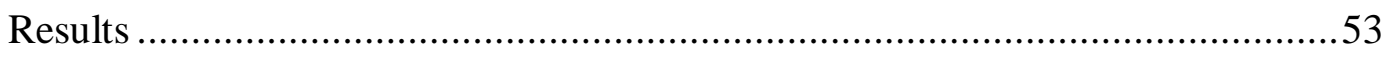

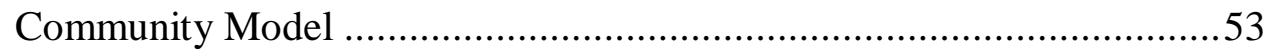

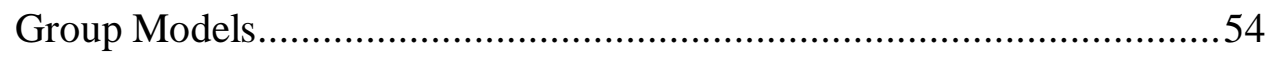

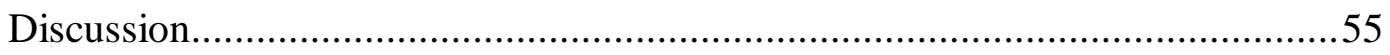

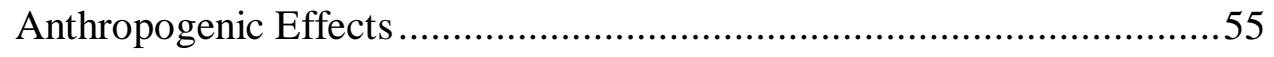

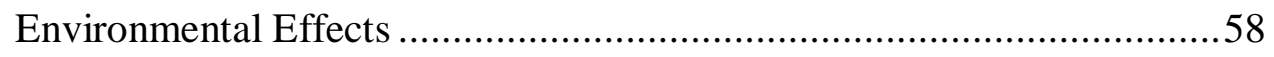


Conclusion ...............................................................................6 60

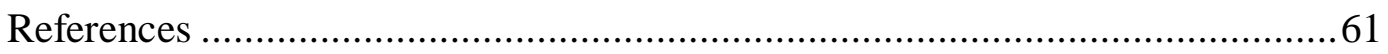

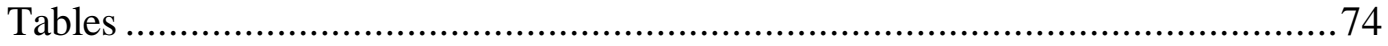

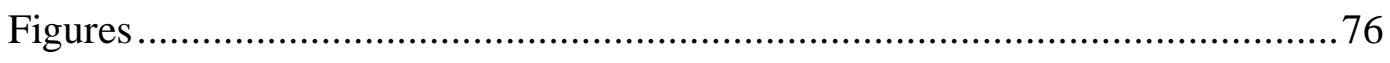

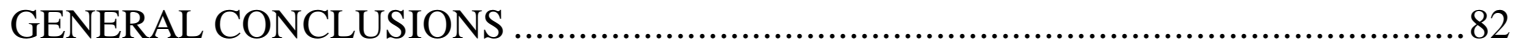

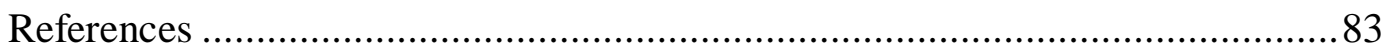

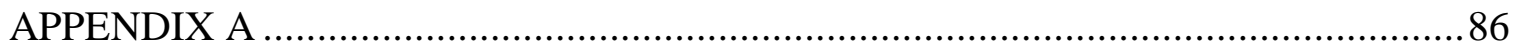

Species information and species-specific model outputs from the community

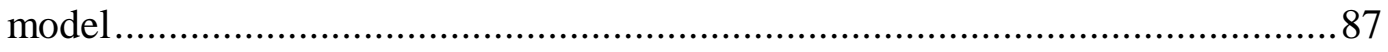

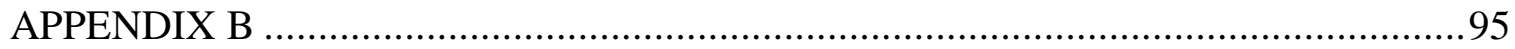

Further explanation of the use of NDVI for land cover and habitat types ...........96 


\section{LIST OF TABLES}

Table 1.1 Ecological characteristics of our three study species. All species are nocturnal and opportunistic generalists. These species consume small vertebrates, invertebrates, fruits, and plants.

Table 1.2 Total number of detections, naïve occupancy (raw number of traps where animal was detected), and naïve co-occurrence (raw number of traps where both species in a pair were detected).

Table 1.3 Mean parameter estimates for each species pair. Asterisks indicate $95 \%$ credibility intervals that do not overlap zero. Bold terms indicate a significant difference in the estimated coefficients between species in a pair.

Table 2.1 Factors predicted to influence community richness, species space use, and species detection.

Table 2.2 Mean parameter estimates of occupancy and detection covariates of the full community model. Probability estimates denote the likelihood that the covariate has a positive or negative effect on species occurrence or detection, calculated by summing the number of draws with a positive or negative estimate, dividing by the total number of draws and multiplying by 100 .

Table 2.3 Group mean coefficient estimates. Standard deviations are in parentheses and bold terms indicate $95 \%$ credibility intervals that did not overlap zero.

Table A.1 Mammals detected on cameras in a sustainable forestry concession outside of Gorongosa National Park.

Table A.2 Mean detection probabilities and coefficient estimates for each species. Standard deviations are in parentheses. Coefficient estimates are on the logit-scale, and estimates in bold indicate $95 \%$ credibility intervals that do

not overlap zero. .88

Table A.3 Mean occupancy probabilities and coefficient estimates for each species. Standard deviations are in parentheses. Coefficient estimates are on the 
logit-scale, and estimates in bold indicate $95 \%$ credibility intervals that do

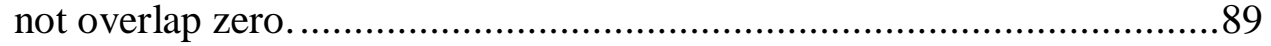




\section{LIST OF FIGURES}

Figure 1.1 Map of our study site within a sustainable forestry concession adjacent to Gorongosa National Park and its buffer zone in central Mozambique.......34

Figure 1.2 Average detection frequency across sites per 100 trap days for each carnivore species detected. The red box highlights the three study species, and the number of detections for each of these three species is displayed on top of the bars.

Figure 1.3 Overlap of daily activity patterns for (A) civet and mongoose across all sites, (AA) civet and mongoose where both were detected, (B) civet and genet across all sites, (BB) civet and genet where both were detected, (C) genet and mongoose across all sites, and (CC) genet and mongoose where both were detected. The estimate of overlap ( $\Delta$, with 0 indicating no overlap and 1 indicating complete overlap) is indicated by the grey area. Grey and black ticks indicate the raw time stamps used to create the density curves, and $95 \%$ confidence intervals are given in parentheses. ...36

Figure 1.4 Estimated correlations between civet and genet abundances for each iteration, represented by the black lines. The red line indicates the mean estimate (-0.08 on the logit scale).

Figure 1.5 Mean coefficient estimates and 95\% credibility bars of each covariate for each species. The coefficient estimates for distance from settlements for civets were significantly higher than the estimates for genets, as indicated by the black box.

Figure 1.6 Estimated correlations between civet and mongoose abundances for each iteration. The red line indicates the mean estimate $(-0.26$ on the logit scale).

Figure 1.7 Mean coefficient estimates and 95\% credibility bars of each covariate for each species. The coefficient estimates for NDVI for mongoose were significantly higher than the estimates for civets, as indicated by the black box. Both species occurred more often farther away from settlements. ...38

Figure 1.8 Estimated correlations between civet and genet abundances for each iteration. The red line indicates the mean estimate ( 0.25 on the logit scale). 
Figure 1.9 Mean coefficient estimates and 95\% credibility bars of each covariate for each species. Genets and mongoose did not have any statistically significant differences in their relationships to these covariates.

Figure 2.1 Map of our study site in a sustainable use forestry concession in central Mozambique, adjacent to Gorongosa National Park and its buffer zone. .76

Figure 2.2 Average detection frequency per 100 trap days for 30 detected mammal species across all traps

Figure 2.3 Mean site-specific estimates of species richness in relation to each trap's (a) distance to the nearest settlement, (b) distance to the nearest river, (c) average NDVI within a 500m radius around each trap, and (d) distance to the nearest active roads.

Figure 2.4 Inverse-distance weighted interpolation of model-predicted richness at each site from the full community model. Richness estimates ranged from three to 17 species at each trap. We set the boundaries of the interpolation at $1.5 \mathrm{~km}$ because that was the average distance between all traps.

Figure 2.5 Posterior distributions of the occupancy model coefficient estimates for each taxonomic or functional group. Vertical bars mark estimates of zero.

Figure 2.6 Posterior distributions of the occupancy model coefficient estimates for each body size group. 81

Figure A.1 Mean species-specific coefficient estimates for distance to settlement with $95 \%$ credibility bars. 90

Figure A.2 Mean species-specific coefficient estimates for distance to rivers with $95 \%$ credibility bars.

Figure A.3 Mean species-specific coefficient estimates for NDVI with $95 \%$ credibility bars.

Figure A.4 Mean species-specific coefficient estimates for distance to active roads with $95 \%$ credibility bars.

Figure A.5 Kernel density estimates for snares seized $(n=468)$ by concession rangers in 2016. Snares included wire, rope, and gin traps. Patrols were nonsystematic. .94

Figure B.1 Satellite image (left) and NDVI raster (right) of our study site. .96 
Figure B.2 NDVI values significantly differed between land cover categories $\left(\mathrm{F}_{2,72}=\right.$

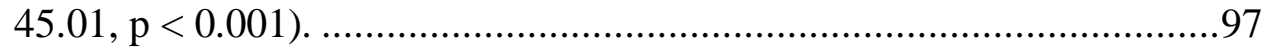




\section{GENERAL INTRODUCTION}

The 7 billion people and counting on this planet have had profound effects on the natural world, driving rapid land use change, causing species extinctions, and altering environmental processes (Dobson et al. 2006; Prugh et al. 2009; Estes et al. 2011; Dirzo et al. 2014; Ceballos et al. 2017). Scientists now understand that these impacts extend far beyond urban and agricultural areas, and even protected areas are vulnerable to the cascading effects of human presence and land use (Hansen \& DeFries 2007; Lindsey et al. 2017). In this human-dominated era, where human and environmental systems are intricately intertwined, holistic conservation strategies and research is needed to preserve ecosystem function and services (Dirzo et al. 2014; O’Bryan et al. 2018). Examples of this include maintaining habitat connectivity between protected areas (Belote et al. 2016; Brodie et al. 2016; Pitman et al. 2016; Saura et al. 2018), and establishing management strategies that benefit multiple species (Zipkin et al. 2010; White et al. 2013; Tobler et al. 2015; Rich et al. 2016).

Gorongosa National Park in central Mozambique is a recently re-established protected area in a biologically rich landscape that was devastated by Mozambique's civil war that ended in 1992. Now, park managers are working to not only restore wildlife populations to pre-war levels within the park, but also to connect viable habitats in both multi-use and protected areas throughout the Greater Gorongosa landscape to maintain this region's rich biodiversity. To do this, however, managers need information on how anthropogenic and natural factors affect species interactions, community distributions and 
composition in multi-use landscapes. I conducted research in a sustainable-use forestry concession adjacent to Gorongosa National Park and its buffer zone. This concession is one of the first areas that Gorongosa managers began working in to conserve wildlife, hoping to connect large landscapes for biodiversity while considering the economic needs of local communities.

Species interactions drive community assemblage patterns, trophic cascades, and niche partitioning and are therefore essential to understand for conservation planning (Maddock \& Perrin 1993; Linnell \& Strand 2000; Schuette et al. 2013; Suraci et al. 2016; de Satgé et al. 2017; Ramesh et al. 2017; Rich et al. 2017). This is especially true for multi-use landscapes, where human presence and activities may themselves affect these patterns (Kiffner et al. 2015; Rota et al. 2016; Moll et al. 2018). My first chapter examines how small, sympatric carnivores interact with each other in time and space. I focused on small carnivores because they are diverse and relatively abundant worldwide but incredibly understudied in Africa, where most carnivore studies focus on the ecologies and interactions of large and medium-sized species (Creel \& Creel 1996; de Satgé et al. 2017; Ramesh et al. 2017; Rich et al. 2017). However, given how ubiquitous small carnivores are, they likely play important roles in ecosystem functioning that we know little about.

Conservationists often have limited resources and need to prioritize efforts to maximize the preservation of entire wildlife communities (Brodie et al. 2014; Rich et al. 2016). My second chapter examines how natural and anthropogenic factors influence animal space-use and richness in this multi-use area. The community-level approach I utilized allows us to infer patterns in space use and movement for even rarely detected 
species of conservation concern, such as threatened large carnivores (White et al. 2013; Tobler et al. 2018). For both chapters, I used presence/absence data for species detected on motion-detecting field cameras (referred to as camera traps) that my partners at the Gorongosa Lion Project, a team of trained technicians, and I deployed over Mozambique's dry season in 2017. Camera traps have become one of the most efficient ways to study elusive wildlife, and occupancy analyses used for camera data are continuously evolving to answer new ecological and applied-conservation research questions (Ahumada et al. 2011, 2013; Carter et al. 2015; Rich et al. 2016).

For the first chapter, I chose three common, but understudied species as a case study for small carnivore spatiotemporal interactions: large-spotted genets (Genetta maculata), African civets (Civettictis civetta), and bushy-tailed mongoose (Bdeogale crassicauda). Based on daily activity times, we found no evidence for temporal partitioning among these three nocturnal carnivores. Spatially, the three species exhibited significant differences in habitat preferences and anthropogenic tolerance, but only the detection frequencies of bushy-tailed mongoose and African civets were negatively related, indicating spatial niche partitioning between these two species. Both of these species also had a negative relationship with settlement proximity, whereas genet site use was unaffected by civet site use, positively related to mongoose site use, and unaffected by human settlements or activity. Because these species typically dominate multi-use landscapes where larger predators are rare, interactions between them, and the effects of human presence and activity could have large consequences for ecosystem services and biodiversity conservation. 
In the second chapter, I quantified the effects of natural and anthropogenic factors on the distributions and space use of all 30 mammals that we detected at the individual, group, and community levels. Because certain species may be more sensitive to human activities or dependent on environmental features (Cardillo et al. 2005; Kleynhans et al. 2011; Ripple et al. 2014; Rich et al. 2016), we also examined the effects of these variables for different groups of species according to body size (small, medium, large, or extra-large) or their taxonomic and functional groups (carnivore, ungulate, primate, insectivore, other forager). Overall, mammalian richness was highest far from human settlements and close to rivers within the study site. Distance to settlements also significantly affected the space use and local richness of carnivores, insectivores, and other foragers, as well as all four body size groups. Results from this study provide a starting point for connectivity planning for this concession and surrounding protected areas, and indicate a need to understand what about settlement proximity negatively affects species occupancies.

\section{References}

Ahumada JA et al. 2011. Community structure and diversity of tropical forest mammals: data from a global camera trap network. Philosophical Transactions of the Royal Society B: Biological Sciences 366:2703-2711.

Ahumada JA, Hurtado J, Lizcano D. 2013. Monitoring the Status and Trends of Tropical Forest Terrestrial Vertebrate Communities from Camera Trap Data: A Tool for Conservation. PLoS ONE 8:6-9.

Belote TR, Dietz MS, McRae BH, Theobald DM, McClure ML, Hugh Irwin G, McKinley PS, Gage JA, Aplet GH. 2016. Identifying corridors among large protected areas in the United States. PLoS ONE 11:1-16. 
Brodie JF, Giordano AJ, Dickson B, Hebblewhite M, Bernard H, Mohd-azlan J, Anderson J. 2014. Evaluating Multispecies Landscape Connectivity in a Threatened Tropical Mammal Community 0:1-11.

Brodie JF, Paxton M, Nagulendran K, Balamurugan G, Clements GR, Reynolds G, Jain A, Hon J. 2016. Connecting science, policy, and implementation for landscapescale habitat connectivity. Conservation Biology 30:950-961.

Cardillo M, Cardillo M, Mace GM, Jones KE, Bielby J, Bininda-Emonds ORP, Sechrest W, Orme CDL, Purvis A. 2005. Multiple Causes of High Extinction Risk in Large Mammal Species. Science 309:1239-1241.

Carter N, Jasny M, Gurung B, Liu J. 2015. Impacts of people and tigers on leopard spatiotemporal activity patterns in a global biodiversity hotspot. Global Ecology and Conservation 3:149-162.

Ceballos G, Ehrlich PR, Dirzo R. 2017. Biological annihilation via the ongoing sixth mass extinction signaled by vertebrate population losses and declines.

Proceedings of the National Academy of Sciences:201704949.

Creel S, Creel NM. 1996. Limitation of African Wild Dogs by Competition with Larger Carnivores. Conservation Biology 10:526-538.

de Satgé J, Teichman K, Cristescu B. 2017. Competition and coexistence in a small carnivore guild. Oecologia 184:873-884.

Dirzo R, Young HS, Galetti M, Ceballos G, Isaac NJB, Collen B. 2014. Defaunation in the Anthropocene. Science (New York, N.Y.) 345:401-6.

Dobson A et al. 2006. Habitat loss, trophic collapse, and the decline of ecosystem services. Ecology 87:1915-1924.

Estes JA et al. 2011. Trophic downgrading of planet Earth. Science (New York, N.Y.) 333:301-306.

Hansen AJ, DeFries R. 2007. Ecological mechanisms linking protected areas to surrounding lands. Ecological Applications 17:974-988. 
Kleynhans EJ, Jolles AE, Bos MRE, Olff H. 2011. Resource partitioning along multiple niche dimensions in differently sized African savanna grazers. Oikos 120:591600.

Lindsey PA et al. 2017. The performance of African protected areas for lions and their prey. Biological Conservation 209:137-149.

Linnell JDC, Strand O. 2000. Interference interactions, co-existence and conservation of mammalian carnivores. Biodiversity Research 6:169-176.

Maddock AH, Perrin MR. 1993. Spatial and temporal ecology of an assemblage of viverrids in Natal, South Africa. Journal of Zoology 229:277-287.

O’Bryan CJ, Braczkowski AR, Beyer HL, Carter NH, Watson JEM, McDonald-Madden E. 2018. The contribution of predators and scavengers to human well-being. Nature Ecology \& Evolution 2:229-236.

Pitman RT et al. 2016. Cats, connectivity and conservation: incorporating datasets and integrating scales for wildlife management. Journal of Applied Ecology.

Prugh LR, Stoner CJ, Epps CW, Bean WT, Ripple WJ. 2009. The Rise of the Mesopredator 59:779-791.

Ramesh T, Kalle R, Downs CT. 2017. Staying safe from top predators: patterns of cooccurrence and inter-predator interactions. Behavioral Ecology and Sociobiology 71.

Rich LN, Miller DAW, Robinson HS, McNutt JW, Kelly MJ. 2016. Using camera trapping and hierarchical occupancy modelling to evaluate the spatial ecology of an African mammal community. Journal of Applied Ecology 53:1225-1235.

Rich LN, Miller DAW, Robinson HS, McNutt JW, Kelly MJ. 2017. Carnivore distributions in Botswana are shaped by resource availability and intraguild species. Journal of Zoology 303:90-98.

Ripple WJ et al. 2014. Status and ecological effects of the world's largest carnivores. Science 343: 1241484 . 
Saura S, Bertzky B, Bastin L, Battistella L, Mandrici A, Dubois G. 2018. Protected area connectivity: Shortfalls in global targets and country-level priorities. Biological Conservation 219:53-67.

Schuette P, Wagner AP, Wagner ME, Creel S. 2013. Occupancy patterns and niche partitioning within a diverse carnivore community exposed to anthropogenic pressures. Biological Conservation 158:301-312.

Suraci JP, Clinchy M, Dill LM, Roberts D, Zanette LY. 2016. Fear of large carnivores causes a trophic cascade. Nature Communications 7:10698.

Tobler MW, Garcia Anleu R, Carrillo-Percastegui SE, Ponce Santizo G, Polisar J, Zuñiga Hartley A, Goldstein I. 2018. Do responsibly managed logging concessions adequately protect jaguars and other large and medium-sized mammals? Two case studies from Guatemala and Peru. Biological Conservation 220:245-253.

Tobler MW, Zúñiga Hartley A, Carrillo-Percastegui SE, Powell GVN. 2015. Spatiotemporal hierarchical modelling of species richness and occupancy using camera trap data. Journal of Applied Ecology 52:413-421.

White AM, Zipkin EF, Manley PN, Schlesinger MD. 2013. Conservation of Avian Diversity in the Sierra Nevada: Moving beyond a Single-Species Management Focus. PLoS ONE 8:e63088.

Zipkin EF, Andrew Royle J, Dawson DK, Bates S. 2010. Multi-species occurrence models to evaluate the effects of conservation and management actions. Biological Conservation 143:479-484. 


\title{
CHAPTER ONE: EVIDENCE FOR COMPETITION AND RESOURCE PARTITIONING AMONG AFRICA'S INCONSPICUOUS CARNIVORES
}

\begin{abstract}
Small carnivores constitute a diverse and often abundant group of species, capable of providing ecosystem services and structuring ecosystems. Yet we know very little about their interactions with each other, especially in human-altered landscapes. We used camera trap data to examine the spatiotemporal relationships and potential for intraguild competition among three common, but understudied African carnivores: African civets (Civettictis civetta), bushy-tailed mongoose (Bdeogale crassicauda), and large-spotted genets (Genetta maculata). After accounting for habitat preferences and tolerance to anthropogenic factors, we found that civets and mongoose avoid each other, indicated by the strong negative relationship between their predicted number of visits at each trap site. In contrast, genets exhibited a positive relationship with mongoose, and no significant relationship with civets. Such interspecific interactions are important to consider for multi-species conservation planning in multi-use landscapes, as these relationships may change as human populations grow.
\end{abstract}

\section{Introduction}

Despite their relative abundance worldwide, small carnivores constitute a group of species for which we have little information about intraguild interactions. For example, African civets (Civettictis civetta) and large-spotted genets (Genetta maculata) are some of the most abundant and widespread carnivores in Africa, and also are among the most 
understudied (Admasu et al. 2004; Ramesh \& Downs 2014). This lack of attention on small carnivores is perhaps due to their nocturnal, elusive behaviors making them difficult to detect in surveys (de Satgé et al. 2017). However, through diverse dietary and habitat preferences, small carnivores potentially provide several ecosystem services, ranging from pest control to seed dispersal (Roemer et al. 2009; Nakashima et al. 2010; Caughlin et al. 2014; Williams et al. 2017). Furthermore, as human populations grow, driving land use changes and declines of apex predator populations (Ripple et al. 2014), small carnivores are occupying higher trophic levels than in the past, likely resulting in having a larger influence on ecosystem dynamics (i.e., mesocarnivore release, Crooks \& Soulé 1999; Ritchie \& Johnson 2009).

Interspecific interactions among carnivores can alter trophic cascades and shape community dynamics. For example, in North America, coyotes (Canis latrans) suppress bobcat (Felis rufus), gray foxes (Urocyon cinereoargenteus), and red foxes (Vulpes vulpes), but gray wolves (Canis lupus) may indirectly benefit these species by suppressing coyotes (Fedriani et al. 2000; Levi \& Wilmers 2012). Such interactions among large and medium-sized African carnivores have also been documented (de Satgé et al. 2017; Ramesh et al. 2017; Rich et al. 2017). For example, Creel \& Creel (1996) found that lions (Panthera leo) suppress hyenas (Crocuta crocuta), indirectly benefitting wild dogs (Lycaon pictus). Although a few studies have investigated interactions among small carnivores in Africa, researchers know very little about this diverse guild of species (Waser 1980; Do Linh San et al. 2013). Waser (1980) documented broad overlap in dietary and habitat preferences among small, nocturnal carnivores in Serengeti National Park, Tanzania, and observed little evidence of competition through territoriality or 
aggression. The author noted that food availability may not be a limiting resource there, and that species that do not avoid each other in space might suppress each other's abundances. In contrast, Maddock and Perrin (1993) observed spatial and temporal segregation among small carnivores in a reserve in South Africa and suggested intraguild competition as a reason for spatial separation even with abundant resources.

Unlike the protected areas where these studies occurred, however, species in multi-use areas must also navigate human-altered landscapes, where people have had profound impacts on entire animal communities through the exploitation of species, altering landscapes of fear, changing the physical environment, and fundamentally changing how species interact with each other (Ellis 2011; Oriol-Cotterill et al. 2015; Moll et al. 2018). For example, in multi-use landscapes, sympatric species that avoid people may have fewer opportunities to partition in time and space from each other (Kiffner et al. 2015; Rota et al. 2016; Moll et al. 2018). Alternatively, species more tolerant of anthropogenic landscapes and activity may use these areas as refuges from competitors (i.e., the "human shield" hypothesis, Berger 2007). Therefore, predictions on how small carnivores will interact, and the implications on those interactions on ecosystem services, may not play out as expected in human-modified landscapes. Understanding these interactions in multi-use landscapes is increasingly important as human land-uses prevail worldwide and human activities occur throughout much of the world (Dirzo et al. 2014). Yet, few studies have examined competitive dynamics between small carnivores in anthropogenic landscapes. To help fill this knowledge gap, we used camera trap data to investigate the potential for competitive interactions between small 
carnivores in space and time in a multi-use landscape in the Greater Gorongosa ecosystem of central Mozambique.

Gorongosa's wildlife populations have been recovering after a long civil war (Daskin et al. 2016). Large carnivore populations remain diminished (Pringle 2017), and smaller carnivores face relatively few top-down pressures aside from potentially competing among each other. This creates an interesting case study on how small carnivores interact with each other in human-modified landscapes, testing theories about interspecific competition among species with shared ranges, habitats, diets, and body sizes (Maddock \& Perrin 1993; de Satgé et al. 2017). For example, the avoidance of human activity during the day could facilitate more interactions or drive spatial partitioning among competing predators at night (Carter et al. 2015). We investigated the potential for competitive interactions among three common but understudied species: African civets, large-spotted genets, and bushy-tailed mongoose (Bdeogale crassicauda; Table 1.1). We explored two hypotheses. First, we predicted that if these nocturnal species do not avoid each other in time, species will segregate based on habitat preferences. For example, several studies have shown that genets often occupy areas closer to people, which other carnivores avoid (Fuller et al. 1990; Pettorelli et al. 2010; Schuette et al. 2013; Ramesh \& Downs 2014), and bushy-tailed mongoose prefer forested areas (Caro et al. 2003; Pettorelli et al. 2010). Second, body size often drives dominant and subordinate interactions among species, with larger species able to outcompete or directly harm smaller species (Palomares \& Caro 1999; Donadio \& Buskirk 2006). We therefore predicted that mongoose and genets will avoid civets in space or time, given that civets are larger in size and could outcompete smaller species for resources. Species 
interactions drive community structure, abundance, and distributions, and may have important cascading effects on ecosystem services and function (Crooks \& Soulé 1999; Schuette et al. 2013; Williams et al. 2017). Understanding intraguild interactions among species in varying environmental conditions (e.g., high to low competition risk from large carnivores, varying degrees of anthropogenic disturbance) is important if we are to conserve habitats that support diverse wildlife communities amid a burgeoning human population (Cardillo et al. 2005; Pettorelli et al. 2010).

\section{Methods}

Study Area

Our study site is situated in central Mozambique, east of Gorongosa National Park's buffer zone. This area has a sub-tropical climate with a wet season from October to March and dry season April to September. We conducted our surveys in a sustainablecertified forestry concession $\left(460 \mathrm{~km}^{2}\right.$, Figure 1.1$)$ comprised mostly of miombo woodlands (Brachystegia spp.) with a range of tree cover from patches of dry miombo woodlands and open grasslands to moist, closed-canopy riverine forests (Stalmans \& Beilfuss 2008). Elevation decreases gradually from approximately 350 to $150 \mathrm{~m}$ from the Cheringoma Plateau in the west to the confluence of the Chiteme and Chimiziua Rivers to the east. There are two settlements within the concession: Condue to the southwest and the forestry's sawmill and living headquarters in the southeast. All roads in the concession are single-track, dirt roads, created mainly for timber harvest, and a larger road and parallel railway bisects the concession and the park's buffer zone. Roads not currently in use for concession activities are mostly inactive and grown-over. 
Leopards are the only large carnivore known to occur in this area, though their presence is rare. As such, this an interesting site for studying how small carnivores interact without the additional influence of larger, dominant predators in the area. Additionally, the concession's proximity to the park creates an interesting system for future studies as large carnivores recover and community dynamics change in the Gorongosa ecosystem.

\section{$\underline{\text { Carnivore Detection Data }}$}

To measure carnivore site use, we deployed motion-detecting, infrared camera traps (Bushnell Trophy Cam 24MP and 14MP no-glow Aggressors) at 77 sites within the forestry concession. We used a $4 \mathrm{~km}^{2}$ hexagonal grid with approximately $2 \mathrm{~km}$ separating each site to guide our camera placement, but we prioritized roads and animal trails where possible, following protocols from other studies that quantified carnivore space use (Carter et al. 2012; Rosenblatt et al. 2016). Due to a limited number of cameras and time for deployment, traps consisted of either pairs or single cameras to protect against possible failures while covering greater areas, and we rotated traps in four successive blocks from June to October 2017 (Sollmann et al. 2012; Ahumada et al. 2013; Rovero et al. 2016). Each block operated for approximately 20 days (Karanth et al. 2004; Wegge et al. 2009; Athreya et al. 2013). We mounted each camera at knee height relative to the area or trail of interest. At each station, we recorded elevation, took notes on habitat characteristics, and estimated the amount of canopy cover at the station in categories $(0$ $25 \%, 25-50 \%$, etc.). Identifying individuals with these cameras, especially at sites with only one camera, is challenging, so we considered detections of the same species 
independent if they occurred at least 30 minutes after the last time that species was detected at that trap (Wang et al. 2015; O'Connor et al. 2017).

Temporal Overlap

To investigate the interactions between small carnivores, we first examined their daily activity patterns for temporal overlap. Each species is considered nocturnal (Estes 2012), but fine scale avoidance between species could lead to temporal niche partitioning (Schuette et al. 2013; Carter et al. 2015). We extracted the time stamps from each photo of bushy-tailed mongoose, civet, and genet and used the R package 'overlap' (Meredith \& Ridout 2017) to determine if these carnivores may avoid each other in time. We used the timestamps of each species' detections across all sites as well as only at sites where the given competitor in a species pair also occurred. We used the $\widehat{D}$ metric, where the amount of temporal overlap is estimated from 0 to 1 , with 1 representing complete overlap, and bootstrapping to calculate confidence intervals (Meredith \& Ridout 2017). We report $\widehat{D_{1}}$ due to smaller sample sizes in some comparisons (fewer than 75 observations) and consider $\widehat{D_{1}}>0.80$ to be a strong overlap (Allen et al. 2018).

\section{$\underline{\text { Co-Abundance }}$}

$\underline{\text { Analysis }}$

We used recently developed, two-species, N-mixture models to estimate the abundance of small carnivores relative to each other while accounting for differential environmental effects and imperfect detection (Royle 2004; Brodie et al. 2018). Because we did not identify individuals, a site where 20 mongoose, for example, were detected could actually be 20 detections of the same individual repeatedly using that site in front of the camera. Therefore, we refer to the predicted abundances produced by these models 
as a metric for how often a species used a given site. $\mathrm{N}$-mixture models use repeated counts of a population over time to estimate local abundance for a species $i$ at location $j$ $\left(\mathrm{N}_{i, j}\right)$ by assuming $\mathrm{N}_{i, j} \sim$ Poisson $\left(\lambda_{i, j}\right)$. We modeled the expected count of a species $i$ at each location $j\left(\lambda_{i, j}\right)$ given environmental and anthropogenic covariates using a log-link function (Royle 2004). To include the effect of one species' abundance on another, we added a term that estimates the coefficient, or effect $(\delta)$, of a species' abundance $\left(\mathrm{N}_{1}\right)$ to the model of the other species in a pair: $\log \left(\lambda_{2}\right)=\alpha_{2, i}+\alpha_{2} *$ Covariate $_{j} \ldots+\delta_{2} * \mathrm{~N}_{1, \mathrm{j}}$.

An estimated negative value of $\delta$ would therefore indicate a negative correlation between the abundances of species 1 and species 2, suggesting the potential of competitive exclusion (Brodie et al. 2018). Estimates that overlap zero suggest no effect of one species on another, and a positive estimate indicates that abundances of the two species increase together, which could indicate a lack of competitive effects (Brodie et al. 2018), optimal habitat and sufficient resources for both species (Rich et al. 2017), or, in some cases, mutualistic relationships. Similar to other occupancy models (MacKenzie et al. 2002; Mackenzie \& Royle 2005), N-mixture models assume population closure.

\section{Covariates}

We hypothesized that these species would vary in their habitat preferences and tolerance to human disturbance, so we incorporated natural and anthropogenic covariates into our co-abundance models. We predicted that habitat type and cover, water availability, settlements, and human activity would influence species abundance (Schuette et al. 2013; Ramesh et al. 2017; Rich et al. 2017).

We used the Normalized Vegetation Index (NDVI) calculated from a cloud free, Landsat 8 image (Path 67, Row 73) acquired July 2017 and downloaded from USGS 
Earth Explorer (https://earthexplorer.usgs.gov/) to represent habitat type, cover, and forage availability (DeFries \& Townshend 1994; Pettorelli et al. 2005; Ladle et al. 2018). We created a land cover map using random forest and our field notes and Google Earth imagery, but based on the results of an ANOVA test and visual assessments of the two maps, we determined that NDVI values provided the same information as our land cover map (App. B). We therefore used NDVI instead of the categorical land cover map because it is a continuous variable frequently used in occupancy analyses (Burton et al. 2012; Rich et al. 2017). We created 500m buffers surrounding each camera trap and calculated the mean NDVI within them to determine how many of each carnivore would likely use that area (Carter et al. 2013; Ladle et al. 2018). We chose 500m because it is the approximate size of a genet's home range, which is the smallest known home range of our three species (Estes 2012; Williams et al. 2017).

To measure how water availability affects species abundance, we combined the GPS points we took from the ground where we followed creeks and rivers with spatial river data from the HydroSHEDS dataset (Lehner et al. 2006) to determine the location of permanent water sources in our study area. We then calculated the distance from each camera trap to the nearest water source in ArcGIS 10.5.1.

For our anthropogenic variables, we estimated human activity levels as the proportion of days people or vehicles were detected each camera trap, for the number of days each trap was active. We did not believe that human activity would impact detection because these species are nocturnal, but we predicted that more active areas, such as those where logging was occurring or near an active road, may affect the abundance of 
carnivores using that area. We also included the distance of each trap to the nearest settlement, calculated in ArcGIS 10.5.1. The abundance model is therefore specified as:

$$
\lambda 0=\alpha 0_{i}+\alpha 1(\mathrm{NDVI})_{i}+\alpha 2(\text { water })_{i}+\alpha 3(\text { settle })_{i}+\alpha 4(\text { human })_{i}+\alpha 5\left(\mathrm{~N}_{1}\right)_{i}
$$

We included a different set of covariates for the detection model. Carnivores often utilize trails and roads when traveling (Cusack et al. 2015; Kolowski \& Forrester 2017), so we included a binary variable for whether or not a trap was located on (1) or off (0) a trail. We also included a binary variable for if a trap consisted of two cameras (1) or one (0) which may affect the detectability of smaller species. To account for unequal sampling effort between blocks of traps, we also included the number of days each trap was out (Brodie et al. 2018). Finally, we calculated the slope at each camera trap using a Digital Elevation Model in ArcGIS 10.5.1 (Ahumada et al. 2013; Rovero et al. 2014; Brodie et al. 2018). We therefore specified the detection model as:

$$
\operatorname{logit}(\mathrm{p})=\beta 0_{i}+\beta 1(\text { trail })_{i}+\beta 2(\text { paired })_{i}+\beta 3(\text { slope })_{i}+\beta 4(\text { survey days })_{i}
$$

We checked all continuous covariates for collinearity with the Pearson's correlation coefficient. We initially considered including elevation in our models, but it was significantly correlated with distance from water (Pearson $r=0.71)$, so we discarded this covariate. In addition to these covariates, we subtracted the values of each estimated parameter between species pairs for each iteration to determine if one covariate had a significantly different effect on one species from the other (Brodie et al. 2018). We used 
a Bayesian approach with minimally informative priors (McElreath 2015) to estimate model parameters. This approach provides two advantages. First, Bayesian analysis allows for the explicit estimates of latent $\mathrm{N}_{1, j}$ values which are used to estimate $\mathrm{N}_{0, j}$ values. Second, by assigning regularizing priors to all the parameter coefficients, we reduce overfitting while creating a "skeptical" model which interprets values above or below zero to be less plausible. Therefore, we are more confident in the significance of a parameter estimate if, for example, the $95 \%$ credibility intervals (CIs) do not overlap zero (McElreath 2015). We implemented our models with R and R2jags (Plummer 2011). We ran three chains of 100,000 iterations and discarded the first 50,000 as a burn-in for each species pair, and thinned the remaining 50,000 iterations by 20. We assessed model convergence by visually examining trace plots and with the Gelman-Rubin diagnostic, where Rhat values > 1.1 indicate poor convergence (Gelman et al. 2014).

\section{Results}

\section{$\underline{\text { Carnivore Detection Data }}$}

Camera traps were out for 2,090 days, and two of the traps had malfunctioning cameras, leaving 75 sites to analyze. We obtained 168 independent detections of bushytailed mongoose, 152 of African civets, and 120 of large spotted genets (Table 1.2). These three species were detected about eight times more frequently than the other five carnivores at our site, including larger species such as leopards (Panthera pardus) and servals (Leptailurus serval, Figure 1.2).

\section{$\underline{\text { Temporal Partitioning }}$}

Temporal activities of each carnivore pair of our three species strongly overlapped across all sites $\left(\widehat{D_{1}} \geq 0.9\right)$. At sites where both species in a species pair were 
detected, temporal overlap decreased slightly, with the civet-mongoose pair showing the largest decrease in overlap. However, confidence intervals overlapped between activity patterns across all sites and activity patterns at co-occurring sites for each species pair (Figure 1.3).

\section{Spatial Partitioning}

\section{$\underline{\text { Civet-Genet }}$}

Civet abundance did not have a significant relationship with genet abundance (even 50\% CI overlapped 0; Figure 1.4). In the civet-genet model, civet abundance was strongly related to distance from the nearest settlement, with abundance expected to increase as distance from settlements increased. This relationship was significantly different from the relationship between settlement distance and genet abundance (95\% CI of estimated difference did not overlap zero). Other occupancy factors did not have strong effects on either genet or civet abundance (Table 1.3, Figure 1.5).

The detection probability of both species significantly increases for camera traps that are located on a trail. Civet detection probability also decreased further into the dry season. The other detection covariates did not significantly change either species' detection probabilities.

\section{Civet-Mongoose}

We estimated a $98 \%$ probability of a negative relationship between civet and bushy-tailed mongoose abundance (Figure 1.6). Both species' abundances were positively related to increasing distance from settlements. Bushy-tailed mongoose abundance was also significantly related to NDVI and distance to water with higher abundances predicted in forested areas near water. However, only NDVI coefficient 
estimates for mongoose were significantly different from estimates for civets. (Table 1.3, Figure 1.7).

Civet detection probabilities remained significantly related to camera placement on trails and survey dates. Bushy-tailed mongoose detection probabilities decreased for traps located near steeper slopes.

\section{Genet-Mongoose}

Genet and bushy-tailed mongoose abundances were positively correlated (estimated $99 \%$ probability of a positive relationship; Figure 1.8). None of the parameter coefficient estimates significantly differed between the two species, despite mongoose abundance being more strongly related to NDVI, distance from water, and distance from settlement (Table 1.3, Figure 1.9).

\section{Discussion}

We have provided evidence for fine-scale spatial partitioning and coexistence among sympatric carnivores in a multi-use area of Mozambique, with little evidence for temporal segregation between these nocturnal species. Our results indicate that, after accounting for differences in habitat preferences and sensitivities to anthropogenic factors, bushy-tailed mongoose and African civets partition in space, while genet site use was not affected by either of the other two species. To the best of our knowledge, this interaction between civets and bushy-tailed mongoose has not been documented by any other study.

We predicted that both genets and mongoose would avoid civets due to being smaller, and therefore at a competitive disadvantage (Palomares \& Caro 1999; Schuette et al. 2013; Ramesh et al. 2017; Palomares et al. 1995). Because our models estimate a 
correlation, rather than a directional causation, it is difficult to tell which species may be avoiding the other or why, but body size differences may play a partial role in the negative relationship between civet and mongoose space use, as has been found in other studies. For example, de Satgé and colleagues (2017) found that striped polecats (Ictonyx striatus) and small-spotted genets (Genetta genetta) avoided their larger competitor, the African wildcat (Felis silvestris lybica). However, genet site use did not have a negative relationship with civet site use, rejecting our body-size hypothesis. Indeed, civet occupancy was negatively related to the detection rate of similarly sized carnivores in Botswana, but this relationship switched in the wet season, possibly due to greater resource availability (Rich et al. 2017). Unaccounted for resources that these three species may be competing over (mongoose-civet) or partitioning (genet-civet) may better explain our results than differences in body size. The unique foraging habits of genets, for example, may facilitate their coexistence with mongoose and civets. Genets are known to be more carnivorous than civets, and they often stalk and hunt prey whereas civets are ambush predators and more opportunistic omnivores (Ray \& Sunquist 2001; Estes 2012). Genets are also more arboreal, which may allow for an even finer scale spatial partition between these two species (Maddock \& Perrin 1993). Such differences in foraging styles mediate competitive exclusion in other systems, such as the avoidance of Iberian lynx (Lynx pardinus) by red foxes but not by Eurasian badgers (Meles meles), which have a more distinctive foraging strategy (Fedriani et al. 1999). Similarly, civets and mongoose may be seeking different resources that were not represented in our models. For example, civets are more frugivorous than others in their guild and have been considered hypo- 
carnivorous (less than $30 \%$ of its diet consists of meat, Waser 1980; Ray \& Sunquist 2001; Amiard et al. 2015).

The positive correlation between genet and mongoose abundance observed in this study, with no significant differences between their likelihood to occupy different habitats was also interesting and difficult to interpret since mutualism seems unlikely (Brodie et al. 2018). Positive relationships among sympatric species have been documented elsewhere, counter to competition theory (Dorazio et al. 2015; Rich et al. 2017; Brodie et al. 2018). Interference competition would be unlikely given their similar size, and the positive relationship between these two species could also be facilitated by differences in the genet's diet, hunting strategies, and fine-scale habitat use previously mentioned (Waser 1980; Ray \& Sunquist 2001; Caro et al. 2003; Angelici \& Luiselli 2005; Estes 2012). Alternatively, shared resources tracked by both species that were unaccounted for in these models (such as specific foods) may be abundant. Our study did not explicitly incorporate forage or prey availability, but Rich and colleagues (2017) found that, generally, carnivore occupancy depended more on resource availability than the presence of competing species. Additionally, if abundant resources can support a higher number of both genets and mongoose, competitive interactions or resource partitioning would not be necessary (Brodie et al. 2018).

These examples of intraguild interactions carry extra weight in multi-use landscapes, where the presence of people may drive different patterns than what would be expected in protected areas (Waser 1980; Schuette et al. 2013; Massara et al. 2016). Civets and mongoose were both more likely to occur in higher numbers farther away from human settlements. Other studies have documented similar patterns, where species 
richness, and carnivore occupancy in particular, is reduced near permanent settlements (Bowkett et al. 2008; Epps et al. 2011; Burton et al. 2012; Carter et al. 2013; Schuette et al. 2013, 2016; Kiffner et al. 2015; Williams et al. 2017). This result is disconcerting because small carnivores likely provide ecosystem services, from which people would benefit. For example, these species likely play a large part in limiting rodent and other pest populations in cropland areas, and, by extension, limiting the spread of zoonotic diseases (Ostfeld \& Holt 2004; Williams et al. 2017). Additionally, civets in particular are considered important seed dispersers (Nakashima et al. 2010; Caughlin et al. 2014). However, these services are reliant on both the abundance and diversity of small and medium-sized carnivores, which, as supported by our results as well as other studies, are often limited in human-dominated areas (Burton et al. 2012; Schuette et al. 2013; Williams et al. 2017).

The selection of habitats farther from settlements by both mongoose and civet likely further limits resource availability and opportunities for niche partitioning (Massara et al. 2016; Moll et al. 2018). Human populations are projected to rapidly grow in Mozambique, including in the Gorongosa region (United Nations 2017). The expansion of settlements may exacerbate the negative interactions between civets and mongoose by pushing them out of viable habitats and facilitating more interactions between these and other potentially competing species whose interactions and basic ecologies remain unknown (Do Linh San et al. 2013). Such interactions could have population-level effects on species with restricted ranges (e.g., the bushy-tailed mongoose's close relative, the Sokoke dog mongoose; Foley \& Do Linh San 2016). 
Competitive interactions are also important to consider for conservation planning, specifically the restoration of large carnivore populations and preservation of wildlife corridors. Small carnivores often spatially or temporally avoid large carnivores to reduce the potential for competition or even predation (Johnson \& VanDerWal 2009). Leopards are the only known large carnivore to occur at our site, and they were rarely detected (Figure 1.2), likely due to low population sizes resulting from Mozambique's civil war (Pringle 2017). The recovery of leopards to pre-war densities and facilitation of their movement between protected areas in the region, including through our study site, is a priority for Gorongosa National Park managers. We were unable to test how leopards affected small carnivore abundance due to low sample sizes, but their presence and recovery could alter intraguild dynamics. For example, in one of the few studies that examined the effect of leopards on small carnivore occupancy, Ramesh and colleagues (2017) found that honey badgers (Mellivora capensis), slender mongoose (Galerella sanguinea), and striped polecats (Ictonyx striatus) were detected less often at sites where leopards were detected. Additionally, leopards have been known to kill and eat civets (Palomares and Caro 1999). Leopards may therefore reduce the amount of available habitat and resources for subordinate carnivores. Alternatively, they may suppress medium-sized carnivores such as civets, releasing mongoose, other competitors, and their prey from interference and predatory pressures. These predator cascades have been noted in North America, Australia, Europe, and East Africa (Creel \& Creel 1996; Johnson \& VanDerWal 2009; Levi \& Wilmers 2012; Pasanen-Mortensen et al. 2013; Sivy et al. 2017). Generally, though, if subordinate carnivores are to avoid dominant carnivores as well as people, corridor planning should consider core areas for large carnivore 
movement, as well as peripheral habitats to support other species (Brodie et al. 2014; Ramesh et al. 2017). These multi-faceted interactions between apex predators, sympatric competitors, and people are critical to consider when planning for the conservation of habitat that supports a diverse wildlife community. Long-term monitoring of this dynamic predator population, continuing to build our baseline understanding of competitive interactions among understudied carnivores, and facilitating greater coexistence between people and carnivores will be essential for successful conservation programs.

\section{References}

Admasu E, Thirgood SJ, Bele A, Laurenson MK. 2004. A note on the spatial ecology of African civet Civettictis civetta and common genet Genetta genetta in farmland in the Ethiopian Highlands. African Journal of Ecology 42:160-162.

Ahumada JA, Hurtado J, Lizcano D. 2013. Monitoring the Status and Trends of Tropical Forest Terrestrial Vertebrate Communities from Camera Trap Data: A Tool for Conservation. PLoS ONE 8:6-9.

Allen ML, Peterson B, Krofel M. 2018. No respect for apex carnivores: Distribution and activity patterns of honey badgers in the Serengeti. Mammalian Biology 89:9094.

Amiard PJ, Kruger C V, Mullers RHE, Schipper J. 2015. The diet of African Civet Civettictis civetta in two vegetation types of the Savannah biome in South Africa. Small Carnivore Conservation $52 \& 53: 4-12$.

Angelici FM, Luiselli L. 2005. Habitat associations and dietary relationships between two genets, Genet ... Revue d Ecologie 60:17370993.

Athreya V, Odden M, Linnell JDC, Krishnaswamy J, Karanth U. 2013. Big Cats in Our Backyards: Persistence of Large Carnivores in a Human Dominated Landscape in India. PLoS ONE 8:2-9. 
Berger J. 2007. Fear, human shields and the redistribution of prey and predators in protected areas. Biology Letters 3:620-623.

Bowkett AE, Rovero F, Marshall AR. 2008. The use of camera-trap data to model habitat use by antelope species in the Udzungwa Mountain forests, Tanzania. African Journal of Ecology 46:479-487.

Brodie JF, Giordano AJ, Dickson B, Hebblewhite M, Bernard H, Mohd-azlan J, Anderson J. 2014. Evaluating Multispecies Landscape Connectivity in a Threatened Tropical Mammal Community 0:1-11.

Brodie JF, Helmy OE, Mohd-Azlan J, Granados A, Bernard H, Giordano AJ, Zipkin E. 2018. Models for assessing local-scale co-abundance of animal species while accounting for differential detectability and varied responses to the environment. Biotropica 50:5-15.

Burton AC, Sam MK, Balangtaa C, Brashares JS. 2012. Hierarchical multi-species modeling of carnivore responses to hunting, habitat and prey in a West African protected area. PLoS ONE 7.

Cardillo M, Cardillo M, Mace GM, Jones KE, Bielby J, Bininda-Emonds ORP, Sechrest W, Orme CDL, Purvis A. 2005. Multiple Causes of High Extinction Risk in Large Mammal Species. Science 309:1239-1241.

Caro TM, Caro TM, Stoner CJ, Stoner CJ. 2003. The potential for interspeci c competition among African carnivores. Biological Conservation 110:67-75.

Carter N, Jasny M, Gurung B, Liu J. 2015. Impacts of people and tigers on leopard spatiotemporal activity patterns in a global biodiversity hotspot. Global Ecology and Conservation 3:149-162.

Carter NH, Gurung B, Viña A, Campa III H, Karki JB, Liu J. 2013. Assessing spatiotemporal changes in tiger habitat across different land management regimes. Ecosphere 4:124.

Carter NH, Shrestha BK, Karki JB, Pradhan NMB, Liu J. 2012. Coexistence between wildlife and humans at fine spatial scales. Proceedings of the National Academy of Sciences 109:15360-15365. 
Caughlin TT, Ferguson JM, Lichstein JW, Zuidema PA, Bunyavejchewin S, Levey DJ. 2014. Loss of animal seed dispersal increases extinction risk in a tropical tree species due to pervasive negative density dependence across life stages. Proceedings of the Royal Society B: Biological Sciences 282:2014209520142095.

Creel S, Creel NM. 1996. Limitation of African Wild Dogs by Competition with Larger Carnivores. Conservation Biology 10:526-538.

Crooks KR, Soulé ME. 1999. Mesopredator release and avifaunal extinctions in a fragmented system. Nature 400:563-566.

Cusack JJ, Dickman AJ, Rowcliffe JM, Carbone C. 2015. Random versus Game TrailBased Camera Trap Placement Strategy for Monitoring Terrestrial Mammal Communities:1-14.

Daskin JH, Stalmans M, Pringle RM. 2016. Ecological legacies of civil war: 35-year increase in savanna tree cover following wholesale large-mammal declines. Journal of Ecology 104:79-89.

de Satgé J, Teichman K, Cristescu B. 2017. Competition and coexistence in a small carnivore guild. Oecologia 184:873-884.

DeFries RS, Townshend JRG. 1994. NDVI-derived land cover classifications at a global scale. International Journal of Remote Sensing 15:3567-3586.

Dirzo R, Young HS, Galetti M, Ceballos G, Isaac NJB, Collen B. 2014. Defaunation in the Anthropocene. Science (New York, N.Y.) 345:401-6.

Do Linh San E, Ferguson AW, Belant JL, Schipper J, Hoffman M, Gaubert P, Angelici FM, Somers MJ. 2013. Conservation status, distribution and species richness of small carnivores in Africa. Small Carnivore Conservation 48:4-18.

Donadio E, Buskirk SW. 2006. Diet, morphology, and interspecific killing in carnivora. The American naturalist 167:524-36.

Dorazio RM, Connor EF, Askins RA. 2015. Estimating the Effects of Habitat and Biological Interactions in an Avian Community:1-16. 
Ellis EC. 2011. Anthropogenic transformation of the terrestrial biosphere. Philosophical transactions. Series A, Mathematical, physical, and engineering sciences 369:1010-35.

Epps CW, Mutayoba BM, Gwin L, Brashares JS. 2011. An empirical evaluation of the African elephant as a focal species for connectivity planning in East Africa. Diversity and Distributions 17:603-612.

Estes RD. 2012. The Behavior Guide to African Mammals, Including Hoofed Mammals, Carnivores, and Primates20th Anniv. University of California Press, Berkeley and Los Angeles, California, and London, England.

Fedriani JM, Fuller TK, Sauvajot RM, York EC. 2000. Competition and intraguild predation among three sympatric carnivores. Oecologia 125:258-270.

Fedriani JM, Palomares F, Delibes M. 1999. Niche relations among three sympatric Mediterranean carnivores. Oecologia 121:138-148.

Foley C, Do Linh San E. 2016. Bdeogale omnivora. The IUCN Red List of Threatened Species 2016: e.T136686A45221619. Available from http://dx.doi.org/10.2305/IUCN.UK.2016-1.RLTS.T136686A45221619.en. (accessed May 9, 2018).

Fuller TK, Biknevicius AR, Kat PW. 1990. Movements and behavior of large spotted genets (genetta maculata Gray 1830) near elmenteita kenya (mammalia viverridae). Tropical Zoology 3:13-19.

Gelman A, Hwang J, Vehtari A. 2014. Understanding predictive information criteria for Bayesian models. Statistics and Computing 24:997-1016.

Johnson CN, VanDerWal J. 2009. Evidence that dingoes limit abundance of a mesopredator in eastern Australian forests. Journal of Applied Ecology 46:641646.

Karanth KU, Chundawat RS, Nichols JD, Kumar NS. 2004. Estimation of tiger densities in the tropical dry forests of Panna, Central India, using photographic capturerecapture sampling. Animal Conservation 7:285-290. 
Kiffner C, Wenner C, LaViolet A, Yeh K, Kioko J. 2015. From savannah to farmland: effects of land-use on mammal communities in the Tarangire-Manyara ecosystem, Tanzania. African Journal of Ecology 53:156-166.

Kolowski JM, Forrester TD. 2017. Camera trap placement and the potential for bias due to trails and other features. PLOS ONE 12:e0186679.

Ladle A, Steenweg R, Shepherd B, Boyce MS. 2018. The role of human outdoor recreation in shaping patterns of grizzly bear-black bear co-occurrence. PLoS ONE 13:1-16.

Lehner, B., Verdin K, Jarvis A. 2006. HydroSHEDS Technical Documentation. World Wildlife Fund US, Washington, DC. Available from http://hydrosheds.cr.usgs.gov. (accessed July 4, 2018).

Levi T, Wilmers C. 2012. Wolves - coyotes - foxes : a cascade among carnivores. Ecology 93:921-929.

MacKenzie DI, Nichols JD, Lachman GB, Droege S, Royle AA, Langtimm CA. 2002. Estimating site occupancy rates when detection probabilities are less than one. Ecology 83:2248-2255.

Mackenzie DI, Royle JA. 2005. Designing occupancy studies : general advice and allocating survey effort:1105-1114.

Maddock AH, Perrin MR. 1993. Spatial and temporal ecology of an assemblage of viverrids in Natal, South Africa. Journal of Zoology 229:277-287.

Massara RL, Paschoal AMO, Bailey LL, Doherty PF, Chiarello AG. 2016. Ecological interactions between ocelots and sympatric mesocarnivores in protected areas of the Atlantic Forest, southeastern Brazil. Journal of Mammalogy 97:1634-1644.

McElreath R. 2015. Statistical Rethinking: A Bayesian Course with Examples in R and Stan. CRC Press, Taylor \& Francis Group.

Meredith M, Ridout M. 2017. Overview of the overlap package. R project:1-9. 
Moll RJ, Cepek JD, Lorch PD, Dennis PM, Robison T, Millspaugh JJ, Montgomery RA. 2018. Humans and urban development mediate the sympatry of competing carnivores. Urban Ecosystems.

Nakashima Y, Inoue E, Inoue-Murayama M, Abd. Sukor JR. 2010. Functional uniqueness of a small carnivore as seed dispersal agents: a case study of the common palm civets in the Tabin Wildlife Reserve, Sabah, Malaysia. Oecologia 164:721-730.

O’Connor KM, Nathan LR, Liberati MR, Tingley MW, Vokoun JC, Rittenhouse TAG. 2017. Camera trap arrays improve detection probability of wildlife: Investigating study design considerations using an empirical dataset. PLoS ONE 12:1-12.

Oriol-Cotterill A, Macdonald DW, Valeix M, Ekwanga S, Frank LG. 2015. Spatiotemporal patterns of lion space use in a human-dominated landscape. Animal Behaviour 101:27-39.

Ostfeld RS, Holt RD. 2004. Are predators good for your health? Evaluating evidence for top-down regulation of zoonotic disease reservoirs. Frontiers in Ecology and the Environment 2:13-20.

Palomares F, Caro TM. 1999. Interspecific killing among mammalian carnivores. The American Naturalist 153:492-508.

Palomares F, Gaona P, Ferreras P, Delibes M. 1995. Positive Effects on Game Species of Top Predators by Controlling Smaller Predator Populations: An Example with Lynx, Mongooses, and Rabbits. Conservation Biology 9:295-305.

Pasanen-Mortensen M, Pyykönen M, Elmhagen B. 2013. Where lynx prevail, foxes will fail - limitation of a mesopredator in Eurasia. Global Ecology and Biogeography $22: 868-877$.

Pettorelli N, Lobora AL, Msuha MJ, Foley C, Durant SM. 2010. Carnivore biodiversity in Tanzania: Revealing the distribution patterns of secretive mammals using camera traps. Animal Conservation 13:131-139. 
Pettorelli N, Vik JO, Mysterud A, Gaillard J-M, Tucker CJ, Stenseth NC. 2005. Using the satellite-derived NDVI to assess ecological responses to environmental change. Trends in Ecology \& Evolution 20:503-510.

Plummer M. 2011. JAGS: a program for the statistical analysis of Bayesian hierarchical models by Markov Chain Monte Carlo.

Pringle RM. 2017. Upgrading protected areas to conserve wild biodiversity. Nature 546:91-99.

Ramesh T, Downs CT. 2014. Modelling large spotted genet (Genetta tigrina) and slender mongoose (Galerella sanguinea) occupancy in a heterogeneous landscape of South Africa. Mammalian Biology 79:331-337.

Ramesh T, Kalle R, Downs CT. 2017. Staying safe from top predators: patterns of cooccurrence and inter-predator interactions. Behavioral Ecology and Sociobiology 71.

Ray JC, Sunquist ME. 2001. Trophic relations in a community of African rainforest carnivores. Oecologia 127:395-408.

Rich LN, Miller DAW, Robinson HS, McNutt JW, Kelly MJ. 2017. Carnivore distributions in Botswana are shaped by resource availability and intraguild species. Journal of Zoology 303:90-98.

Ripple WJ et al. 2014. Status and ecological effects of the world's largest carnivores. Science 343:1241484.

Ritchie EG, Johnson CN. 2009. Predator interactions, mesopredator release and biodiversity conservation. Ecology Letters 12:982-998.

Roemer GW, Gompper ME, Van Valkenburgh B. 2009. The ecological role of the mammalian mesocarnivore. BioScience 59:165-173.

Rosenblatt E, Creel S, Becker MS, Merkle J, Mwape H, Schuette P, Simpamba T. 2016. Effects of a protection gradient on carnivore density and survival: An example with leopards in the Luangwa valley, Zambia. Ecology and Evolution 6:37723785 . 
Rota CT, Ferreira MAR, Kays RW, Forrester TD, Kalies EL, McShea WJ, Parsons AW, Millspaugh JJ. 2016. A multispecies occupancy model for two or more interacting species. Methods in Ecology and Evolution 7:1164-1173.

Rovero F, Owen N, Jones T. 2016. Camera trapping surveys of forest mammal communities in the Eastern Arc Mountains reveal generalized habitat and human disturbance responses. Biodiversity and Conservation:50-52.

Royle JA. 2004. N-Mixture Models for Estimating Population Size from Spatially Replicated Counts. Biometrics 60:108-115.

Schuette P, Wagner AP, Wagner ME, Creel S. 2013. Occupancy patterns and niche partitioning within a diverse carnivore community exposed to anthropogenic pressures. Biological Conservation 158:301-312.

Sivy KJ, Pozzanghera CB, Grace JB, Prugh LR. 2017. Fatal Attraction? Intraguild Facilitation and Suppression among Predators. The American Naturalist.

Sollmann R, Gardner B, Belant JL. 2012. How Does Spatial Study Design Influence Density Estimates from Spatial Capture-Recapture Models. PloS ONE 7:1-8.

Stalmans M, Beilfuss R. 2008. Landscapes of Gorongosa National Park.

United Nations. 2017. World Population Prospects: The 2017 Revision, Key Findings and Advance Tables. Working Paper No. ESA/P/WP/248.

Wang Y, Allen ML, Wilmers CC. 2015. Mesopredator spatial and temporal responses to large predators and human development in the Santa Cruz Mountains of California. Biological Conservation 190:23-33.

Waser PM. 1980. Small nocturnal carnivores: ecological studies in the Serengeti 18:167185.

Wegge P, Odden M, Pokharel CP, Storaas T. 2009. Predator-prey relationships and responses of ungulates and their predators to the establishment of protected areas: A case study of tigers, leopards and their prey in Bardia National Park, Nepal. Biological Conservation 142:189-202. 
Williams ST, Maree N, Taylor P, Belmain SR, Keith M, Swanepoel LH. 2017. Predation by small mammalian carnivores in rural agro-ecosystems: An undervalued ecosystem service? Ecosystem Services.

Tables

Table 1.1 Ecological characteristics of our three study species. All species are nocturnal and opportunistic generalists. These species consume small vertebrates, invertebrates, fruits, and plants.

\begin{tabular}{|l|l|l|l|l|}
\hline Species & Size & Range & $\begin{array}{l}\text { Home } \\
\text { Range Size }\end{array}$ & Habitat Preferences \\
\hline African civet & $7-20 \mathrm{~kg}$ & $\begin{array}{l}\text { Widely distributed in Sub- } \\
\text { Saharan Africa }\end{array}$ & $5-11 \mathrm{~km}^{2}$ & $\begin{array}{l}\text { Anywhere with adequate } \\
\text { cover and food, usually } \\
\text { near water }\end{array}$ \\
\hline $\begin{array}{l}\text { Bushy-tailed } \\
\text { mongoose }\end{array}$ & $2 \mathrm{~kg}$ & $\begin{array}{l}\text { Common within portions } \\
\text { of Tanzania, Mozambique, } \\
\text { Zimbabwe, Zambia, } \\
\text { Malawai }\end{array}$ & Unknown & $\begin{array}{l}\text { Woodland/scrub and } \\
\text { forested areas }\end{array}$ \\
\hline $\begin{array}{l}\text { Large-spotted } \\
\text { genet }\end{array}$ & $2 \mathrm{~kg}$ & $\begin{array}{l}\text { Widely distributed in Sub- } \\
\text { Saharan Africa }\end{array}$ & $0.5-1 \mathrm{~km}^{2}$ & $\begin{array}{l}\text { Anywhere with adequate } \\
\text { cover and food. Tolerant } \\
\text { of human-modified areas }\end{array}$ \\
\hline
\end{tabular}

Sources: Ray \& Sunquist 2001; Pettorelli et al. 2010; Estes 2012; Schuette et al. 2013; Ramesh \& Downs 2014; Rovero et al. 2017; Williams et al. 2017.

Table 1.2 Total number of detections, naïve occupancy (raw number of traps where animal was detected), and naïve co-occurrence (raw number of traps where both species in a pair were detected).

\begin{tabular}{lllll}
\hline Species & Detections & \multicolumn{3}{c}{ Naïve Co-Occurrence } \\
\cline { 3 - 5 } & (Naïve Occupancy) & Mongoose & Genet & Civet \\
\hline Mongoose & $168(36 / 75)$ & - & $19 / 36$ & $16 / 36$ \\
\hline Genet & $152(25 / 75)$ & $19 / 25$ & - & $16 / 29$ \\
\hline Civet & $120(29 / 75)$ & $16 / 29$ & $16 / 29$ & - \\
\hline
\end{tabular}

Table 1.3 Mean parameter estimates for each species pair. Asterisks indicate 95\% credibility intervals that do not overlap zero. Bold terms indicate a significant difference in the estimated coefficients between species in a pair.

\begin{tabular}{|l|l|l|l|l|l|}
\hline Species & $\delta$ & Dist. Settlement & Dist. River & NDVI & Human/Vehicle \\
\hline Civet & \multirow{2}{*}{-0.08} & $\mathbf{0 . 8 5 ^ { * }}$ & -0.13 & -0.32 & 0.1 \\
Genet & $\mathbf{0 . 0 4}$ & -0.17 & 0.01 & -0.13 \\
\hline Civet & \multirow{2}{*}{$-0.26^{*}$} & $0.83^{*}$ & -0.15 & $-\mathbf{0 . 2 6}$ & 0.10 \\
Mongoose & & $0.62^{*}$ & $-0.40^{*}$ & $\mathbf{0 . 3 8 ^ { * }}$ & 0.08 \\
\hline Genet & \multirow{2}{*}{$0.25^{*}$} & 0.03 & -0.01 & -0.01 & -0.13 \\
Mongoose & & $0.40^{*}$ & -0.28 & $0.51^{*}$ & 0.01 \\
\hline
\end{tabular}


Figures

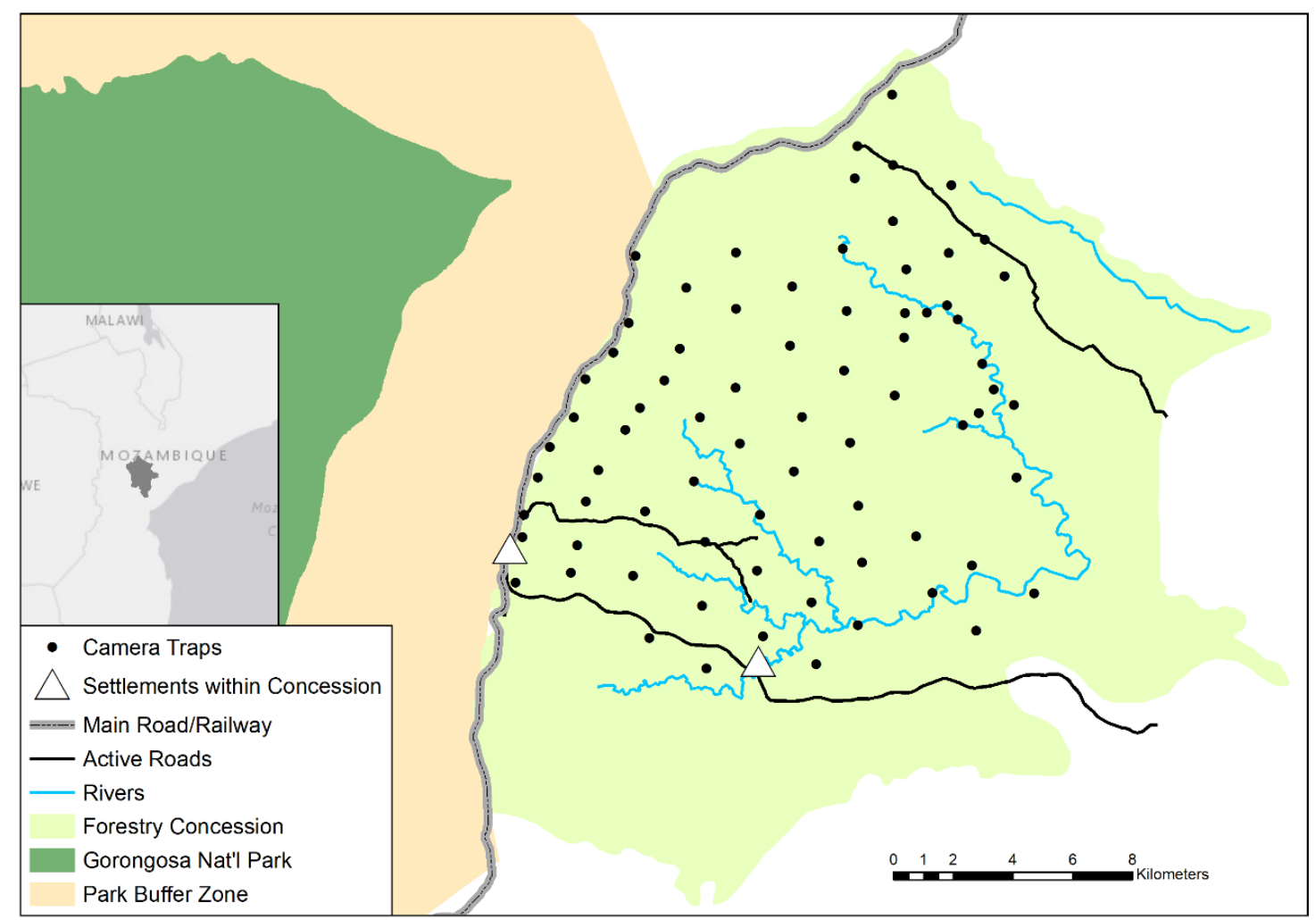

Figure 1.1 Map of our study site within a sustainable forestry concession adjacent to Gorongosa National Park and its buffer zone in central Mozambique. 


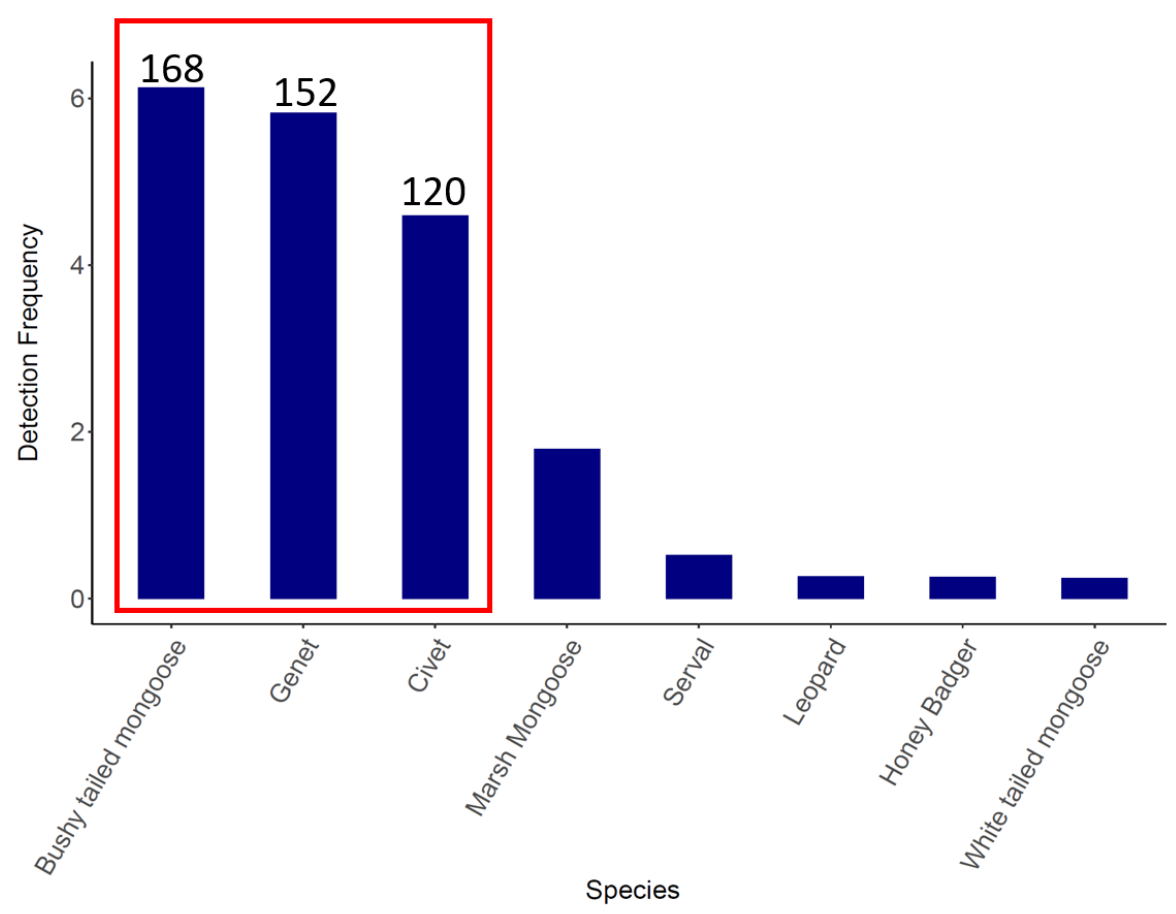

Figure 1.2 Average detection frequency across sites per 100 trap days for each carnivore species detected. The red box highlights the three study species, and the number of detections for each of these three species is displayed on top of the bars. 

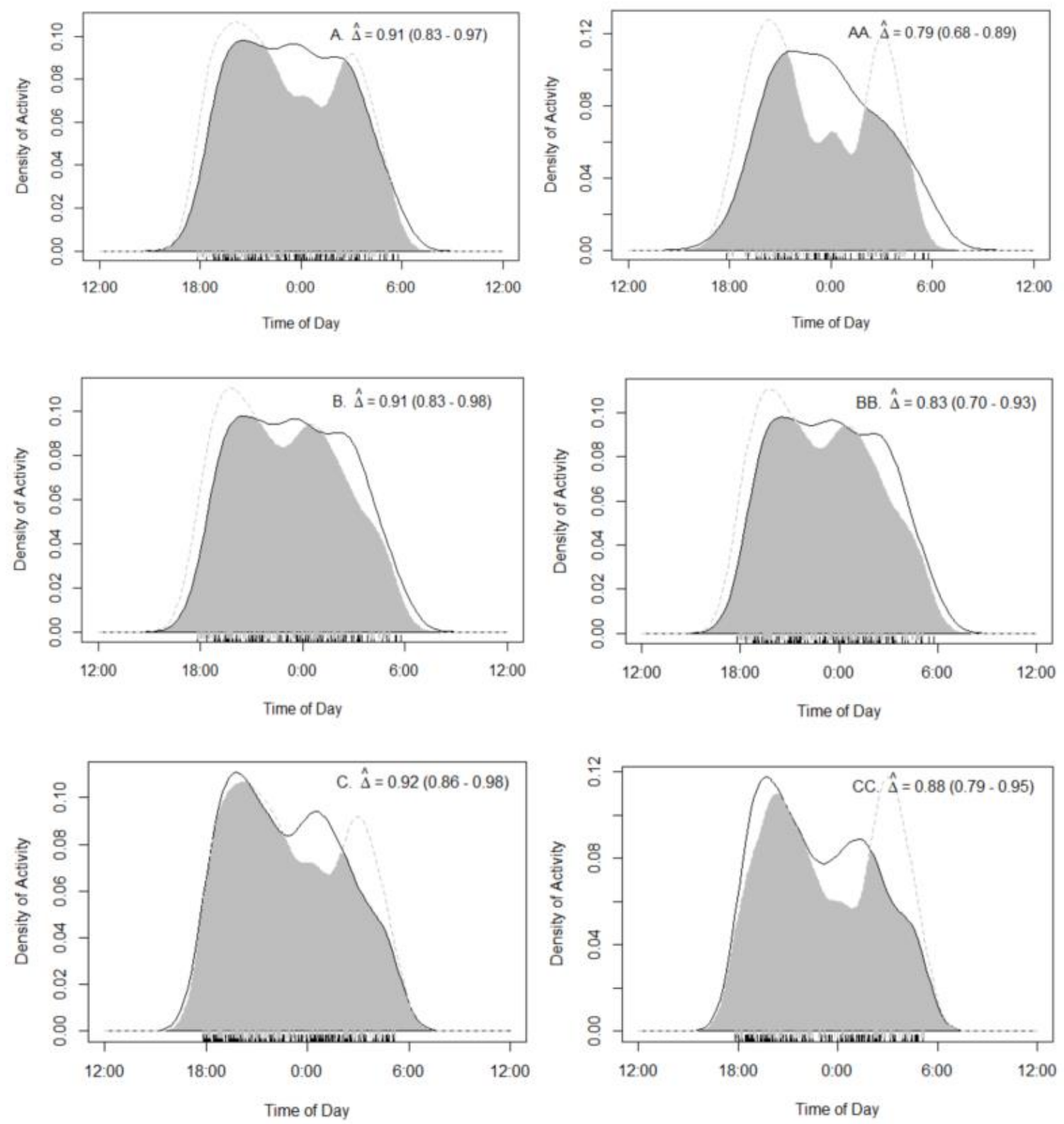

Figure 1.3 Overlap of daily activity patterns for (A) civet and mongoose across all sites, (AA) civet and mongoose where both were detected, (B) civet and genet across all sites, (BB) civet and genet where both were detected, (C) genet and mongoose across all sites, and (CC) genet and mongoose where both were detected. The estimate of overlap ( $\Delta$, with 0 indicating no overlap and 1 indicating complete overlap) is indicated by the grey area. Grey and black ticks indicate the raw time stamps used to create the density curves, and $95 \%$ confidence intervals are given in parentheses. 


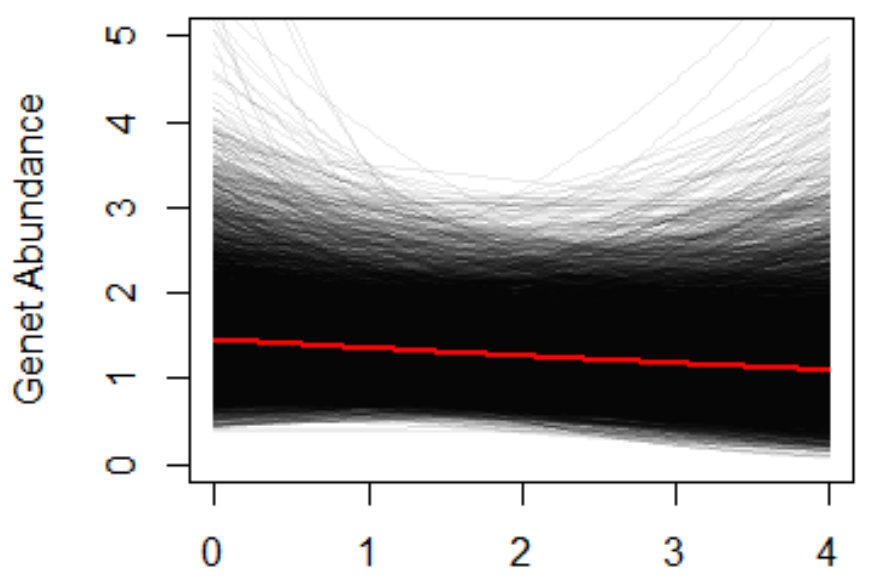

Civet Abundance

Figure 1.4 Estimated correlations between civet and genet abundances for each iteration, represented by the black lines. The red line indicates the mean estimate (0.08 on the logit scale).

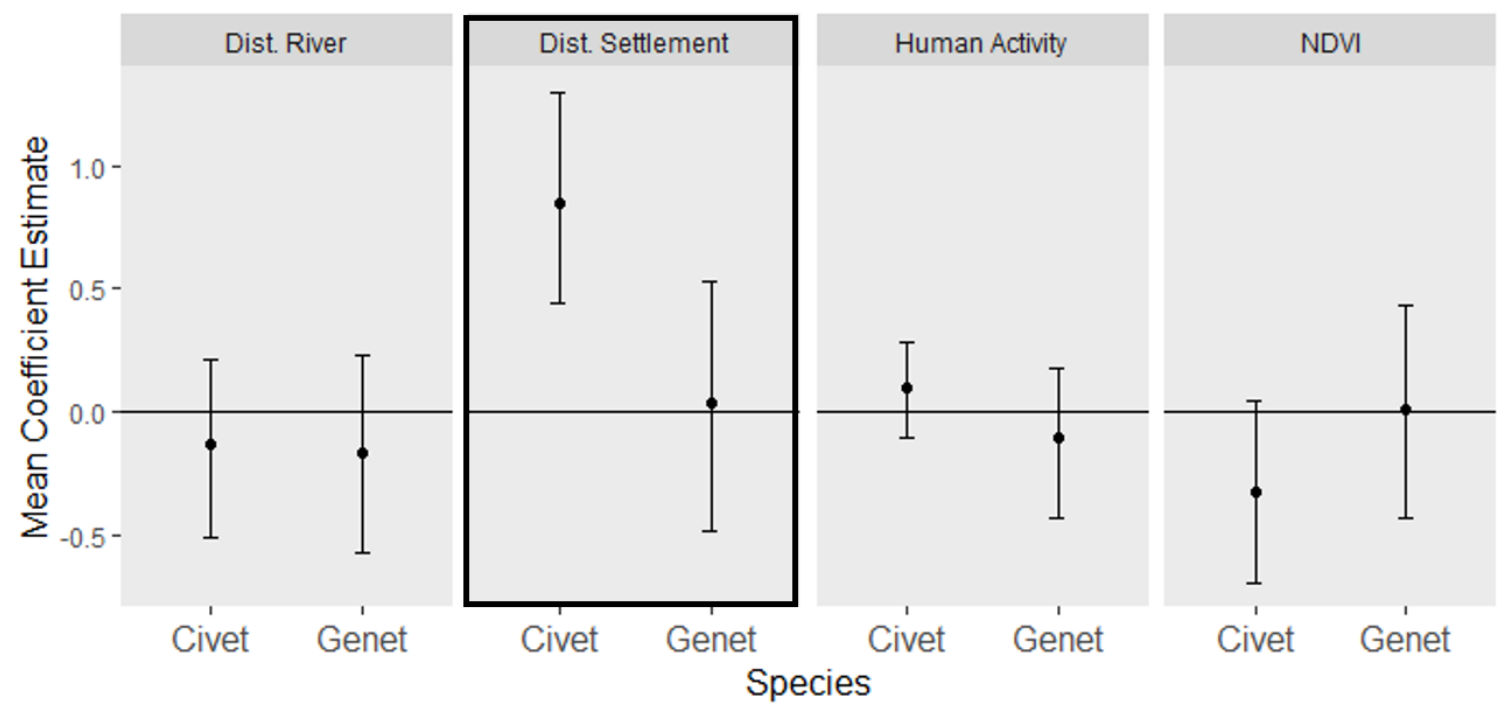

Figure 1.5 Mean coefficient estimates and 95\% credibility bars of each covariate for each species. The coefficient estimates for distance from settlements for civets were significantly higher than the estimates for genets, as indicated by the black box. 


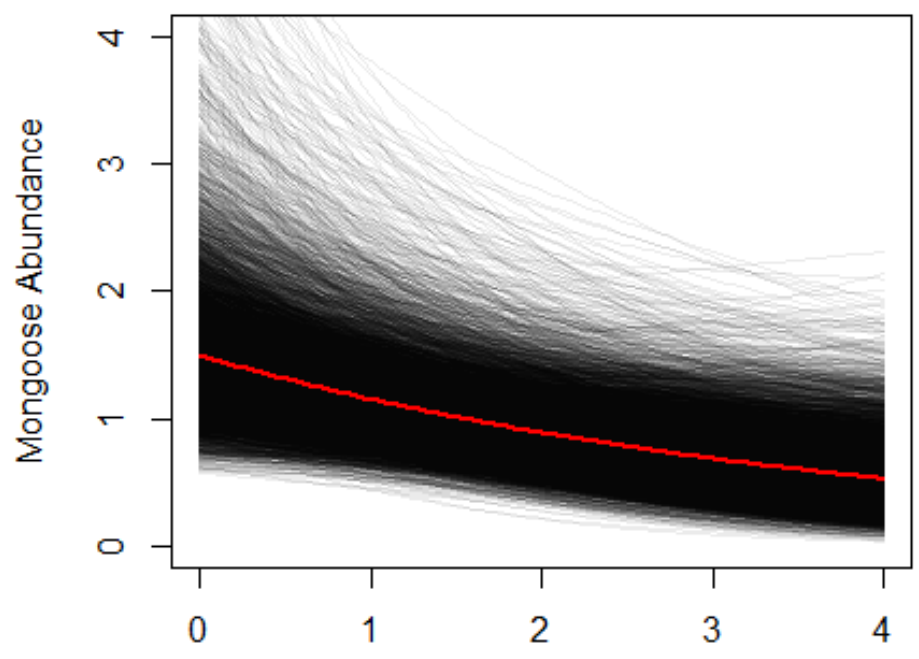

Civet Abundance

Figure 1.6 Estimated correlations between civet and mongoose abundances for each iteration. The red line indicates the mean estimate (-0.26 on the logit scale).
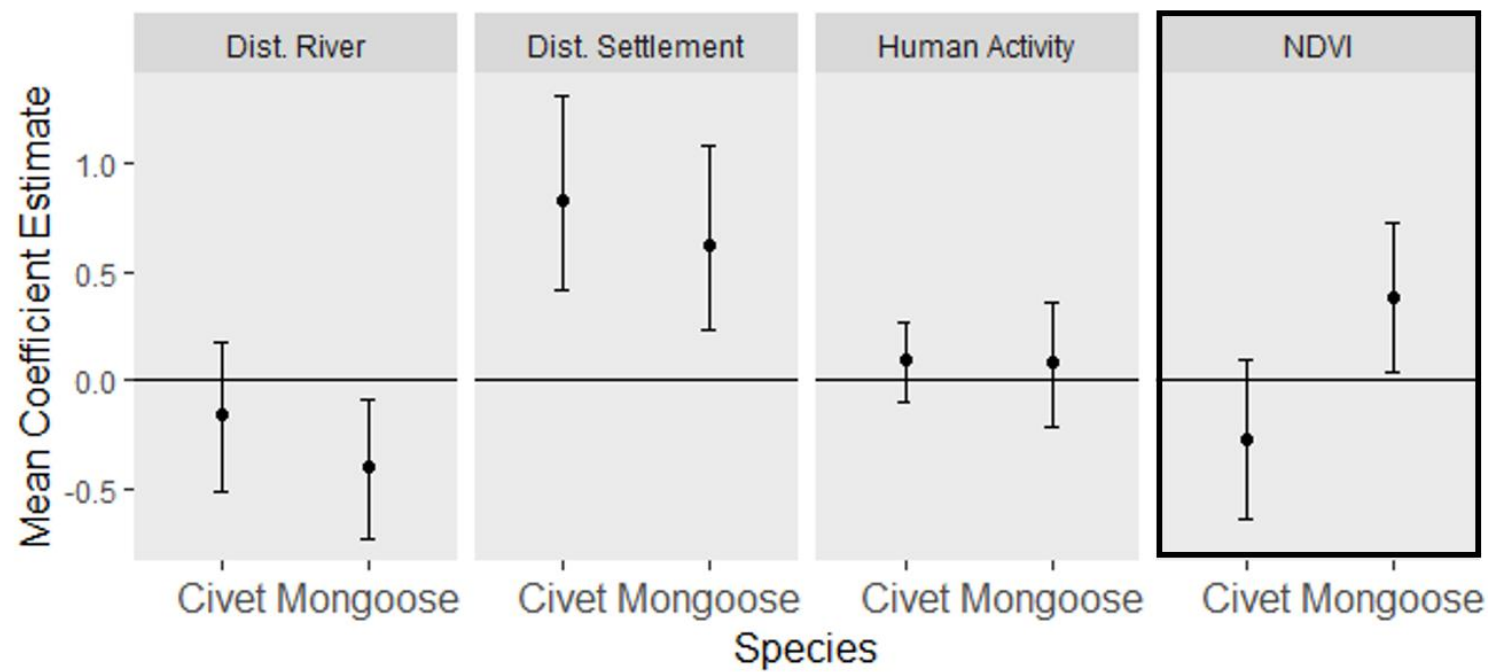

Species

Figure 1.7 Mean coefficient estimates and 95\% credibility bars of each covariate for each species. The coefficient estimates for NDVI for mongoose were significantly higher than the estimates for civets, as indicated by the black box. Both species occurred more often farther away from settlements. 


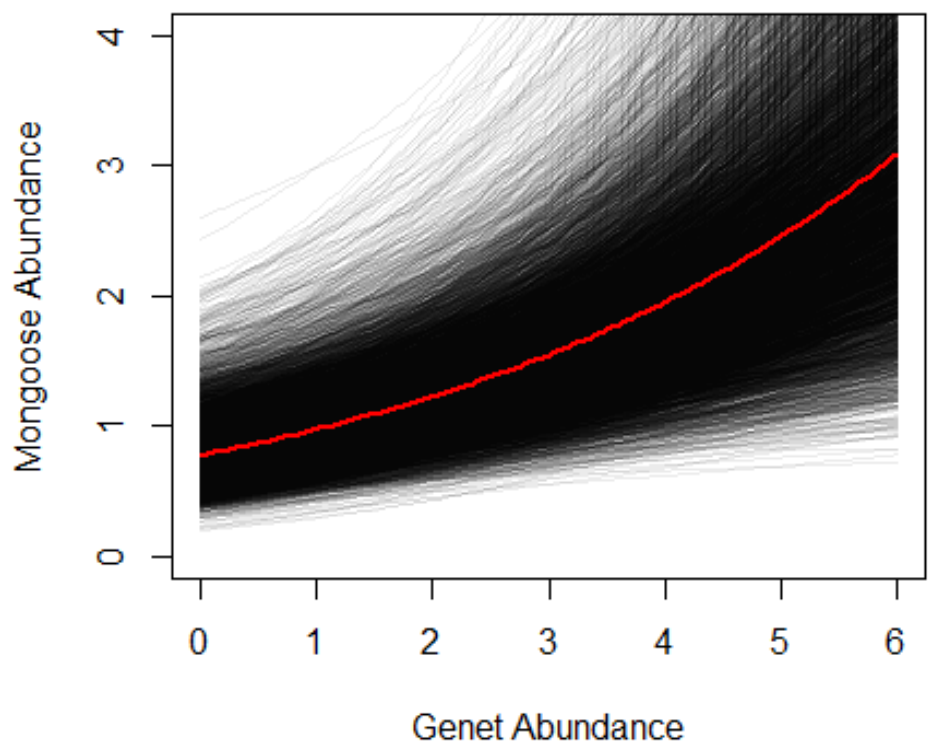

Figure 1.8 Estimated correlations between civet and genet abundances for each iteration. The red line indicates the mean estimate ( 0.25 on the logit scale).
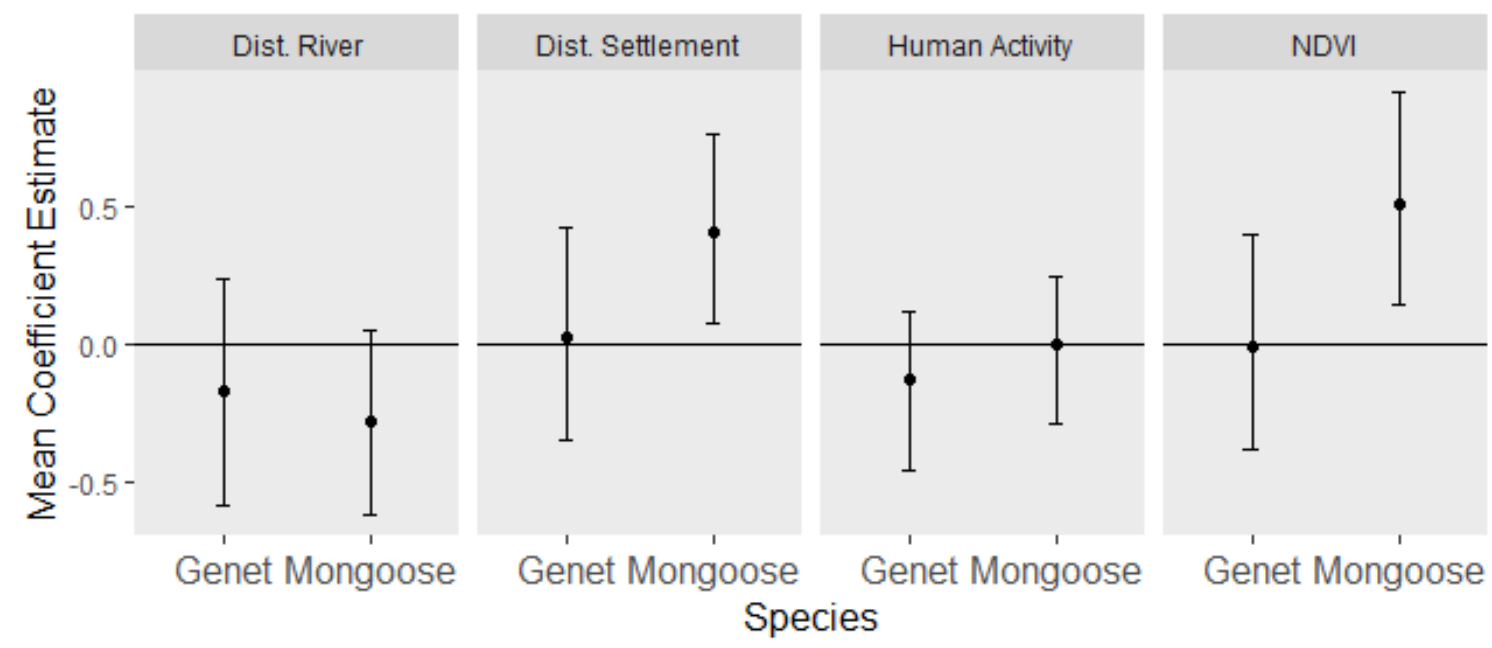

Figure 1.9 Mean coefficient estimates and 95\% credibility bars of each covariate for each species. Genets and mongoose did not have any statistically significant differences in their relationships to these covariates. 


\title{
CHAPTER TWO: SPATIAL PREDICTION OF MAMMAL RICHNESS OUTSIDE MOZAMBIQUE'S GORONGOSA NATIONAL PARK FOR LANDSCAPE CORRIDOR PLANNING
}

\begin{abstract}
Habitat loss and fragmentation threaten wildlife and ecosystems across the globe. Amid rapid land-use changes in Africa especially, managers need tools to prioritize conservation efforts outside of protected areas. We studied how human activities affect the distribution and composition of a mammalian community with various habitat requirements in a multi-use area of central Mozambique. We deployed 75 motiondetecting cameras and photographed 30 mammalian species. We used hierarchical, multispecies occupancy models to estimate species richness at each station and compared the relative effects of natural and anthropogenic features on the presence of individual species and groups of species when categorized into taxonomic/functional groups and body size groups. Richness at each station varied from 3-17 species, and both human and natural parameters varied in their importance for the occupancy likelihood for different species. When species were grouped by taxa and diets, settlement proximity negatively affected the occupancies of carnivores, insectivores, and other foragers. Similarly, settlement proximity negatively affected the occupancies of species in all four body size groups. However, active roads and human activity rates did not have a statistically significant relationship with any species' occupancies or detection rates, respectively. Overall, mammalian richness was highest far from human settlements in the concession
\end{abstract}


and close to rivers. Building on scant knowledge of wildlife communities in multiuse landscapes, our results shed light on understudied species assemblages to guide conservation and connectivity efforts in Mozambique.

\section{Introduction}

Rapid land use change and resulting habitat loss are driving species extinctions and declines across the globe and fundamentally altering ecosystem functions (Sanderson et al. 2002; Dobson et al. 2006; Sodhi et al. 2010). Protected areas (PAs) are critical for mitigating these threats and conserving threatened species (Yackulic et al. 2011; Geldmann et al. 2013). However, PAs cover less than 15\% of the Earth's surface (UNEPWCMC and IUCN 2016) and because they are often unconnected they may only provide temporary refuge for species and habitats vulnerable to change (Hansen \& DeFries 2007; Belote et al. 2016). Global conservation treaties such as the United Nations Convention on Biological Diversity (CBD) have therefore recognized the need for ecosystem-wide monitoring as goals shift from saving endangered species and parks to sustaining biological diversity and ecosystem function (Balmford et al. 2010). Indeed, CBD's Aichi Target 11 - which prompts nations to work together to increase protected area coverage specifies that protected areas must also be well connected (Balmford et al. 2010; Saura et al. 2018).

The need for establishing and maintaining connectivity between PAs is especially great in sub-Saharan Africa where human populations are rapidly growing and are expected to double by 2050 (United Nations 2017). Such growth drives land conversion and competition between people and wildlife over natural resources (Caro et al. 2014; Lindsey et al. 2017; Rogan et al. 2017). Despite immense research on wildlife corridors 
and habitat connectivity, the majority of ecological studies occur within protected areas rather than unprotected areas (Pettorelli et al. 2010; Martin et al. 2012; Balme et al. 2013; Pardo Vargas et al. 2016; Durant et al. 2017) or focus on a single species rather than ecological communities (Beier et al. 2011; Brodie et al. 2014). Even the International Union for the Conservation of Nature's threat assessments rely mostly on information from PAs, which may underestimate the risks to species outside of these well-monitored sites (Durant et al. 2017). Furthermore, the focus on single, endangered species, while important, overlooks recently noted declines in seemingly common species (Inger et al. 2015; Ceballos et al. 2017). Such declines may serve as alarming indicators of wide-scale ecosystem degradation (Conrad et al. 2006; Lindenmayer et al. 2011). To establish effective wildlife corridors, identify areas of high conservation priority, and prevent species extinctions in the face of rapid land use change (Brodie et al. 2014; Rich et al. 2016), we need more information on both species and community-level distributions in multi-use landscapes and their responses to anthropogenic disturbances.

For the first time we assess mammalian occurrence and community distributions in the Greater Gorongosa region - a biodiversity hotspot - in central Mozambique. Wildlife populations and human communities in this region are recovering from a postcolonial civil war that ended in 1992. Parque Nacional da Gorongosa (PNG) and its surrounding communities were in the center of the conflict, which wiped out more than 90\% of the park's megafauna (Daskin et al. 2016). In 2008, the Gregory C. Carr Foundation signed a co-management agreement with the Mozambican government to restore the PNG and its wildlife. Since recovery efforts began, wildlife populations have been steadily increasing to pre-war estimates, but with markedly different community 
compositions (Pringle 2017). Medium-sized antelope exceed pre-war estimates, while the predator community remains low in numbers and richness. Furthermore, lions (Panthera leo) are the only large carnivores established in the park, although PNG historically supported leopard (P. pardus), hyena (Crocuta crocuta) and wild dog (Lycaon pictus). Conservation managers are looking to establish connectivity between PNG and other PAs in the Greater Gorongosa region to maintain biodiversity and healthy ecosystems, and facilitate the movement of species not yet established in the park, such as large carnivores. Yet, there is little information on the wildlife communities outside PNG or on how such communities or individual species are responding to human presence within different habitats. Furthermore, the miombo woodlands, despite covering a vast swath of the African continent, are relatively understudied (Caro 1999). As human activities increase in this ecosystem and in the Gorongosa region, specifically, such baseline information is required for successful conservation planning in these multi-use landscapes.

Collecting baseline information across a range of species is important because certain groups of animals may be more vulnerable to human disturbances, environmental change, and habitat fragmentation than others. For example, the high nutritional requirements and low reproductive rates of large herbivores increase their vulnerability to habitat loss and resource depletion (Cardillo et al. 2005; Ripple et al. 2015). Similarly, large carnivores are wide-ranging and prone to conflict with humans through livestock depredation or competition over prey resources (Ripple et al. 2014; Rogan et al. 2017), which may influence space use patterns and contribute to population decline. In contrast, other species, such as small, opportunistic carnivores and rodents, may readily adapt to 
human presence and utilize multiuse areas (Linzey \& Kesner 1997; Crooks 2002; Roemer et al. 2009; Schuette et al. 2013; Pardo Vargas et al. 2016). Different animal responses to natural and anthropogenic factors drive wildlife community composition and distributions, and have important implications for conservation (Carter \& Linnell 2016).

To capture variation in species responses, we used a multispecies occupancy model to quantify the effects of natural and anthropogenic factors on the space use of animals in different body size and taxonomic classification groups across an active forestry concession outside of PNG. We hypothesized that (1) carnivore and large mammal occupancy will be highest in areas less influenced by human activities (Cardillo et al. 2005; Ripple et al. 2014), (2) overall species richness will be highest in areas less influenced by human activities (Epps et al. 2011), and (3) the influence of environmental variables on species occupancy will vary, depending on species' behavioral niches (Kleynhans et al. 2011; Schuette et al. 2013; Rich et al. 2016). This study adds to scant literature on species communities in multiuse areas and can therefore help inform conservation planning with the aim of connecting large landscapes for multiple wildlife species through human-modified landscapes.

\section{Methods}

\section{Study Area}

We conducted this study in a $460 \mathrm{~km}^{2}$, Forest Stewardship Council-certified forestry concession east of PNG's buffer zone (Figure 2.1) in central Mozambique. We chose this site as a starting point for systematic surveying outside of PNG because this concession borders the park's buffer zone and consequently has higher amounts of human activity while remaining close to a protected area. Because of this, it is also the first area 
involved in the park's efforts to expand conservation efforts eastward to the coast (Pringle 2017).

The concession borders and partly contains one large settlement and several households. The company's headquarters and sawmill are located within the concession toward the southern end. Workers, including a small team of scouts, temporarily live on site at the headquarters. A large dirt road and parallel railway borders the western side of the concession which connects the city of Beira in the south to Marromeu and other roadways in the north. Roads within the concession are single-track, dirt roads created mainly for timber-harvest purposes, with the exception of the southern-most and northern-most roads, which connect the headquarters to the main road in the south and connects communities from east to west in the north (Figure 2.1). Other roads not currently in use for timber harvest are mostly inactive and grown over with vegetation. Other forestry concessions, hunting concessions, the park's buffer zone, and other settlements surround our study site.

Central Mozambique has a sub-tropical climate with a wet season (NovemberApril) and dry season (May-October). Our study area comprises mainly miombo woodlands and includes varying levels of tree densities, from open grasslands to closedcanopy riparian areas. Elevation varies from approximately 150-350 meters and decreases from the Cheringoma Plateau in the west to the east toward the coast. The terrain is relatively flat, but steep areas occur near river drainages and can reach $30 \%$ grades. 


\section{Wildlife Occurrence Data}

We deployed motion-detecting, infrared camera traps (Bushnell Trophy Cam 24MP and 14MP no-glow Aggressors) at 77 sites within the forestry concession (Figure 2.1). We knew from exploratory surveys in 2016 that leopards occur in this forestry concession, but had little information on the presence of other potentially wide-ranging species. We therefore followed field camera protocols from other studies that quantified large carnivore space use (Carter et al. 2012; Rosenblatt et al. 2016). We used a $4 \mathrm{~km}^{2}$ hexagonal grid with approximately $2 \mathrm{~km}$ separating each site to guide our camera placement, but we prioritized roads and animal trails where possible. At most sites, traps consisted of a pair of cameras facing toward each other to protect against possible failures and to begin identifying individual animals with unique markings such as leopards (Carter et al. 2015). We were especially interested in knowing how many animals and which species occur close to the main road that borders the concession to the west. So, to maximize camera coverage along the main road, we had two rows of single-camera traps separated by about $1 \mathrm{~km}$. We rotated traps in four successive blocks from June to October 2017 (Ahumada et al. 2013) to cover roughly 320km² (Sollmann et al. 2012; Rovero et al. 2016) and maintain population closure assumptions (Mackenzie \& Royle 2005). Each block operated for approximately 20 days (Karanth et al. 2004; Wegge et al. 2009; Athreya et al. 2013). We mounted each camera at knee height relative to the area or trail of interest. At each station, we recorded elevation, took notes on habitat characteristics, and estimated the amount of canopy cover at the station in categories $(0-25 \%, 25-50 \%$, etc.). 


\section{Occupancy Modelling}

We used recently developed, multispecies occupancy models to quantify mammalian richness and the influence of natural and human factors on species space use (Russell et al. 2009; Zipkin et al. 2009, 2010; Burton et al. 2012; Jones et al. 2012; Hunt et al. 2013; Sauer et al. 2013; Tingley \& Beissinger 2013; Giovanini et al. 2013; Grant et al. 2013). Multispecies occupancy models allow collective community observations to inform the occurrence probabilities of all species observed, while still accounting for imperfect detection and for the variation in the effects of habitat and sampling factors for different species' occupancy and detection rates, respectively (Dorazio \& Royle 2005; White et al. 2013; Tobler et al. 2015). These community-level approaches also allow for the grouping of different species according to specific hypotheses for better community inference (Pacifici et al. 2014; Rich et al. 2016, 2017) .

We adapted and used a multispecies occupancy model developed by Rich et al. (2016). This approach uses detection records from the cameras (number of detections per species per survey) to estimate the probability of a species $i$ occurring at survey site $j$ while accounting for imperfect detection (MacKenzie et al. 2002; Dorazio \& Royle 2005). We treated each trap day as a repeat survey at each trap site to distinguish between true absences and failures to detect a species (Kéry \& Royle 2008; Zipkin et al. 2010). Additionally, by incorporating the number of nights each trap was out, we utilized unbalanced data from blocks with different sampling lengths and accommodated for camera failure (Tobler et al. 2015).

In this model, occurrence $\left(z_{i, j}\right)$ is defined as a latent binary variable, where $z_{i, j}=1$ if trap site $j$ was within the range occupied by species $i$ and 0 if it was not. We assumed 
that species occurrences were the outcome of a Bernoulli process where $\Psi_{i, j}$ is the probability of a species $i$ occurring at trap site $j: z_{i, j} \sim \operatorname{Bern}\left(\Psi_{i, j}\right)$. Therefore, $z_{i, j}$ is conditional on observed occurrences at each site and the estimated probability of occupancy (Tobler et al. 2015). The probability of occupancy is also conditional on the probability of detection, defined here as: $x_{i, j k} \sim \operatorname{Bern}\left(p_{i, j, k} z_{i, j}\right)$, where the probability of observing species $i$ at camera station $j$ on trap day $k$ is conditional on the site being occupied, given that species $i$ was truly present (MacKenzie et al. 2002).

We fitted a single model to the whole community and sub-groups based on $a$ priori hypotheses (Zipkin et al. 2009, 2010, Tobler et al. 2015, 2018; Rich et al. 2016). Here, we define occupancy as the probability of an animal using the area at each camera trap site within their larger, unknown occupied range (Rich et al. 2016; Van der Weyde et al. 2018).

\section{Predictors of Animal Occupancy}

We included covariates we predicted would explain the natural variation in animal distributions due to differences in habitat needs, as well as anthropogenic variables hypothesized to influence community, group, or species-level space use. Based on previous studies (Bowkett et al. 2008; Epps et al. 2011; Burton et al. 2012; Ahumada et al. 2013; Schuette et al. 2013; Rovero et al. 2014; Pardo Vargas et al. 2016; Rich et al. 2016), we predicted that vegetation, cover, water availability, elevation, settlements, roads, and human presence would affect species space use (Table 2.1).

We assessed vegetation characteristics using the Normalized Difference Vegetation Index (NDVI) calculated from a cloud free, Landsat 8 image (Path 67, Row 73) acquired July 2017 and downloaded from USGS Earth Explorer 
(https://earthexplorer.usgs.gov/). Based on a visual evaluation and the outputs of an ANOVA test, we determined that NDVI values provided the same information as a land cover map we had created for three, general habitat types based on tree cover (App. B). Therefore, because it is a continuous variable and commonly used in occupancy studies (Burton et al. 2012; Rich et al. 2017), we used NDVI values instead of the categorical land cover map in the final model to represent habitat type, cover, and forage availability (DeFries \& Townshend 1994; Pettorelli et al. 2005; Ladle et al. 2018). We used the mean NDVI value from a 500m buffer surrounding each camera trap to determine each animal's likelihood of using that area (Carter et al. 2013). We chose 500m as an approximate middle point for the diversity of home range sizes of the smaller mammals known to occur in this area (Estes 2012; Williams et al. 2017).

To assess the influence of water availability on species occurrences, we adjusted spatial river data from a global HydroSHEDS dataset (Lehner et al. 2006) to match highaccuracy GPS points taken on the ground where we followed river and creek corridors. We then calculated the distance from each camera trap to the nearest river representing a relatively permanent source of water. Ephemeral water sources were not accounted for because they were only partially observed (Rich et al. 2016), and most temporary sources observed during camera deployment were dry once we returned for camera rotation.

Finally, elevation at each camera location was recorded using hand-held GPS receivers. These measurements were consistent with point estimates derived from a global, 30m resolution SRTM dataset. However, we removed elevation as a covariate as it was highly correlated with the distance from rivers (Pearson $r=0.71)$. 
To test the influence of human presence and activities on species' space use, anthropogenic variables included distance from permanent settlements within the concession and active roads (Laurance et al. 2008; Balme et al. 2010; Ogutu et al. 2011; Kiffner et al. 2013; Schuette et al. 2013). Active roads were identified based on the detection of people or vehicles other than our own during our sampling period. We calculated each camera traps' distance from the nearest settlement and active roads in ArcGIS 10.5.1. The locations of two settlements in the concession were identified using Google Earth: Condue to the southwest, and the concession's headquarters in the southeast. The final model for the probability of occupancy for each species $i$ at trap site $j$ was therefore specified as:

$\operatorname{logit}\left(\Psi_{i j}\right)=\alpha 0_{i}+\alpha 1_{i}(\text { distance to river })_{j}+\alpha 2_{i}\left(\mathrm{NDVI}_{500}\right)_{j}+\alpha 3_{i}(\text { distance to settlement })_{j}+$ $\alpha 4_{i}(\text { distance to active roads })_{j}$

\section{Predictors of Animal Detection}

Several variables may influence the process of detecting an animal, such as obstruction of the camera by vegetation, varying habitat preferences of different species, or human disturbance (Rovero et al. 2014). Some animals may be more likely to utilize open pathways for movement, so we included a binary variable for if a camera was placed on or off a trail (Tobler et al. 2015; Cusack et al. 2015; Kolowski \& Forrester 2017). We designated "trails" as being any area that is unobstructed by vegetation and served as an obvious pathway for animal movement, such as old and new roads, wellestablished human foot trails, and large, dry river corridors. We included an additional 
binary variable for whether or not a trap consisted of a pair of cameras (Pease et al. 2016). Human activity may also alter an animal's detection rates depending on if that species is diurnal or typically avoids people (Erb et al. 2012). We therefore included the rate at which people and vehicles were detected on camera as the proportion of days a person or vehicle was detected on camera out of the trap's total number of days operating. Finally, vegetation influences both occupancy and detection processes (Rovero et al. 2014; Burton et al. 2015). We therefore included NDVI values at each camera site (30m resolution) to account for differences in detection among forest-associated species and savannah-associated species (Table 2.1). Our final detection model is:

$\operatorname{logit}\left(p_{i j}\right)=\beta 0_{i}+\beta 1_{i}(\text { paired })_{j}+\beta 2_{i}(\text { trail })_{j}+\beta 3_{i}(\mathrm{NDVI})_{j}+\beta 4_{i}(\text { human } / \text { vehicle trap rate })_{j}$

We standardized all continuous covariates to have a mean of 0 and standard deviation of 1 . We can therefore obtain baseline occurrence and detection probabilities of species $i$ at a camera station with average covariate values by taking the inverse logit of $\alpha 0_{i}$ and $\beta 0_{i}$ (at a station off-trail with one camera), respectively. Each remaining coefficient $\left(\alpha 1_{i, . .,}, \alpha 4_{i}\right.$, and $\left.\beta 3_{i}, \beta 4_{i}\right)$ represents the effect of a one standard deviation increase of that respective covariate value for species $i$. Finally, we specified $\alpha 0_{i}$ and $\beta 0_{i}$ to be jointly distributed (Dorazio \& Royle 2005; Kéry \& Royle 2008) because a species' abundance can significantly affect detection probabilities, often resulting in strong, positive correlations between occupancy and detection (Royle \& Nichols 2003). 


\section{Species Groups}

Estimates of richness are more precise when the model "borrows strength" from the detections of the entire community (Pacifici et al. 2014). However, some covariate effects on individual species may be washed out by generalists or naturally abundant species that are detected more frequently. We therefore modelled group occupancies in addition to community occupancy for further hypothesis testing. First, we grouped species by body size according to their mean body mass as determined by Estes (1991). Groups included extra-large ( $\geq 200 \mathrm{~kg})$-, large (50-200 kg)-, medium (20-50 kg)- and small ( $<20 \mathrm{~kg}$ )-sized species (Rich et al. 2016). We also grouped species based on a combination of their taxonomic order and functional groups, such as carnivores, ungulates, or insectivores. We chose these classifications to answer specific questions about their spatial ecologies, which may be less clear when grouped strictly by diet, as there is considerable variability in species traits among omnivores, for example. We were also especially interested in the carnivore and ungulate groups given the lack of large predators in the system.

We used non-informative priors with uniform distributions for $\alpha 0_{i}$ and $\beta 0_{i}$ parameters, and regularizing priors for remaining parameters $\left(\alpha 1_{i, . .,} \alpha 4_{i}\right.$, and $\left.\beta 3_{i}, \beta 4_{i}\right)$ (McElreath 2015). We assumed species-specific parameters were random effects derived from a normally distributed, community hyper parameter (Zipkin et al. 2010; Rich et al. 2016). We ran all analyses in JAGS using the R package R2jags (Plummer 2011). We ran three chains of 60,000 iterations with a burn in of 10,000 and thinning rate of 50. Model convergence was assessed by visually inspecting trace plots and with the Gelman-Rubin diagnostic, where Rhat values > 1.1 indicate poor convergence (Gelman et al. 2004). 


\section{Results}

We obtained data from 75 of the 77 camera traps. Traps operated for 2,090 nights. We detected 30 mammal species over 1,168 trap days from seven taxonomic orders. We grouped species into five different taxonomic or functional groups: carnivores (order Carnivora), ungulates (order Artiodactyla), primates (order Primates), "other foragers" (orders Rodentia and Lagomorpha), and insectivores (orders Pholidota and Tubulidentata (App. A, Table A1.). Ungulate and carnivore groups included the largest number of species ( 13 and 8 , respectively). Mammals were also grouped by size with the majority of species considered "medium" (12 species) and "small" ( 9 species). On average, common duikers (Sylvicapra grimmia) were the most frequently detected species across sites ( 12 detections/100 trap days), and pangolins (Smutsia temminckii) were the least frequently detected ( 0.07/100 trap days; Figure 2.2).

\section{Community Model}

Model predicted community richness at each camera trap varied between 3 and 17 species. Richness was greatest near rivers and far from settlements and only weakly related to NDVI (Figure 2.3). These three factors were estimated to have a significant effect ( $95 \%$ credible intervals do not overlap zero) on at least one species' occupancy probability (App. A, Table A2). Distances from the nearest permanent settlement had the strongest effect on predicted occurrence with 7 out of 30 species' occupancy probabilities increasing as distance from settlement increases (App. A, Figure A1). Occupancy probabilities were higher for six out of 30 species near rivers, while one species (common duiker) was more likely to occur farther away from rivers (App. A, Figure A2). Similarly, common duikers were the only species to have a negative association with increasing 
NDVI, while sunis (Neotragus moschatus) had a positive relationship with increasing NDVI (App. A, Figure A3). Active roads did not have a significant relationship with any of the species' predicted occupancies; all 95\% credibility intervals overlapped zero, and posterior distributions were wide for even commonly detected species (App. A, Figure A4). Detection covariates did not significantly influence detection probabilities (credibility intervals overlapped 0) except for one; bushy-tailed mongoose detection probabilities decreased as NDVI increased (App. A, Table A3).

\section{Group Models}

\section{Taxonomic/Functional Groups}

Distance from settlements still had a strong, positive relationship with species occurrence and group richness for carnivores, other foragers, and insectivores (Table 2.3, Figure 5). Distance from settlements also had a weakly positive relationship with the occupancies of ungulates and primates, but was not a statistically significant factor. Distance from rivers had a negative relationship with the occurrences of primate and insectivore groups, and distance from active roads was negatively correlated with primate occupancy, likely owing to baboon detections dominating this group and their common utilization of roads. NDVI was not strongly correlated to the predicted richness of any of these groups, and varied from having a weakly positive relationship with carnivores to weakly negative for all other groups.

\section{$\underline{\text { Body Sizes }}$}

Mean occurrence probabilities and richness estimates for all four body size groups were significantly and positively correlated with increasing distances from permanent settlements (Table 2.3, Figure 2.6). Distance from rivers was also a significant predictor 
of medium-sized species, with occurrence probabilities and richness decreasing with increased distance from rivers. Small, large, and extra-large species occupancies also had weakly negative relationships with increasing distance from rivers. NDVI did not have a significant effect at the group level for species sizes, but varied from having a weakly positive relationship with small and medium-sized species occurrences and weakly negative relationship with large and extra-large species (Figure 2.6).

\section{Discussion}

\section{Anthropogenic Effects}

Proximity to human settlements strongly influenced occupancy estimates, negatively affecting species richness and space use at the individual, group, and community levels, while active roads did not have a significant effect on mammals in this community. These results partially supported our first and second hypotheses that large mammals and carnivores would be negatively associated with anthropogenic factors, and that overall richness would be highest farther from human activities. Several other studies in East Africa and elsewhere have also documented lower occupancy probabilities and species richness in areas that are permanently settled or have high human densities (Bowkett et al. 2008; Epps et al. 2011; Burton et al. 2012; Carter et al. 2013; Schuette et al. 2013, 2016; Vanthomme et al. 2013; Kiffner et al. 2015; Williams et al. 2017). For example, Kiffner et al. (2015) found that species richness was lower in permanent agricultural sites than in pastoral or protected areas. Researchers have proposed several explanations for the negative relationships documented between settlement proximity and wildlife occurrence. These include habitat degradation through cultivation and firewood collection (Nagendra et al. 2008; Carter et al. 2013), increased hunting pressure (Bowkett 
et al. 2008), human-wildlife conflict and retaliatory killing (Kiffner et al. 2015), and other perceived threats through sensory inputs such as noise or light (Longcore \& Rich 2004; McKenna et al. 2016). At our site, human-wildlife conflict is relatively minimal due to a lack of livestock, and agricultural areas are small. However, if small carnivores are a perceived threat to chickens in these communities, human-wildlife conflict may explain the negative relationship between settlement proximity and small carnivore occurrence (Williams et al. 2017). The communities in this concession are also relatively small and concentrated. We would not expect the effects of cultivation or resource extraction to propagate very far or be more of a habitat disturbance than timber harvest in the area. Although we did not directly test the effects of logging on animal space use, several studies have shown that sustainably managed concessions can support and even promote diverse mammal communities (Azevedo-Ramos et al. 2006; Clark et al. 2009; Roopsind et al. 2017; Tobler et al. 2018). The noise from the concession's headquarters and sawmill, however, may influence the space use of diurnal mammals (Barber et al. 2010; Clinchy et al. 2016; Drolet et al. 2016). Drolet and colleagues (2016) found that simulated drilling noise negatively affected the habitat use of white-tailed deer (Odocoileus virginianus) but we did not test for the effects of industrial noise at our site. Illegal bushmeat hunting is pervasive in the region, though, and may be altering occupancy in this concession (Lindsey et al. 2012). Snaring is the most common form of poaching in and around PNG (Unpublished data). Watson et al. (2013) found a strong correlation between snaring and human development in protected area buffer zones, but the effect this may have on animal occurrence is difficult to discern. Burton et al. (2012) found that snaring intensity had either no effect or even a positive effect on carnivore 
occupancy predictions and attributed this trend to people likely targeting highly productive areas for hunting success. Our study was unable to measure the effects of poaching on wildlife occurrence due to a lack of data, but our field team and subsequent patrols seized approximately 120 snares during the five months cameras were active, mostly in areas predicted to have high species richness, far from settlements. Furthermore, the effects of snaring compared to other forms of hunting are difficult to measure given their untargeted nature (Gray et al. 2018). Cane (Thryonomys gregorianus) and pouched rats (Cricetomys gambianus) are sought after for consumption, so this may influence the negative correlation between rodent occurrence and distance to settlement if hunting is more intense next to villages. However, if local hunters are targeting ungulates for consumption as in other locations (Bowkett et al. 2008; Henschel et al. 2011; Rogan et al. 2017), we would expect to see the same negative correlation for this group or individual species. Ungulates and primates were the only groups that did not have a significant, negative relationship, but ungulates may be more driven by environmental factors such as forage availability (Parker et al. 2009); and the primates group mostly consisted of baboons, which typically utilize anthropogenically-modified landscapes (Hoffman \& O’Riain 2011; Schuette et al. 2013).

We hypothesized that carnivores would be more sensitive to human factors (Cardillo et al. 2005; Ripple et al. 2014), and this group's strong negative association with settlement proximity partially supported that hypothesis. However, the carnivore guild in our site was mostly composed of small, generalist species that adapt well to human environments, such as genets and civets (Estes 2012). We were therefore surprised that distance to settlement significantly affected both the carnivore group and 
the small mammal group. The lack of large carnivores in this area may contribute to this response. Mesocarnivore release theory suggests that where dominant predators have declined or occur at low densities, subordinate species, relieved of competitive or predatory pressures, may occupy optimal habitats, farther from people, in greater abundances (Creel \& Creel 1996; Durant 1998; Crooks \& Soulé 1999; Ritchie \& Johnson 2009). As large carnivores recover in the Gorongosa ecosystem, they may suppress mesocarnivores or push them into marginal habitats, thereby potentially reversing the relationship between mesocarnivore occupancy and settlement proximity that we found in this study.

\section{Environmental Effects}

Responses to environmental covariates varied more among species, often in accordance to their behavioral niches, supporting our third hypothesis. For example, riverine-associated species such as marsh mongoose (Atilax paludinosus) were less likely to occur away from rivers, as were leopard, suni, red duiker (Cephalophus natalensis), giant pouched rat (Cricetomys gambianus), and samango (Cercopithecus albogularis). Common duikers, which tend to be more abundant in dry woodlands and savannahs (Estes 2012), were more likely to occur farther away from rivers in areas with low NDVI, corresponding to grassy areas in the dry season, while suni, a forest-associated species (Estes 2012), was more likely to occur in areas with high NDVI, corresponding to closedcanopy riverine forests. Distances from rivers was generally a more important factor in our study system than in Rich et al.'s (2016), which is expected given other wildlife studies (Pettorelli et al. 2010; Epps et al. 2011; Schuette et al. 2013). However, our camera traps were only out during the dry season, and our inferences on the importance 
of rivers are limited to a time period when species may be more bound to these permanent water sources. Nevertheless, the spatial distribution of rivers is an important component to consider for conservation planning.

Implications for Connectivity Planning

We identified areas most likely to support the highest levels of species richness and factors influencing the space use of species groups and rarely detected individuals of conservation concern such as leopards. Areas with high mammalian richness are predicted to be farther away from the settlements in the south, and furthermore, are adjacent to portions of the park's buffer zone with lower densities of people and settlements. This provides a potential starting point for connectivity planning and conservation efforts. Managers with limited time and resources could focus on alleviating pressures from illegal hunting and working with land managers to maintain these areas with high species richness to begin establishing wildlife corridors between multi-use and protected areas that benefit the mammal community. When managed well, sustainableuse forestry concessions can stimulate the local economy while also providing important habitat for smaller species and connectivity between protected areas for larger, more mobile species, such as large carnivores (Clark et al. 2009; Tobler et al. 2018).

The recovery of large carnivores is of particular interest to the managers of PNG, given their population declines globally and in the region during and after the civil war (Pringle 2017). Of concern among some scientists, however, is the efficacy of the "umbrella species" approach, which is when conservation efforts focus on one species, assuming these efforts will in turn benefit species at lower trophic levels or those which use similar habitats (Caro 2003; Brodie et al. 2014; Thornton et al. 2016). Although 
preliminary, areas used by leopards correspond with areas predicted to have high species richness, which may indicate their ability to serve as an umbrella species in this system. Several studies have shown that leopard occurrence is best predicted by prey availability, and as generalists, this may encompass a wide variety of species (Hayward et al. 2006, 2007; Henschel et al. 2011). Small carnivore diversity and space use may change, however, as leopards and other large carnivores recover (Durant 1998; Caro et al. 2003; Ramesh et al. 2017). Miombo woodlands typically support lower biomass densities than more heterogeneous landscapes (Waltert et al. 2009), though, which may keep large carnivores populations small and alleviate intraguild competition. Interspecific interactions will be important to monitor over time. Furthermore, to the north and northwest of our study site, there is another forestry concession that may harbor similar species abundances and diversity. We suggest extending camera surveys to these areas for connectivity planning, and to see if similar patterns are observed between species richness and distance from settlements farther north, including from the much larger town, Inhaminga.

$\underline{\text { Conclusion }}$

Our research has documented mammal occurrence and community composition in the miombo woodlands of a multi-use area of Mozambique, providing baseline information useful for connectivity planning. Generally, miombo woodlands and the wildlife they support are becoming increasingly threatened throughout Africa as a result of burgeoning human populations (Dewees et al. 2011; Cabral et al. 2011; Jew et al. 2016). In the Sofala Province of Mozambique, deforestation may result in the loss of this ecosystem and its services by 2040 (Garrett 2008). Despite these impending threats and 
their vast coverage in sub-Saharan Africa, these woodlands are a relatively understudied ecosystem, are largely unprotected, and have the potential to provide connectivity to and safeguard wildlife communities through multi-use landscapes (Caro 1999; Waltert et al. 2009; Jew et al. 2016).

\section{References}

Ahumada JA, Hurtado J, Lizcano D. 2013. Monitoring the Status and Trends of Tropical Forest Terrestrial Vertebrate Communities from Camera Trap Data: A Tool for Conservation. PLoS ONE 8:6-9.

Athreya V, Odden M, Linnell JDC, Krishnaswamy J, Karanth U. 2013. Big Cats in Our Backyards: Persistence of Large Carnivores in a Human Dominated Landscape in India. PLoS ONE 8:2-9.

Azevedo-Ramos C, de Carvalho O, do Amaral BD. 2006. Short-term effects of reducedimpact logging on eastern Amazon fauna. Forest Ecology and Management 232:26-35.

Balme GA, Lindsey PA, Swanepoel LH, Hunter LTB, Noss R. 2013. Failure of Research to Address the Rangewide Conservation Needs of Large Carnivores: Leopards in South Africa as a Case Study. Conservation Letters 7:3-11.

Balme GA, Slotow R, Hunter LTB. 2010. Edge effects and the impact of non-protected areas in carnivore conservation: Leopards in the Phinda-Mkhuze Complex, South Africa. Animal Conservation 13:315-323.

Balmford A et al. 2010. The Convention on Biological Diversity’s 2010 Target 2003:212-214.

Barber JR, Crooks KR, Fristrup KM. 2010. The costs of chronic noise exposure for terrestrial organisms. Trends in Ecology and Evolution 25:180-189.

Beier P, Spencer W, Baldwin RF, McRae BH. 2011. Toward Best Practices for Developing Regional Connectivity Maps. Conservation Biology 25:879-892. 
Belote TR, Dietz MS, McRae BH, Theobald DM, McClure ML, Hugh Irwin G, McKinley PS, Gage JA, Aplet GH. 2016. Identifying corridors among large protected areas in the United States. PLoS ONE 11:1-16.

Bowkett AE, Rovero F, Marshall AR. 2008. The use of camera-trap data to model habitat use by antelope species in the Udzungwa Mountain forests, Tanzania. African Journal of Ecology 46:479-487.

Brodie JF, Giordano AJ, Dickson B, Hebblewhite M, Bernard H, Mohd-azlan J, Anderson J. 2014. Evaluating Multispecies Landscape Connectivity in a Threatened Tropical Mammal Community 0:1-11.

Burton AC, Neilson E, Moreira D, Ladle A, Steenweg R, Fisher JT, Bayne E, Boutin S. 2015. Wildlife camera trapping : a review and recommendations for linking surveys to ecological processes. Journal of Applied Ecology 52:675-685.

Burton AC, Sam MK, Balangtaa C, Brashares JS. 2012. Hierarchical multi-species modeling of carnivore responses to hunting, habitat and prey in a West African protected area. PLoS ONE 7.

Cabral AIR, Vasconcelos MJ, Oom D, Sardinha R. 2011. Spatial dynamics and quantification of deforestation in the central-plateau woodlands of Angola (19902009). Applied Geography 31:1185-1193.

Cardillo M, Cardillo M, Mace GM, Jones KE, Bielby J, Bininda-Emonds ORP, Sechrest W, Orme CDL, Purvis A. 2005. Multiple Causes of High Extinction Risk in Large Mammal Species. Science 309:1239-1241.

Caro T, Darwin J, Forrester T, Ledoux-Bloom C, Wells C. 2014. Conservation in the anthropocene. Keeping the Wild: Against the Domestication of Earth 26:109-113.

Caro TM. 1999. Abundance and distribution of mammals in Katavi National Park, Tanzania. African Journal of Ecology 37:305-313.

Caro TM. 2003. Umbrella species: Critique and lessons from East Africa. Animal Conservation 6:171-181. 
Caro TM, Caro TM, Stoner CJ, Stoner CJ. 2003. The potential for interspeci c competition among African carnivores. Biological Conservation 110:67-75.

Carter N, Jasny M, Gurung B, Liu J. 2015. Impacts of people and tigers on leopard spatiotemporal activity patterns in a global biodiversity hotspot. Global Ecology and Conservation 3:149-162.

Carter NH, Gurung B, Viña A, Campa III H, Karki JB, Liu J. 2013. Assessing spatiotemporal changes in tiger habitat across different land management regimes. Ecosphere 4:124.

Carter NH, Linnell JDC. 2016. Co-Adaptation Is Key to Coexisting with Large Carnivores. Trends in ecology \& evolution 31:575-578.

Carter NH, Shrestha BK, Karki JB, Pradhan NMB, Liu J. 2012. Coexistence between wildlife and humans at fine spatial scales. Proceedings of the National Academy of Sciences 109:15360-15365.

Ceballos G, Ehrlich PR, Dirzo R. 2017. Biological annihilation via the ongoing sixth mass extinction signaled by vertebrate population losses and declines. Proceedings of the National Academy of Sciences:201704949.

Clark CJ, Poulsen JR, Malonga R, Elkan PW. 2009. Logging concessions can extend the conservation estate for central African tropical forests. Conservation Biology 23: $1281-1293$.

Clinchy M, Zanette LY, Roberts D, Suraci JP, Buesching CD, Newman C, Macdonald DW. 2016. Fear of the human "super predator" far exceeds the fear of large carnivores in a model mesocarnivore. Behavioral Ecology 0:117.

Conrad KF, Warren MS, Fox R, Parsons MS, Woiwod IP. 2006. Rapid declines of common, widespread British moths provide evidence of an insect biodiversity crisis. Biological Conservation 132:279-291.

Creel S, Creel NM. 1996. Limitation of African Wild Dogs by Competition with Larger Carnivores. Conservation Biology 10:526-538. 
Crooks KR. 2002. Relative Sensitivities of Mammalian Carnivores to Habitat Fragmentation. Conservation Biology 16:488-502.

Crooks KR, Soulé ME. 1999. Mesopredator release and avifaunal extinctions in a fragmented system. Nature 400:563-566.

Cusack JJ, Dickman AJ, Rowcliffe JM, Carbone C, Macdonald DW, Coulson T. 2015. Random versus Game Trail-Based Camera Trap Placement Strategy for Monitoring Terrestrial Mammal Communities. PLOS ONE 10:e0126373.

Daskin JH, Stalmans M, Pringle RM. 2016. Ecological legacies of civil war: 35-year increase in savanna tree cover following wholesale large-mammal declines. Journal of Ecology 104:79-89.

DeFries RS, Townshend JRG. 1994. NDVI-derived land cover classifications at a global scale. International Journal of Remote Sensing 15:3567-3586.

Dewees PA, Campbell BM, Katerere Y, Sitoe A, Cunningham AB, Angelsen A, Wunder S. 2011. Managing the Miombo Woodlands of Southern Africa : Policies, Incentives, and Options for the Rural Poor. World Bank, Washington, DC.

Dobson A et al. 2006. Habitat loss, trophic collapse, and the decline of ecosystem services. Ecology 87:1915-1924.

Dorazio RM, Royle JA. 2005. Estimating Size and Composition of Biological Communities by Modeling the Occurrence of Species. Journal of the American Statistical Association 100:389-398.

Drolet A, Dussault C, Côté SD. 2016. Simulated drilling noise affects the space use of a large terrestrial mammal. Wildlife Biology 22:284-293.

Durant SM. 1998. Competition refuges and coexistence: an example from Serengeti carnivores. Journal of Animal Ecology 67:370-386.

Durant SM et al. 2017. The global decline of cheetah (Acinonyx jubatus) and what it means for conservation. Proceedings of the National Academy of Sciences 114:528-533. 
Epps CW, Mutayoba BM, Gwin L, Brashares JS. 2011. An empirical evaluation of the African elephant as a focal species for connectivity planning in East Africa. Diversity and Distributions 17:603-612.

Erb PL, McShea WJ, Guralnick RP. 2012. Anthropogenic Influences on Macro-Level Mammal Occupancy in the Appalachian Trail Corridor. PLoS ONE 7:e42574.

Estes RD. 1991. The Behavior Guide to African Mammals: Including Hoofed Mammals, Carnivores, and Primates. The University of California Press, Berkeley.

Estes RD. 2012. The Behavior Guide to African Mammals, Including Hoofed Mammals, Carnivores, and Primates20th Anniv. University of California Press, Berkeley and Los Angeles, California, and London, England.

Garrett W. 2008. Conservation of miombo woodland in central Mozambique.

Geldmann J, Barnes M, Coad L, Craigie ID, Hockings M, Burgess ND. 2013. Effectiveness of terrestrial protected areas in reducing habitat loss and population declines. Biological Conservation 161:230-238.

Gelman A, Carlin JB, Stern HS, Rubin DB. 2004. Bayesian Data Analysis. Chapman and Hall, Boca Raton, FL.

Giovanini J, Kroll AJ, Jones JE, Altman B, Arnett EB. 2013. Effects of Management Intervention on Post-Disturbance Community Composition: An Experimental Analysis Using Bayesian Hierarchical Models. PLoS ONE 8:e59900.

Grant EHC, Zipkin EF, Nichols JD, Campbell JP. 2013. A Strategy for Monitoring and Managing Declines in an Amphibian Community. Conservation Biology 27:1245-1253.

Gray TNE, Hughes AC, Laurance WF, Long B, Lynam AJ, O'Kelly H, Ripple WJ, Seng T, Scotson L, Wilkinson NM. 2018. The wildlife snaring crisis: an insidious and pervasive threat to biodiversity in Southeast Asia. Biodiversity and Conservation 27:1031-1037.

Hansen AJ, DeFries R. 2007. Ecological mechanisms linking protected areas to surrounding lands. Ecological Applications 17:974-988. 
Hayward MW, Henschel P, O’Brien J, Hofmeyr M, Balme G, Kerley GIH. 2006. Prey preferences of the Leopard (Panthera pardus). Journal of Zoology 270:298-313.

Hayward MW, O’Brien J, Kerley GIH. 2007. Carrying capacity of large African predators: Predictions and tests. Biological Conservation 139:219-229.

Henschel P, Hunter LTB, Coad L, Abernethy KA, Mühlenberg M. 2011. Leopard prey choice in the Congo Basin rainforest suggests exploitative competition with human bushmeat hunters. Journal of Zoology 285:11-20.

Hoffman TS, O’Riain MJ. 2011. The Spatial Ecology of Chacma Baboons (Papio ursinus) in a Human-modified Environment. International Journal of Primatology 32:308-328.

Hunt SD, Guzy JC, Price SJ, Halstead BJ, Eskew EA, Dorcas ME. 2013. Responses of riparian reptile communities to damming and urbanization. Biological Conservation 157:277-284.

Inger R, Gregory R, Duffy JP, Stott I, Voř́ššek P, Gaston KJ. 2015. Common European birds are declining rapidly while less abundant species' numbers are rising. Ecology Letters 18:28-36.

Jew EKK, Dougill AJ, Sallu SM, O’Connell J, Benton TG. 2016. Miombo woodland under threat: Consequences for tree diversity and carbon storage. Forest Ecology and Management 361:144-153.

Jones JE, Kroll AJ, Giovanini J, Duke SD, Ellis TM, Betts MG. 2012. Avian Species Richness in Relation to Intensive Forest Management Practices in Early Seral Tree Plantations. PLoS ONE 7:e43290.

Karanth KU, Chundawat RS, Nichols JD, Kumar NS. 2004. Estimation of tiger densities in the tropical dry forests of Panna, Central India, using photographic capturerecapture sampling. Animal Conservation 7:285-290.

Kéry M, Royle JA. 2008. Hierarchical Bayes estimation of species richness and occupancy in spatially replicated surveys. Journal of Applied Ecology 45:589598. 
Kiffner C, Stoner C, Caro T. 2013. Edge effects and large mammal distributions in a national park. Animal Conservation 16:97-107.

Kiffner C, Wenner C, LaViolet A, Yeh K, Kioko J. 2015. From savannah to farmland: effects of land-use on mammal communities in the Tarangire-Manyara ecosystem, Tanzania. African Journal of Ecology 53:156-166.

Kleynhans EJ, Jolles AE, Bos MRE, Olff H. 2011. Resource partitioning along multiple niche dimensions in differently sized African savanna grazers. Oikos 120:591600.

Kolowski JM, Forrester TD. 2017. Camera trap placement and the potential for bias due to trails and other features. PLOS ONE 12:e0186679.

Ladle A, Steenweg R, Shepherd B, Boyce MS. 2018. The role of human outdoor recreation in shaping patterns of grizzly bear-black bear co-occurrence. PLoS ONE 13:1-16.

Laurance WF, Croes BM, Guissouegou N, Buij R, Dethier M, Alonso A. 2008. Impacts of Roads, Hunting, and Habitat Alteration on Nocturnal Mammals in African Rainforests. Conservation Biology 22:721-732.

Lehner, B., Verdin K, Jarvis A. 2006. HydroSHEDS Technical Documentation. World Wildlife Fund US, Washington, DC. Available from http://hydrosheds.cr.usgs.gov. (accessed July 4, 2018).

Lindenmayer DB, Wood JT, McBurney L, MacGregor C, Youngentob K, Banks SC. 2011. How to make a common species rare: A case against conservation complacency. Biological Conservation 144:1663-1672.

Lindsey PA et al. 2017. The performance of African protected areas for lions and their prey. Biological Conservation 209:137-149.

Lindsey P, Bento C, Traffic. 2012. Illegal Hunting and the Bushmeat Trade in Central Mozambique: a Case-Study From Coutada 9, Manica Province. 
Linzey A V., Kesner MH. 1997. Small mammals of a woodland-savannah ecosystem in Zimbabwe. I. Density and habitat occupancy patterns. Journal of Zoology 243:137-152.

Longcore T, Rich C. 2004. Ecological Light Pollution. Frontiers in Ecology and the Environment 2:191.

MacKenzie DI, Nichols JD, Lachman GB, Droege S, Royle AA, Langtimm CA. 2002. Estimating site occupancy rates when detection probabilities are less than one. Ecology 83:2248-2255.

Mackenzie DI, Royle JA. 2005. Designing occupancy studies : general advice and allocating survey effort:1105-1114.

Martin LJ, Blossey B, Ellis E. 2012. Mapping where ecologists work: biases in the global distribution of terrestrial ecological observations. Frontiers in Ecology and the Environment 10:195-201.

McElreath R. 2015. Statistical Rethinking: A Bayesian Course with Examples in R and Stan. CRC Press, Taylor \& Francis Group.

Mckenna MF, Shannon G, Fristrup K. 2016. Characterizing anthropogenic noise to improve understanding and management of impacts to wildlife. Endangered Species Research 31:279-291.

Nagendra H, Pareeth S, Sharma B, Schweik CM, Adhikari KR. 2008. Forest fragmentation and regrowth in an institutional mosaic of community, government and private ownership in Nepal. Landscape Ecology 23:41-54.

Ogutu JO, Owen-Smith N, Piepho HP, Said MY. 2011. Continuing wildlife population declines and range contraction in the Mara region of Kenya during 1977-2009. Journal of Zoology 285:99-109.

Pacifici K, Zipkin EF, Collazo JA, Irizarry JI, Dewan A. 2014. Guidelines for a priori grouping of species in hierarchical community models. Ecology and Evolution 4:877-888. 
Pardo Vargas LE, Cove M V, Spinola RM, de la Cruz JC, Saenz JC. 2016. Assessing species traits and landscape relationships of the mammalian carnivore community in a neotropical biological corridor. Biodiversity \& Conservation 25:739-752.

Parker KL, Barboza PS, Gillingham MP. 2009. Nutrition integrates environmental responses of ungulates. Functional Ecology 23:57-69.

Pease BS, Nielsen CK, Holzmueller EJ. 2016. Single-Camera Trap Survey Designs Miss Detections: Impacts on Estimates of Occupancy and Community Metrics. PLOS ONE 11:e0166689.

Pettorelli N, Lobora AL, Msuha MJ, Foley C, Durant SM. 2010. Carnivore biodiversity in Tanzania: Revealing the distribution patterns of secretive mammals using camera traps. Animal Conservation 13:131-139.

Pettorelli N, Vik JO, Mysterud A, Gaillard J-M, Tucker CJ, Stenseth NC. 2005. Using the satellite-derived NDVI to assess ecological responses to environmental change. Trends in Ecology \& Evolution 20:503-510.

Plummer M. 2011. JAGS: a program for the statistical analysis of Bayesian hierarchical models by Markov Chain Monte Carlo.

Pringle RM. 2017. Upgrading protected areas to conserve wild biodiversity. Nature 546:91-99.

Ramesh T, Kalle R, Downs CT. 2017. Staying safe from top predators: patterns of cooccurrence and inter-predator interactions. Behavioral Ecology and Sociobiology 71.

Rich LN, Miller DAW, Robinson HS, McNutt JW, Kelly MJ. 2016. Using camera trapping and hierarchical occupancy modelling to evaluate the spatial ecology of an African mammal community. Journal of Applied Ecology 53:1225-1235.

Rich LN, Miller DAW, Robinson HS, McNutt JW, Kelly MJ. 2017. Carnivore distributions in Botswana are shaped by resource availability and intraguild species. Journal of Zoology 303:90-98. 
Ripple WJ et al. 2014. Status and ecological effects of the world's largest carnivores. Science 343:1241484.

Ripple WJ et al. 2015. Collapse of the world's largest herbivores. Ecology.

Ritchie EG, Johnson CN. 2009. Predator interactions, mesopredator release and biodiversity conservation. Ecology Letters 12:982-998.

Roemer GW, Gompper ME, Van Valkenburgh B. 2009. The ecological role of the mammalian mesocarnivore. BioScience 59:165-173.

Rogan MS, Lindsey PA, Tambling CJ, Golabek KA, Chase MJ, Collins K, McNutt JW. 2017. Illegal bushmeat hunters compete with predators and threaten wild herbivore populations in a global tourism hotspot. Biological Conservation 210:233-242.

Roopsind A, Caughlin TT, Sambhu H, Fragoso JMV, Putz FE. 2017. Logging and indigenous hunting impacts on persistence of large Neotropical animals. Biotropica 49:565-575.

Rosenblatt E, Creel S, Becker MS, Merkle J, Mwape H, Schuette P, Simpamba T. 2016. Effects of a protection gradient on carnivore density and survival: An example with leopards in the Luangwa valley, Zambia. Ecology and Evolution 6:37723785 .

Rovero F, Martin E, Rosa M, Ahumada JA, Spitale D. 2014. Estimating Species Richness and Modelling Habitat Preferences of Tropical Forest Mammals from Camera Trap Data. PLoS ONE 9.

Rovero F, Owen N, Jones T. 2016. Camera trapping surveys of forest mammal communities in the Eastern Arc Mountains reveal generalized habitat and human disturbance responses. Biodiversity and Conservation:50-52.

Royle JA, Nichols JD. 2003. Estimating abundance from repeated presence - absence data or point counts. Ecology 84:777-790. 
Russell RE, Royle JA, Saab VA, Lehmkuhl JF, Block WM, Sauer JR. 2009. Modeling the effects of environmental disturbance on wildlife communities: avian responses to prescribed fire. Ecological Applications 19:1253-1263.

Sanderson EW, Jaiteh M, Levy MA, Redford KH, Wannebo A V., Woolmer G. 2002. The Human Footprint and the Last of the Wild. BioScience 52:891.

Sauer JR, Blank PJ, Zipkin EF, Fallon JE, Fallon FW. 2013. Using multi-species occupancy models in structured decision making on managed lands. The Journal of Wildlife Management 77:117-127.

Saura S, Bertzky B, Bastin L, Battistella L, Mandrici A, Dubois G. 2018. Protected area connectivity: Shortfalls in global targets and country-level priorities. Biological Conservation 219:53-67.

Schuette P, Creel S, Christianson D. 2016. Ungulate distributions in a rangeland with competitors, predators and pastoralists. Journal of Applied Ecology 53:10661077.

Schuette P, Wagner AP, Wagner ME, Creel S. 2013. Occupancy patterns and niche partitioning within a diverse carnivore community exposed to anthropogenic pressures. Biological Conservation 158:301-312.

Sodhi NS, Koh LP, Clements R, Wanger TC, Hill JK, Hamer KC, Clough Y, Posa MRC, Lee TM. 2010. Conserving Southeast Asian forest biodiversity in humanmodified landscapes. Biological Conservation 143:2375-2384.

Sollmann R, Gardner B, Belant JL. 2012. How Does Spatial Study Design Influence Density Estimates from Spatial Capture-Recapture Models? 7:1-8.

Thornton D, Zeller K, Rondinini C, Boitani L, Crooks K, Burdett C, Rabinowitz A, Quigley H. 2016. Assessing the umbrella value of a range-wide conservation network for jaguars (Panthera onca). Ecological Applications 26:1112-1124.

Tingley MW, Beissinger SR. 2013. Cryptic loss of montane avian richness and high community turnover over 100 years. Ecology 94:598-609. 
Tobler MW, Garcia Anleu R, Carrillo-Percastegui SE, Ponce Santizo G, Polisar J, Zuñiga Hartley A, Goldstein I. 2018. Do responsibly managed logging concessions adequately protect jaguars and other large and medium-sized mammals? Two case studies from Guatemala and Peru. Biological Conservation 220:245-253.

Tobler MW, Zúñiga Hartley A, Carrillo-Percastegui SE, Powell GVN. 2015. Spatiotemporal hierarchical modelling of species richness and occupancy using camera trap data. Journal of Applied Ecology 52:413-421.

UNEP-WCMC and IUCN. 2016. Protected Planet Report 2016. How protected areas contribute to achieving global targets for biodiversity.

United Nations. 2017. World Population Prospects: The 2017 Revision, Key Findings and Advance Tables. Working Paper No. ESA/P/WP/248.

Van der Weyde LK, Mbisana C, Klein R. 2018. Multi-species occupancy modelling of a carnivore guild in wildlife management areas in the Kalahari. Biological Conservation 220:21-28.

Vanthomme H, Kolowski J, Korte L, Alonso A. 2013. Distribution of a Community of Mammals in Relation to Roads and Other Human Disturbances in Gabon, Central Africa. Conservation Biology 27:281-291.

Waltert M, Meyer B, Kiffner C. 2009. Habitat availability, hunting or poaching: What affects distribution and density of large mammals in western Tanzanian woodlands? African Journal of Ecology 47:737-746.

Watson F, Becker MS, McRobb R, Kanyembo B. 2013. Spatial patterns of wire-snare poaching: Implications for community conservation in buffer zones around National Parks. Biological Conservation 168:1-9.

Wegge P, Odden M, Pokharel CP, Storaas T. 2009. Predator-prey relationships and responses of ungulates and their predators to the establishment of protected areas: A case study of tigers, leopards and their prey in Bardia National Park, Nepal. Biological Conservation 142:189-202. 
White AM, Zipkin EF, Manley PN, Schlesinger MD. 2013. Conservation of Avian Diversity in the Sierra Nevada: Moving beyond a Single-Species Management Focus. PLoS ONE 8:e63088.

Williams ST, Maree N, Taylor P, Belmain SR, Keith M, Swanepoel LH. 2017. Predation by small mammalian carnivores in rural agro-ecosystems: An undervalued ecosystem service? Ecosystem Services.

Yackulic CB, Sanderson EW, Uriarte M. 2011. Anthropogenic and environmental drivers of modern range loss in large mammals. Proceedings of the National Academy of Sciences 108:4024-4029.

Zipkin EF, Andrew Royle J, Dawson DK, Bates S. 2010. Multi-species occurrence models to evaluate the effects of conservation and management actions. Biological Conservation 143:479-484.

Zipkin EF, DeWan A, Andrew Royle J. 2009. Impacts of forest fragmentation on species richness: a hierarchical approach to community modelling. Journal of Applied Ecology 46:815-822. 
Tables

Table 2.1 Factors predicted to influence community richness, species space use, and species detection.

\begin{tabular}{lll}
\multicolumn{2}{l}{ Occupancy Covariates } & Predicted Effect \\
\hline$\alpha 1_{i}$ & Distance from River & - \\
$\alpha 2_{i}$ & NDVI $_{500 \mathrm{~m}}$ & $+/-$ \\
$\alpha 3_{i}$ & Distance from Settlement & + \\
$\alpha 4_{i}$ & Distance from Active Road & $+/-$ \\
Detection Covariates & Predicted Effect \\
\hline$\beta 1_{i}$ & Paired Cameras & + \\
$\beta 2_{i}$ & On Trail & + \\
$\beta 3_{i}$ & NDVI $_{30 \mathrm{~m}}$ & $+/-$ \\
$\beta 4_{i}$ & Human/Vehicle Detection Rate & -
\end{tabular}

Table 2.2 Mean parameter estimates of occupancy and detection covariates of the full community model. Probability estimates denote the likelihood that the covariate has a positive or negative effect on species occurrence or detection, calculated by summing the number of draws with a positive or negative estimate, dividing by the total number of draws and multiplying by 100.

\begin{tabular}{lllll}
\multicolumn{2}{l}{ Community Level Covariate } & Mean & Probability (+) & Probability (-) \\
\hline$\alpha 1_{i}$ & Distance from River & -0.374 & 70 & 30 \\
$\alpha 2_{i}$ & NDVI $_{500 \mathrm{~m}}$ & -0.104 & 44 & 56 \\
$\alpha 3_{i}$ & Distance from Settlement & 0.431 & 92 & 8 \\
$\alpha 4_{i}$ & Distance from Active Road & -0.132 & 81 & 19 \\
\hline$\beta 1_{i}$ & Paired Cameras & -0.012 & 43 & 57 \\
$\beta 2_{i}$ & On Trail & -0.001 & 47 & 53 \\
$\beta 3_{i}$ & $\mathrm{NDVI}_{30 \mathrm{~m}}$ & -0.011 & 50 & 50 \\
$\beta 4_{i}$ & Human/Vehicle Detection Rate & 0.046 & 54 & 46
\end{tabular}


Table 2.3 Group mean coefficient estimates. Standard deviations are in parentheses and bold terms indicate $95 \%$ credibility intervals that did not overlap zero.

\begin{tabular}{lllll} 
Group & $\begin{array}{l}\text { Distance to } \\
\text { River }\end{array}$ & NDVI & $\begin{array}{l}\text { Distance to } \\
\text { Settlement }\end{array}$ & $\begin{array}{l}\text { Distance to } \\
\text { Active Roads }\end{array}$ \\
\hline Small & $-0.51(0.34)$ & $0.36(0.36)$ & $\mathbf{0 . 6 4}(\mathbf{0 . 3 1})$ & $-0.27(0.37)$ \\
Medium & $\mathbf{- 0 . 5 7 ( \mathbf { 0 . 2 9 } )}$ & $0.01(0.27)$ & $\mathbf{0 . 5 1}(\mathbf{0 . 2 2})$ & $-0.21(0.23)$ \\
Large & $-0.36(0.23)$ & $-0.14(0.21)$ & $\mathbf{0 . 3 7}(\mathbf{0 . 1 6})$ & $-0.11(0.15)$ \\
Extra-Large & $-0.30(0.24)$ & $-0.31(0.24)$ & $\mathbf{0 . 5 0}(\mathbf{0 . 1 9})$ & $-0.09(0.16)$ \\
\hline Carnivore & $-0.37(0.24)$ & $0.08(0.23)$ & $\mathbf{0 . 5 0}(\mathbf{0 . 1 6})$ & $0.01(0.15)$ \\
Ungulate & $-0.51(0.38)$ & $-0.22(0.35)$ & $0.13(0.29)$ & $-0.21(0.28)$ \\
Primate & $\mathbf{- 0 . 6 5 ( 0 . 3 2 )}$ & $-0.25(0.32)$ & $0.35(0.30)$ & $-\mathbf{0 . 7 6}(\mathbf{0 . 2 6})$ \\
Insectivore & $\mathbf{- 0 . 9 4 ( \mathbf { 0 . 5 0 } )}$ & $-0.60(0.48)$ & $\mathbf{0 . 9 7}(\mathbf{0 . 3 9})$ & $-0.57(0.48)$ \\
Other Forager & $-0.23(0.27)$ & $-0.25(0.27)$ & $\mathbf{0 . 4 9}(\mathbf{0 . 2 0})$ & $0.07(0.17)$
\end{tabular}




\section{Figures}

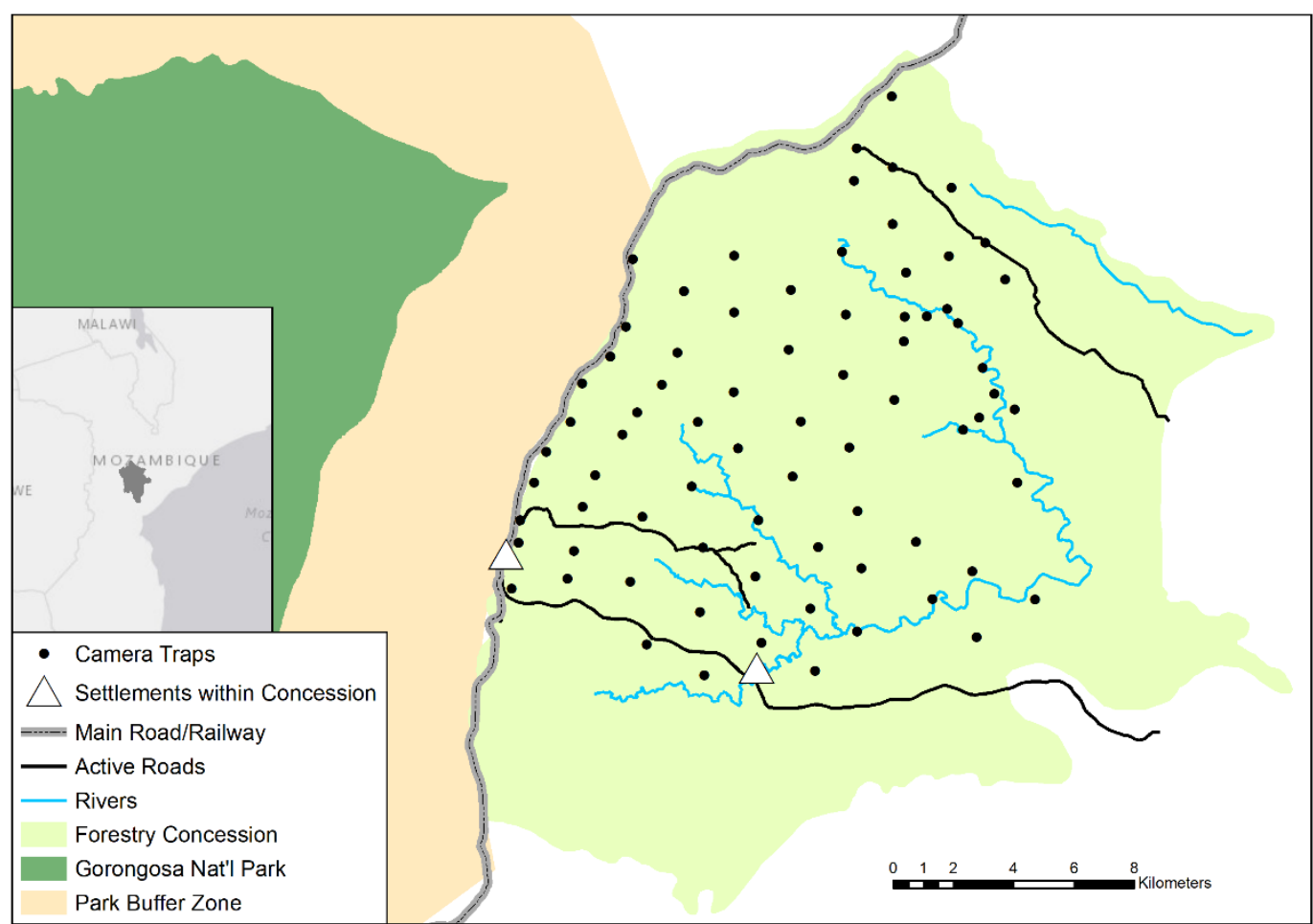

Figure 2.1 Map of our study site in a sustainable use forestry concession in central Mozambique, adjacent to Gorongosa National Park and its buffer zone. 


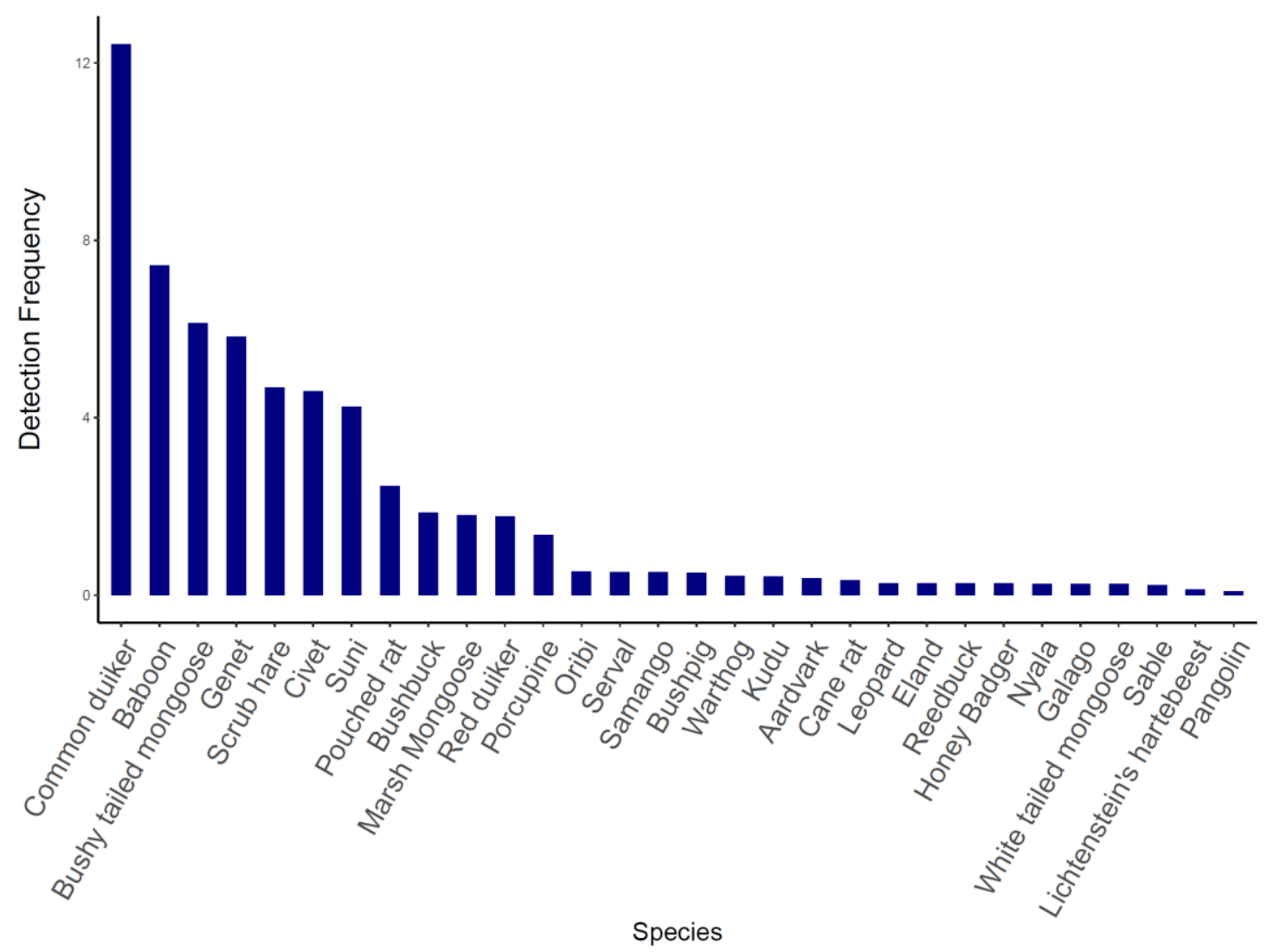

Figure 2.2 Average detection frequency per 100 trap days for 30 detected mammal species across all traps. 

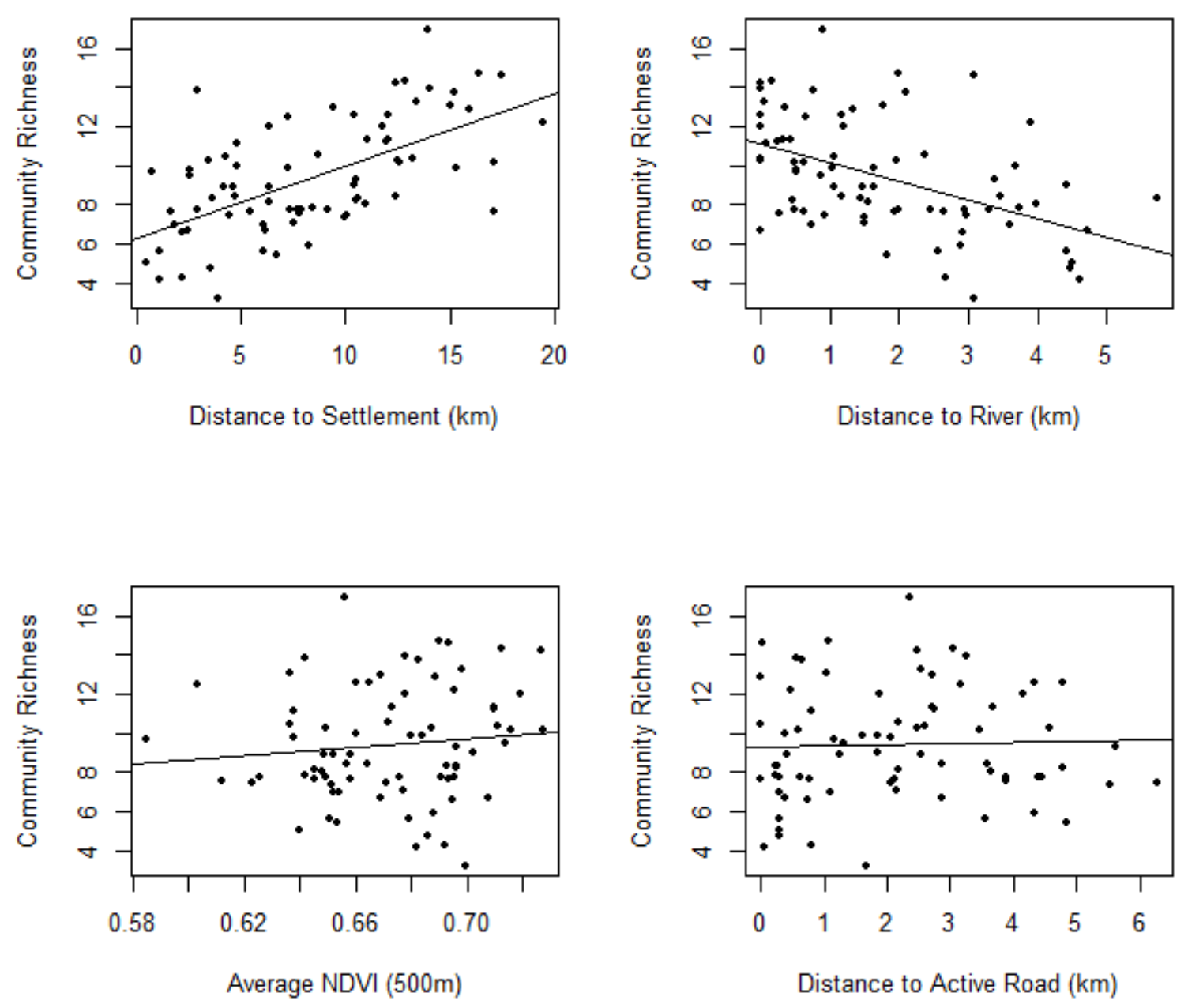

Figure 2.3 Mean site-specific estimates of species richness in relation to each trap's (a) distance to the nearest settlement, (b) distance to the nearest river, (c) average NDVI within a 500m radius around each trap, and (d) distance to the nearest active roads. 


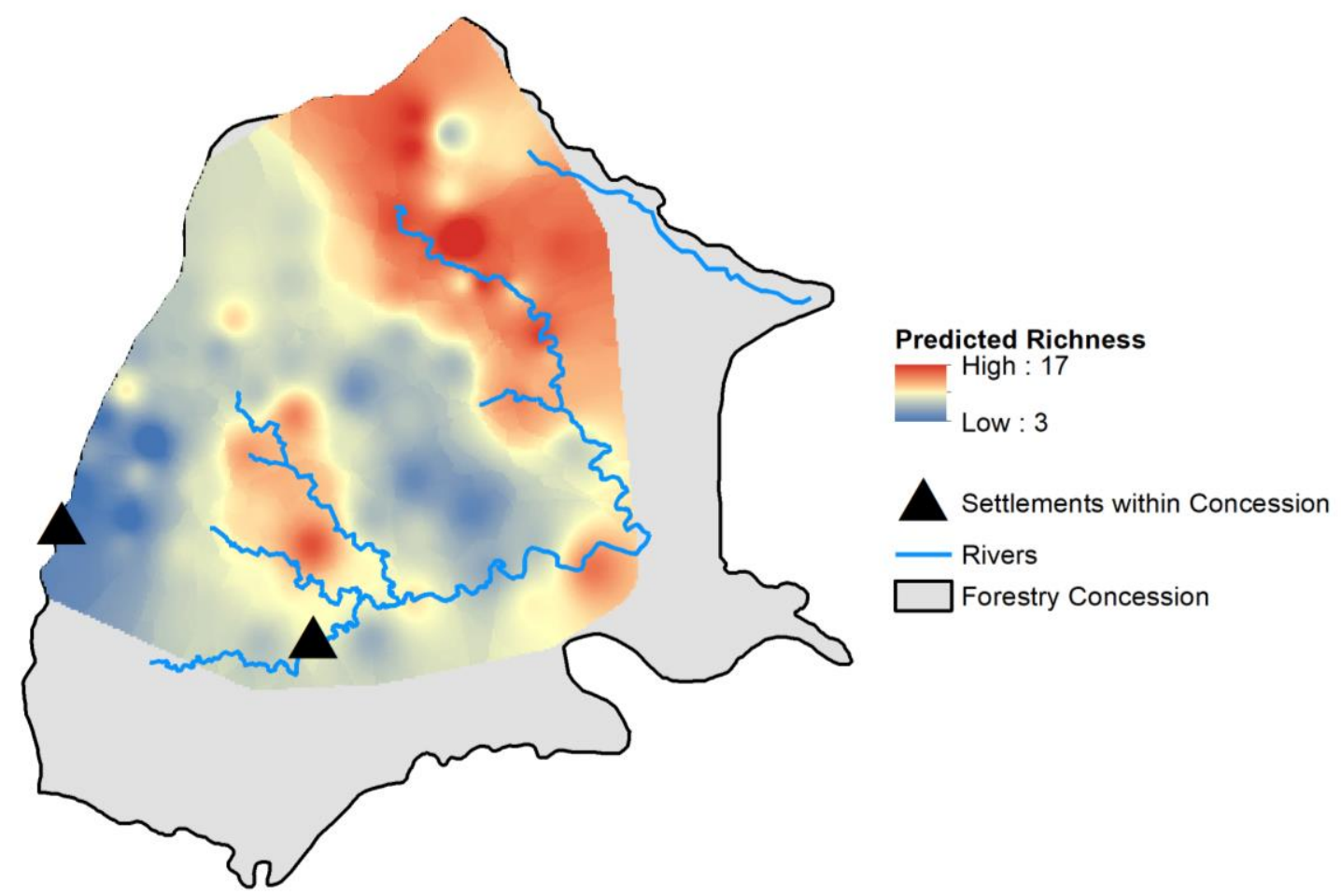

Figure 2.4 Inverse-distance weighted interpolation of model-predicted richness at each site from the full community model. Richness estimates ranged from three to 17 species at each trap. We set the boundaries of the interpolation at $1.5 \mathrm{~km}$ because that was the average distance between all traps. 


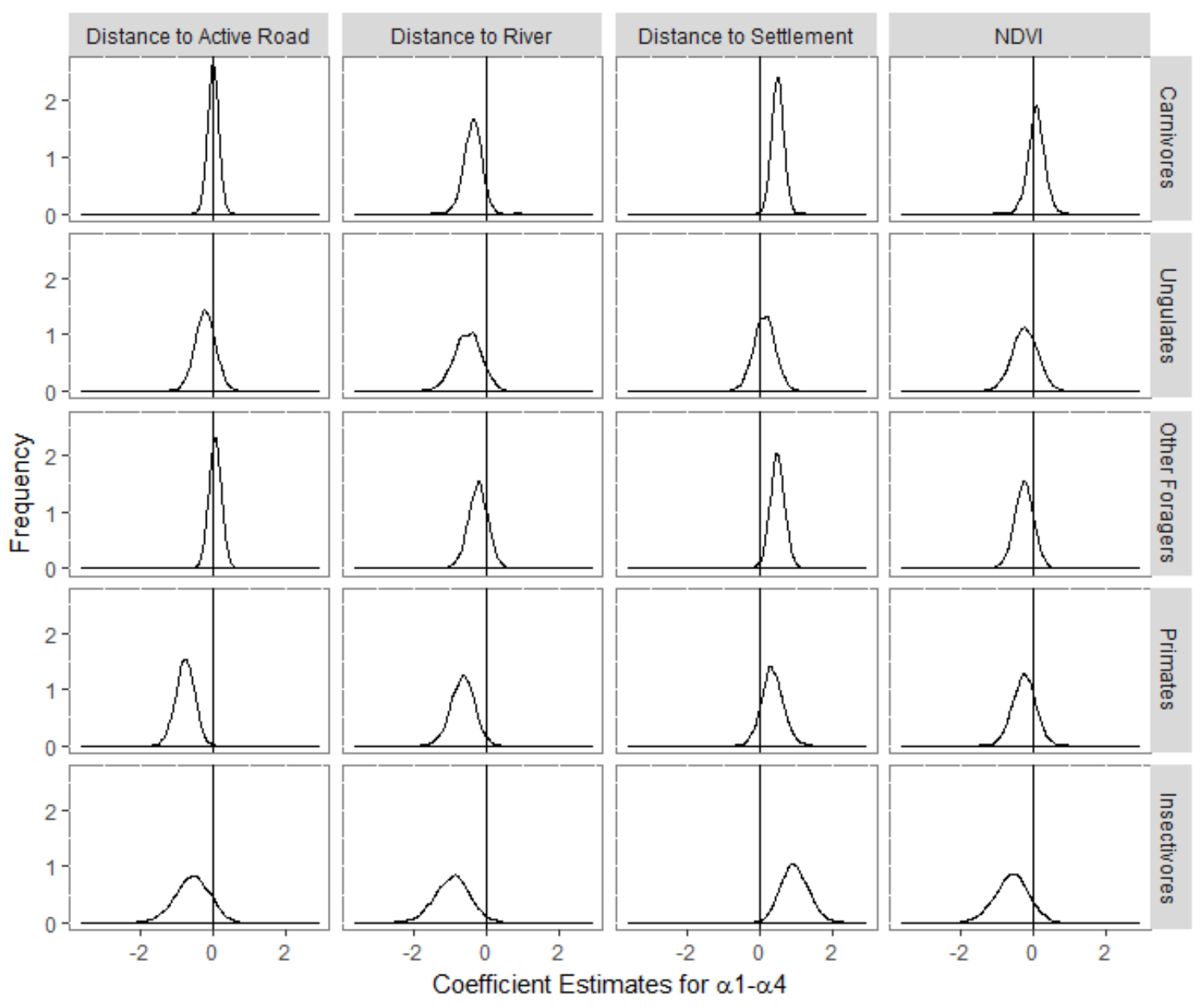

Figure 2.5 Posterior distributions of the occupancy model coefficient estimates for each taxonomic or functional group. Vertical bars mark estimates of zero. 


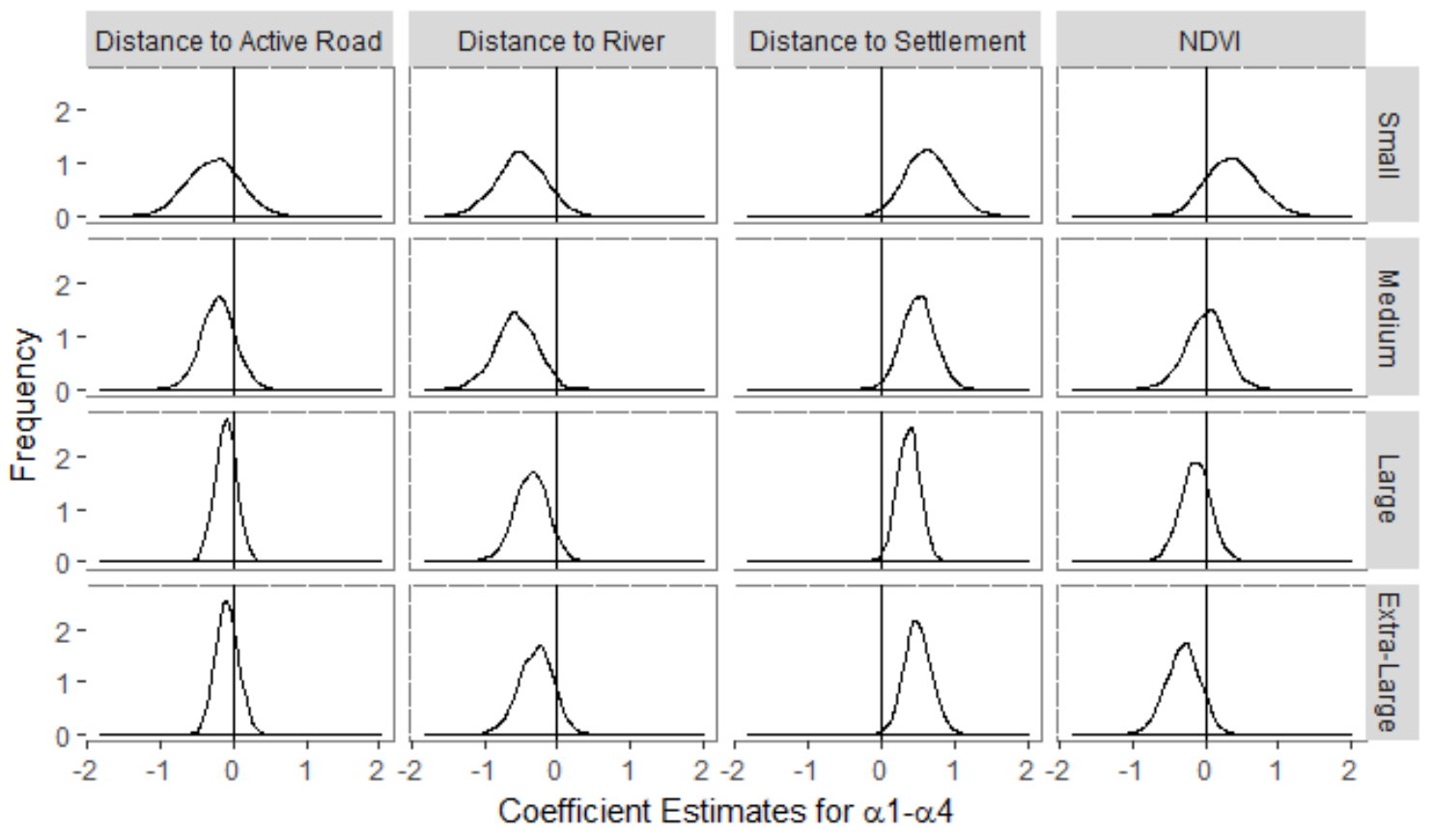

Figure 2.6 Posterior distributions of the occupancy model coefficient estimates for each body size group. 


\section{GENERAL CONCLUSIONS}

For my thesis research, I evaluated species interactions, space use and richness amid various anthropogenic and natural features hypothesized to influence occupancy and abundance. In the first chapter, I found that after accounting for imperfect detection and variation in habitat preferences, civet site use negatively influenced bushy-tailed mongoose site use, while genets were unaffected by civets and positively associated with mongoose. Although bushy-tailed mongoose were more strongly associated with forested areas than civets, the negative correlation between predicted abundances for this species pair indicates spatial niche partitioning and potentially local avoidance (Brodie et al. 2018). Genets were more likely to utilize areas closer to human settlements than mongoose and civets, but that mongoose and civets utilized sites farther away from settlements, and that they limit each other's site use is cause for concern for two reasons. First, diverse and abundant small carnivores provide ecosystem services such as seed dispersal and pest control (Roemer et al. 2009; Nakashima et al. 2010; Caughlin et al. 2014; Williams et al. 2017), but if species are avoiding local communities, they are not benefitting from such services. Second, several studies have demonstrated the suppression of small carnivores by apex predators (Palomares \& Caro 1999; PasanenMortensen et al. 2013; Ramesh et al. 2017). As large carnivores recover in the region, they may push civets, mongoose, and the other small carnivores in our system to suboptimal areas (i.e. close to settlements), or suppress these species' populations altogether. 
In the second chapter, we found that community and group-level richness was strongly associated with settlement proximity, while responses to environmental factors varied more among individual species. Although human settlements had a significant influence on occupancies, active roads and human/vehicle activity rates had no significant effect on any of the 30 species' occupancy or detection, respectively, indicating avoidance only of areas with permanent human presence. Our results are supported by several other studies, and researchers have proposed several reasons for this negative relationship, such as: habitat degradation, higher amounts of hunting, and human-wildlife conflict all surrounding and within permanent settlements (Bowkett et al. 2008; Epps et al. 2011; Burton et al. 2012; Carter et al. 2013; Schuette et al. 2013, 2016; Kiffner et al. 2015; Williams et al. 2017). Of these explanations, overexploitation of wildlife through illegal bushmeat hunting seems to be the most plausible explanation at our site, as snaring for bushmeat consumption and wildlife trade is prolific, though spatial patterns of snaring warrant further investigation (Lindsey et al. 2012). While future studies should investigate the causes for species' avoidance of settlements, results from this study provide a starting point for connectivity planning between protected areas in the Greater Gorongosa region.

\section{References}

Bowkett AE, Rovero F, Marshall AR. 2008. The use of camera-trap data to model habitat use by antelope species in the Udzungwa Mountain forests, Tanzania. African Journal of Ecology 46:479-487.

Brodie JF, Helmy OE, Mohd-Azlan J, Granados A, Bernard H, Giordano AJ, Zipkin E. 2018. Models for assessing local-scale co-abundance of animal species while accounting for differential detectability and varied responses to the environment. Biotropica 50:5-15. 
Burton AC, Sam MK, Balangtaa C, Brashares JS. 2012. Hierarchical multi-species modeling of carnivore responses to hunting, habitat and prey in a West African protected area. PLoS ONE 7.

Carter NH, Gurung B, Viña A, Campa III H, Karki JB, Liu J. 2013. Assessing spatiotemporal changes in tiger habitat across different land management regimes. Ecosphere 4:124.

Caughlin TT, Ferguson JM, Lichstein JW, Zuidema PA, Bunyavejchewin S, Levey DJ. 2014. Loss of animal seed dispersal increases extinction risk in a tropical tree species due to pervasive negative density dependence across life stages. Proceedings of the Royal Society B: Biological Sciences 282:2014209520142095.

Epps CW, Mutayoba BM, Gwin L, Brashares JS. 2011. An empirical evaluation of the African elephant as a focal species for connectivity planning in East Africa. Diversity and Distributions 17:603-612.

Kiffner C, Wenner C, LaViolet A, Yeh K, Kioko J. 2015. From savannah to farmland: effects of land-use on mammal communities in the Tarangire-Manyara ecosystem, Tanzania. African Journal of Ecology 53:156-166.

Lindsey P, Bento C, Traffic. 2012. Illegal Hunting and the Bushmeat Trade in Central Mozambique: a Case-Study From Coutada 9, Manica Province.

Nakashima Y, Inoue E, Inoue-Murayama M, Abd. Sukor JR. 2010. Functional uniqueness of a small carnivore as seed dispersal agents: a case study of the common palm civets in the Tabin Wildlife Reserve, Sabah, Malaysia. Oecologia 164:721-730.

Palomares F, Caro TM. 1999. Interspecific killing among mammalian carnivores. The American Naturalist 153:492-508.

Pasanen-Mortensen M, Pyykönen M, Elmhagen B. 2013. Where lynx prevail, foxes will fail - limitation of a mesopredator in Eurasia. Global Ecology and Biogeography 22:868-877. 
Ramesh T, Kalle R, Downs CT. 2017. Staying safe from top predators: patterns of cooccurrence and inter-predator interactions. Behavioral Ecology and Sociobiology 71. Behavioral Ecology and Sociobiology.

Roemer GW, Gompper ME, Van Valkenburgh B. 2009. The ecological role of the mammalian mesocarnivore. BioScience 59:165-173.

Schuette P, Creel S, Christianson D. 2016. Ungulate distributions in a rangeland with competitors, predators and pastoralists. Journal of Applied Ecology 53:10661077.

Schuette P, Wagner AP, Wagner ME, Creel S. 2013. Occupancy patterns and niche partitioning within a diverse carnivore community exposed to anthropogenic pressures. Biological Conservation 158:301-312.

Williams ST, Maree N, Taylor P, Belmain SR, Keith M, Swanepoel LH. 2017. Predation by small mammalian carnivores in rural agro-ecosystems: An undervalued ecosystem service? Ecosystem Services. 
APPENDIX A 


\section{Species information and species-specific model outputs from the community model}

\section{Table A.1 Mammals detected on cameras in a sustainable forestry concession outside of Gorongosa National Park.}

\begin{tabular}{|c|c|c|c|c|c|}
\hline Species & Species Name & Body Size & $\begin{array}{l}\text { Taxonomic or } \\
\text { Functional Group }\end{array}$ & $\begin{array}{l}\text { Total } \\
\text { Detections }\end{array}$ & $\begin{array}{l}\text { Mean Detection } \\
\text { Rate/100 Days }\end{array}$ \\
\hline Aardvark & Orycteropus afer & Large & Insectivore & 7 & $0.38(1.39)$ \\
\hline Baboon & Papio ursinus & Medium & Primate & 147 & $7.43(7.94)$ \\
\hline Bushbuck & Tragelaphus scriptus & Medium & Ungulate & 36 & $1.86(3.58)$ \\
\hline Bushpig & Potamochoerus larvatus & Large & Ungulate & 12 & $0.50(1.64)$ \\
\hline Bushy tailed mongoose & Bdeogale crassicauda & Small & Carnivore & 168 & $6.13(11.36)$ \\
\hline Cane rat & Thryonomys gregorianus & Small & Other Forager & 6 & $0.33(1.69)$ \\
\hline Civet & Civettictis civetta & Medium & Carnivore & 120 & $4.60(10.87)$ \\
\hline Common duiker & Sylvicapra grimmia & Medium & Ungulate & 267 & $12.42(15.64)$ \\
\hline Eland & Taurotragus oryx & Extra-Large & Ungulate & 6 & $0.27(1.13)$ \\
\hline Galago & Otolemur crassicaudatus & Small & Primate & 4 & $0.25(1.79)$ \\
\hline Genet & Genetta genetta & Small & Carnivore & 152 & $5.83(16.83)$ \\
\hline Honey badger & Mellivora capensis & Medium & Carnivore & 5 & $0.26(1.03)$ \\
\hline Kudu & Tragelaphus strepsiceros & Extra-Large & Ungulate & 7 & $0.42(1.55)$ \\
\hline Leopard & Panthera pardus & Large & Carnivore & 8 & $0.27(0.98)$ \\
\hline Lichtenstein's hartebeest & Alcelaphus lichtensteinii & Large & Ungulate & 3 & $0.13(0.91)$ \\
\hline Marsh mongoose & Atilax paludinosus & Small & Carnivore & 40 & $1.79(6.46)$ \\
\hline Nyala & Tragelaphus angasii & Large & Ungulate & 5 & $0.26(1.01)$ \\
\hline Oribi & Ourebia ourebi & Medium & Ungulate & 17 & $0.53(2.61)$ \\
\hline Pangolin & Smutsia gigantea & Medium & Insectivore & 2 & $0.08(0.52)$ \\
\hline Porcupine & Hystrix cristata & Medium & Other Forager & 27 & $1.35(3.97)$ \\
\hline Pouched rat & Cricetomys gambianus & Small & Other Forager & 53 & $2.46(7.27)$ \\
\hline Red duiker & Cephalophus natalensis & Medium & Ungulate & 42 & $1.77(3.71)$ \\
\hline Reedbuck & Redunca arundinum & Medium & Ungulate & 5 & $0.26(1.04)$ \\
\hline Sable & Hippotragus niger & Extra-Large & Ungulate & 5 & $0.22(1.06)$ \\
\hline Samango & Cercopithecus albogularis & Medium & Primate & 18 & $0.52(2.68)$ \\
\hline Scrub hare & Lepus saxatilis & Small & Other Forager & 106 & $4.68(14.05)$ \\
\hline Serval & Leptailurus serval & Medium & Carnivore & 12 & $0.52(1.44)$ \\
\hline Suni & Neotragus moschatus & Small & Ungulate & 95 & $4.24(13.92)$ \\
\hline Warthog & Phacochoerus africanus & Large & Ungulate & 10 & $0.42(1.42)$ \\
\hline White tailed mongoose & Ichneumia albicauda & Small & Carnivore & 6 & $0.25(1.37)$ \\
\hline
\end{tabular}


Table A.2 Mean detection probabilities and coefficient estimates for each species. Standard deviations are in parentheses. Coefficient estimates are on the logit-scale, and estimates in bold indicate $95 \%$ credibility intervals that do not overlap zero.

\begin{tabular}{|c|c|c|c|c|c|}
\hline Species & $\begin{array}{l}\text { Detection } \\
\text { Probability }\end{array}$ & $\begin{array}{l}\text { Single/Paired } \\
\text { Cameras (0/1) }\end{array}$ & $\begin{array}{l}\text { Off/On } \\
\text { Trail (0/1) }\end{array}$ & $\mathrm{NDVI}_{30 \mathrm{~m}}$ & $\begin{array}{l}\text { Human/Vehicle } \\
\text { Detection Rate }\end{array}$ \\
\hline Aardvark & $0.01(0.01)$ & $0.14(0.41)$ & $-0.42(0.74)$ & $-0.13(0.36)$ & $0.02(0.48)$ \\
\hline Baboon & $0.08(0.02)$ & $0(0.22)$ & $-0.20(0.33)$ & $0.08(0.37)$ & $-0.06(0.49)$ \\
\hline Bushbuck & $0.04(0.03)$ & $0.15(0.40)$ & $0.03(0.75)$ & $0.13(0.21)$ & $0.03(0.14)$ \\
\hline Bushpig & $0.01(0.01)$ & $-0.06(0.45)$ & $-0.03(0.89)$ & $0.07(0.35)$ & $0.03(0.49)$ \\
\hline Bushy tailed mongoose & $0.09(0.04)$ & $0.16(0.46)$ & $0.08(0.62)$ & $-0.36(0.14)$ & $0.02(0.23)$ \\
\hline Cane rat & $0.02(0.02)$ & $0.12(0.45)$ & $0.48(0.72)$ & $0.36(0.38)$ & $0.01(0.50)$ \\
\hline Civet & $0.09(0.03)$ & $0.32(0.36)$ & $0.41(0.44)$ & $-0.08(0.33)$ & $-0.18(0.58)$ \\
\hline Common duiker & $0.15(0.03)$ & $0.12(0.25)$ & $-0.03(0.87)$ & $-0.04(0.31)$ & $-0.15(0.31)$ \\
\hline Eland & $0.02(0.01)$ & $0.10(0.41)$ & $-0.35(0.89)$ & $-0.03(0.37)$ & $-0.06(0.51)$ \\
\hline Galago & $0.05(0.04)$ & $-0.12(0.49)$ & $-0.17(0.96)$ & $0.11(0.35)$ & $-0.07(0.50)$ \\
\hline Genet & $0.16(0.03)$ & $-0.39(0.46)$ & $0(0.87)$ & $0.18(0.20)$ & $-0.09(0.51)$ \\
\hline Honey badger & $0.01(0.01)$ & $0.01(0.41)$ & $-0.03(0.88)$ & $0.06(0.33)$ & $0.02(0.50)$ \\
\hline Kudu & $0.01(0.01)$ & $0.04(0.49)$ & $-0.03(0.89)$ & $0.01(0.34)$ & $0.03(0.47)$ \\
\hline Leopard & $0.01(0.01)$ & $0.03(0.47)$ & $-0.01(0.88)$ & $0.02(0.35)$ & $0.01(0.35)$ \\
\hline Lichtenstein's hartebeest & $0.02(0.02)$ & $0.13(0.44)$ & $-0.24(0.77)$ & $-0.09(0.37)$ & $0.03(0.51)$ \\
\hline Marsh mongoose & $0.09(0.03)$ & $0.05(0.48)$ & $-0.01(0.92)$ & $0.15(0.36)$ & $-0.09(0.43)$ \\
\hline Nyala & $0.01(0.01)$ & $0.02(0.43)$ & $-0.08(0.62)$ & $-0.08(0.38)$ & $0.04(0.51)$ \\
\hline Oribi & $0.06(0.05)$ & $0.04(0.49)$ & $0.20(0.68)$ & $0(0.38)$ & $-0.03(0.49)$ \\
\hline Pangolin & $0.01(0.01)$ & $0.04(0.43)$ & $-0.27(0.88)$ & $0.04(0.38)$ & $0.03(0.48)$ \\
\hline Porcupine & $0.04(0.02)$ & $0.06(0.42)$ & $0.68(0.59)$ & $-0.03(0.19)$ & $-0.03(0.52)$ \\
\hline Pouched rat & $0.10(0.04)$ & $0.21(0.47)$ & $-0.51(0.77)$ & $0.09(0.21)$ & $-0.06(0.48)$ \\
\hline Red duiker & $0.05(0.01)$ & $0.01(0.27)$ & $-0.01(0.88)$ & $-0.38(0.32)$ & $-0.03(0.46)$ \\
\hline Reedbuck & $0.01(0.01)$ & $-0.07(0.47)$ & $0(0.89)$ & $-0.03(0.33)$ & $0.04(0.51)$ \\
\hline Sable & $0.01(0.01)$ & $-0.12(0.48)$ & $0.11(0.62)$ & $0.13(0.35)$ & $0.04(0.51)$ \\
\hline Samango & $0.05(0.03)$ & $0.11(0.45)$ & $0.42(0.50)$ & $-0.26(0.37)$ & $0.06(0.48)$ \\
\hline Scrub hare & $0.15(0.03)$ & $0.19(0.39)$ & $0(0.86)$ & $0.15(0.17)$ & $-0.08(0.50)$ \\
\hline Serval & $0.03(0.03)$ & $0.00(0.46)$ & $-0.16(0.74)$ & $0.03(0.36)$ & $-0.22(0.47)$ \\
\hline Suni & $0.09(0.04)$ & $0.16(0.45)$ & $0.46(0.68)$ & $-0.20(0.30)$ & $0.18(0.27)$ \\
\hline Warthog & $0.01(0.01)$ & $0.03(0.41)$ & $-0.40(0.90)$ & $0.13(0.29)$ & $0.03(0.48)$ \\
\hline White tailed mongoose & $0.02(0.02)$ & $-0.03(0.45)$ & $-0.26(0.77)$ & $-0.07(0.31)$ & $0.14(0.16)$ \\
\hline
\end{tabular}


Table A.3 Mean occupancy probabilities and coefficient estimates for each species. Standard deviations are in parentheses. Coefficient estimates are on the logit-scale, and estimates in bold indicate $95 \%$ credibility intervals that do not overlap zero.

\begin{tabular}{|c|c|c|c|c|c|}
\hline Species & $\begin{array}{l}\text { Occupancy } \\
\text { Probability }\end{array}$ & $\begin{array}{l}\text { Distance to } \\
\text { River }\end{array}$ & NDVI & $\begin{array}{l}\text { Distance to } \\
\text { Settlement }\end{array}$ & $\begin{array}{l}\text { Distance to } \\
\text { Active Roads }\end{array}$ \\
\hline Aardvark & $0.36(0.22)$ & $-0.46(0.63)$ & $-0.37(0.47)$ & $0.32(0.33)$ & $-0.09(0.20)$ \\
\hline Baboon & $0.86(0.06)$ & $0.24(0.38)$ & $-0.51(0.44)$ & $0.23(0.30)$ & $-0.08(0.18)$ \\
\hline Bushbuck & $0.47(0.12)$ & $0.01(0.34)$ & $-0.07(0.39)$ & $0.35(0.26)$ & $-0.12(0.18)$ \\
\hline Bushpig & $0.37(0.17)$ & $-0.68(0.53)$ & $0.71(0.59)$ & $0.46(0.31)$ & $-0.16(0.19)$ \\
\hline Bushy tailed mongoose & $0.50(0.07)$ & $-0.28(0.27)$ & $0.42(0.28)$ & $0.63(0.24)$ & $-0.20(0.16)$ \\
\hline Cane rat & $0.15(0.11)$ & $-1.02(0.61)$ & $-0.33(0.56)$ & $0.43(0.29)$ & $-0.13(0.19)$ \\
\hline Civet & $0.38(0.06)$ & $-0.52(0.28)$ & $-0.15(0.27)$ & $0.52(0.22)$ & $-0.13(0.15)$ \\
\hline Common duiker & $0.75(0.06)$ & $0.78(0.37)$ & $-0.79(0.33)$ & $0.29(0.24)$ & $-0.17(0.16)$ \\
\hline Eland & $0.23(0.18)$ & $0(0.62)$ & $-0.37(0.56)$ & $0.45(0.31)$ & $-0.09(0.20)$ \\
\hline Galago & $0.06(0.06)$ & $-0.28(0.54)$ & $-0.59(0.48)$ & $0.36(0.31)$ & $-0.11(0.20)$ \\
\hline Genet & $0.30(0.06)$ & $-0.28(0.26)$ & $0.26(0.27)$ & $0.55(0.21)$ & $-0.20(0.16)$ \\
\hline Honey badger & $0.34(0.21)$ & $-0.15(0.62)$ & $-0.29(0.60)$ & $0.51(0.32)$ & $-0.12(0.20)$ \\
\hline Kudu & $0.34(0.21)$ & $0.46(0.58)$ & $-0.60(0.51)$ & $0.14(0.37)$ & $-0.08(0.19)$ \\
\hline Leopard & $0.22(0.15)$ & $-1.22(0.69)$ & $0.49(0.54)$ & $0.52(0.34)$ & $-0.11(0.19)$ \\
\hline Lichtenstein's hartebeest & $0.11(0.11)$ & $0.40(0.61)$ & $0.15(0.56)$ & $0.49(0.30)$ & $-0.09(0.20)$ \\
\hline Marsh mongoose & & $-0.81(0.39)$ & & $0.32(0.25)$ & $-0.09(0.17)$ \\
\hline Nyala & $0.28(0.18)$ & $-1.01(0.71)$ & $-0.53(0.51)$ & $0.38(0.32)$ & $-0.13(0.19)$ \\
\hline Oribi & $0.08(0.04)$ & $0.08(0.42)$ & $-0.51(0.42)$ & $0.68(0.32)$ & $-0.09(0.18)$ \\
\hline Pangolin & $0.21(0.19)$ & $-0.45(0.70)$ & $0.16(0.62)$ & $0.38(0.32)$ & $-0.18(0.20)$ \\
\hline Porcupine & $0.26(0.09)$ & $0.01(0.34)$ & $0.17(0.34)$ & $0.16(0.28)$ & $-0.14(0.17)$ \\
\hline Pouched rat & $0.13(0.05)$ & $-1.14(0.46)$ & $0.24(0.32)$ & $0.39(0.26)$ & $-0.08(0.18)$ \\
\hline Red duiker & $0.33(0.09)$ & $-1.00(0.44)$ & $0.63(0.40)$ & $0.36(0.24)$ & $-0.18(0.17)$ \\
\hline Reedbuck & $0.25(0.17)$ & $0.21(0.58)$ & $-0.89(0.57)$ & $0.39(0.31)$ & $-0.19(0.20)$ \\
\hline Sable & $0.30(0.20)$ & $-0.27(0.65)$ & $-0.35(0.64)$ & $0.56(0.35)$ & $-0.05(0.22)$ \\
\hline Samango & $0.05(0.03)$ & $-1.03(0.55)$ & $0.30(0.41)$ & $0.35(0.30)$ & $-0.12(0.19)$ \\
\hline Scrub hare & $0.19(0.05)$ & $-0.05(0.30)$ & $-0.38(0.31)$ & $0.81(0.31)$ & $-0.18(0.16)$ \\
\hline Serval & $0.29(0.15)$ & $-0.60(0.55)$ & $-0.63(0.48)$ & $0.56(0.29)$ & $-0.16(0.18)$ \\
\hline Suni & $0.19(0.05)$ & $-0.79(0.34)$ & $0.63(0.33)$ & $0.29(0.24)$ & $-0.17(0.16)$ \\
\hline Warthog & $0.33(0.18)$ & $-1.09(0.65)$ & $-0.30(0.55)$ & $0.40(0.30)$ & $-0.15(0.19)$ \\
\hline White tailed mongoose & $0.16(0.12)$ & $-0.25(0.55)$ & $0.02(0.53)$ & $0.64(0.34)$ & $-0.15(0.18)$ \\
\hline
\end{tabular}




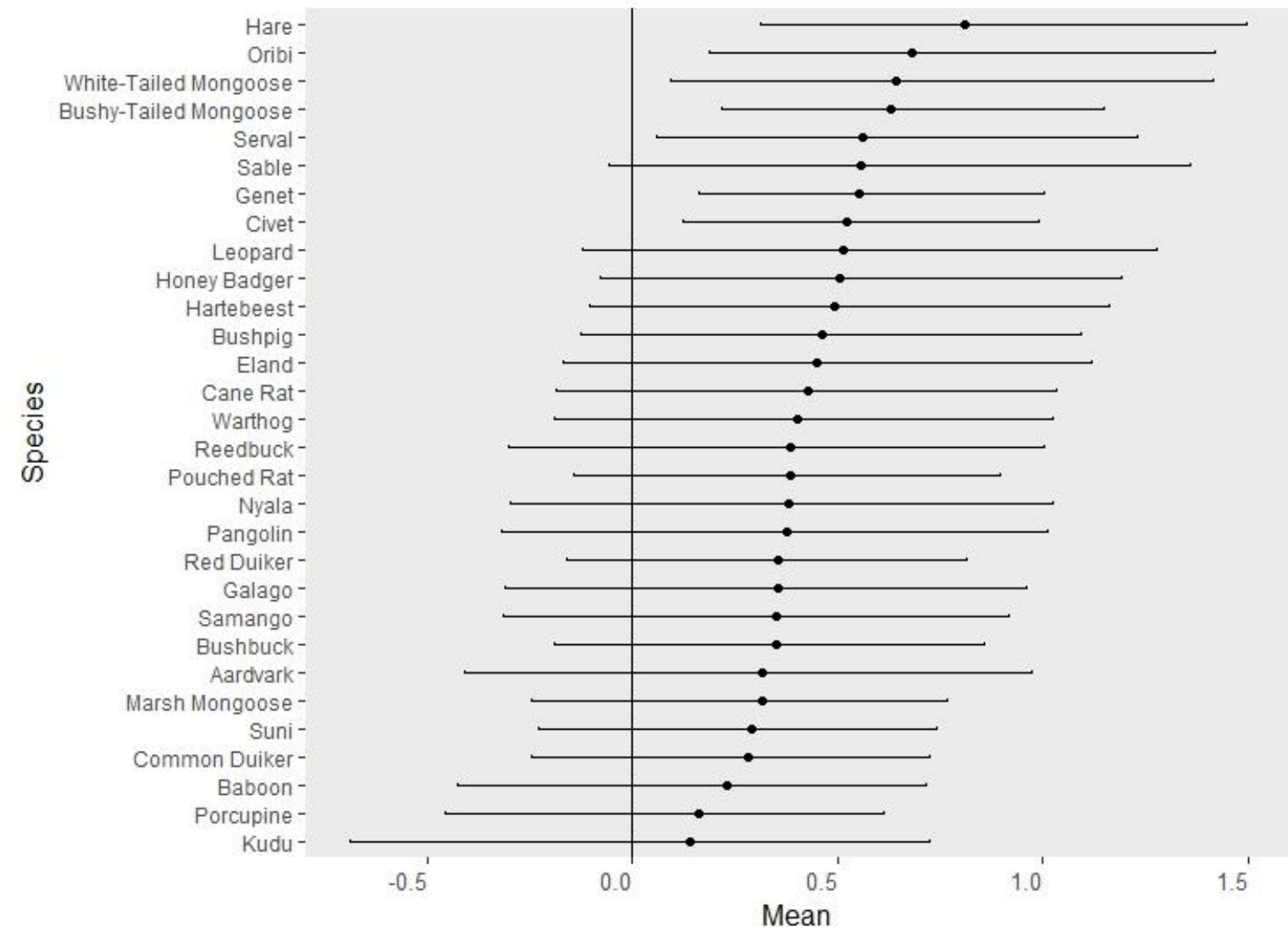

Figure A.1 Mean species-specific coefficient estimates for distance to settlement with $95 \%$ credibility bars. 


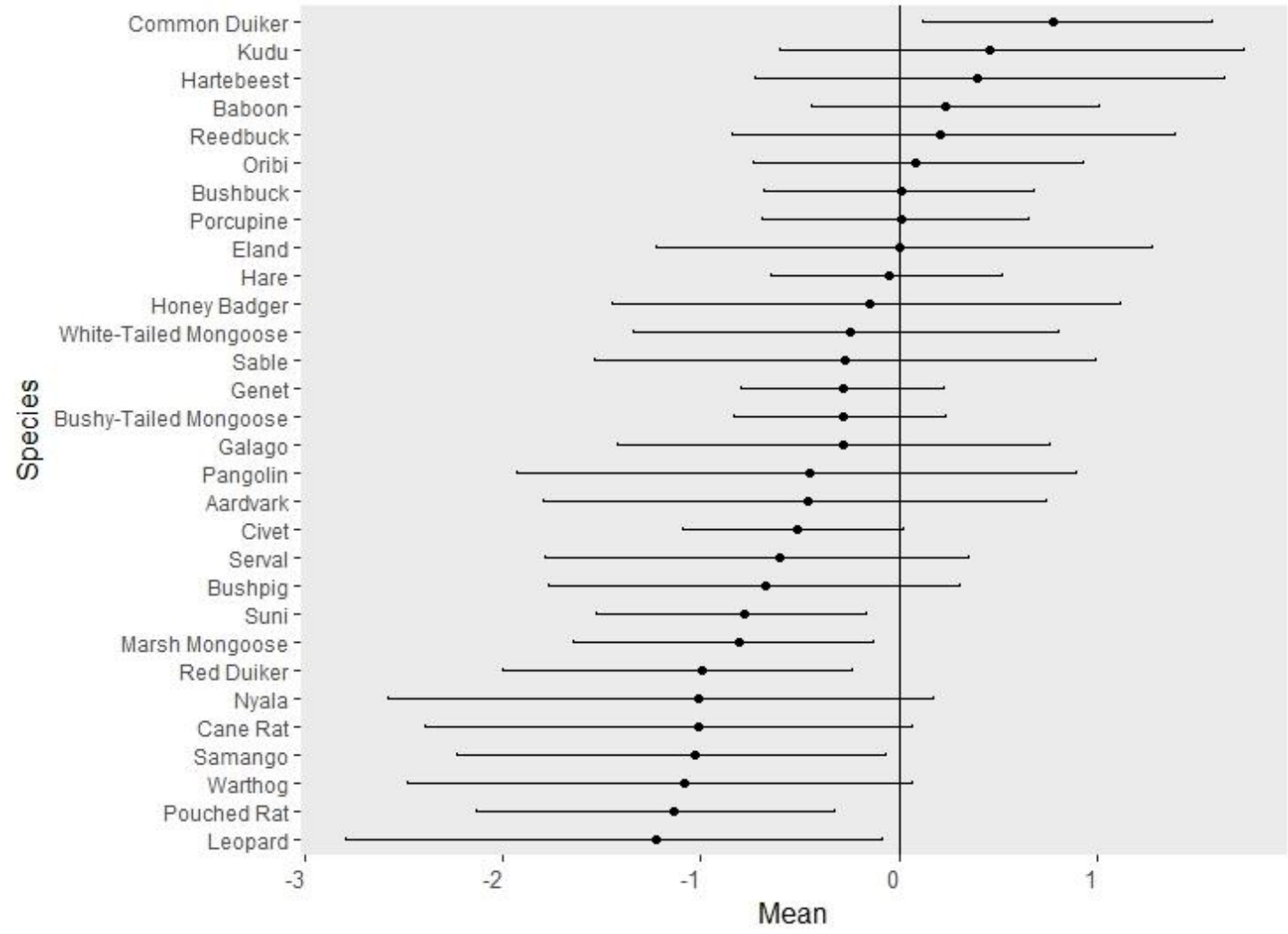

Figure A.2 Mean species-specific coefficient estimates for distance to rivers with $\mathbf{9 5 \%}$ credibility bars. 


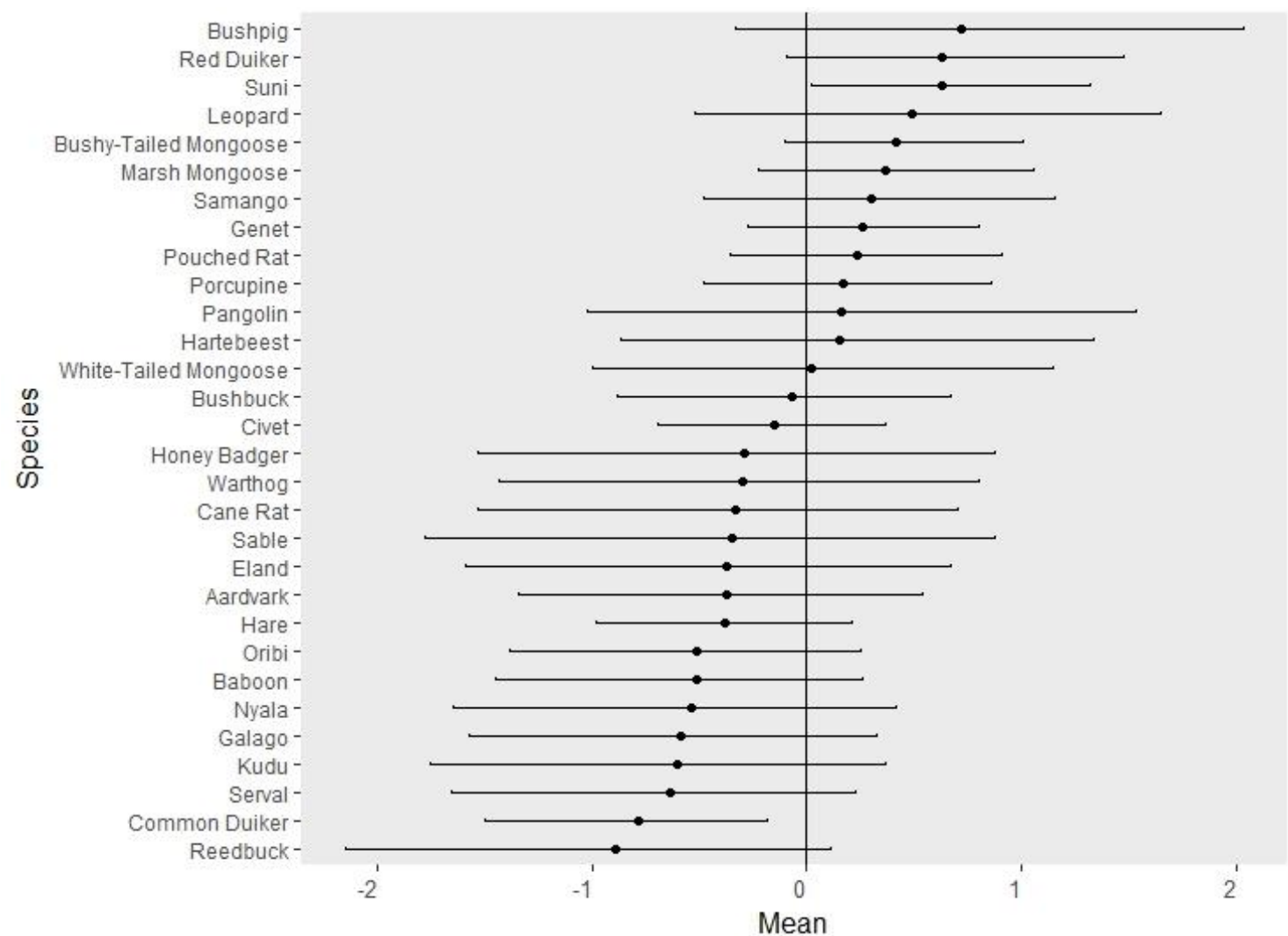

Figure A.3 Mean species-specific coefficient estimates for NDVI with $95 \%$ credibility bars. 


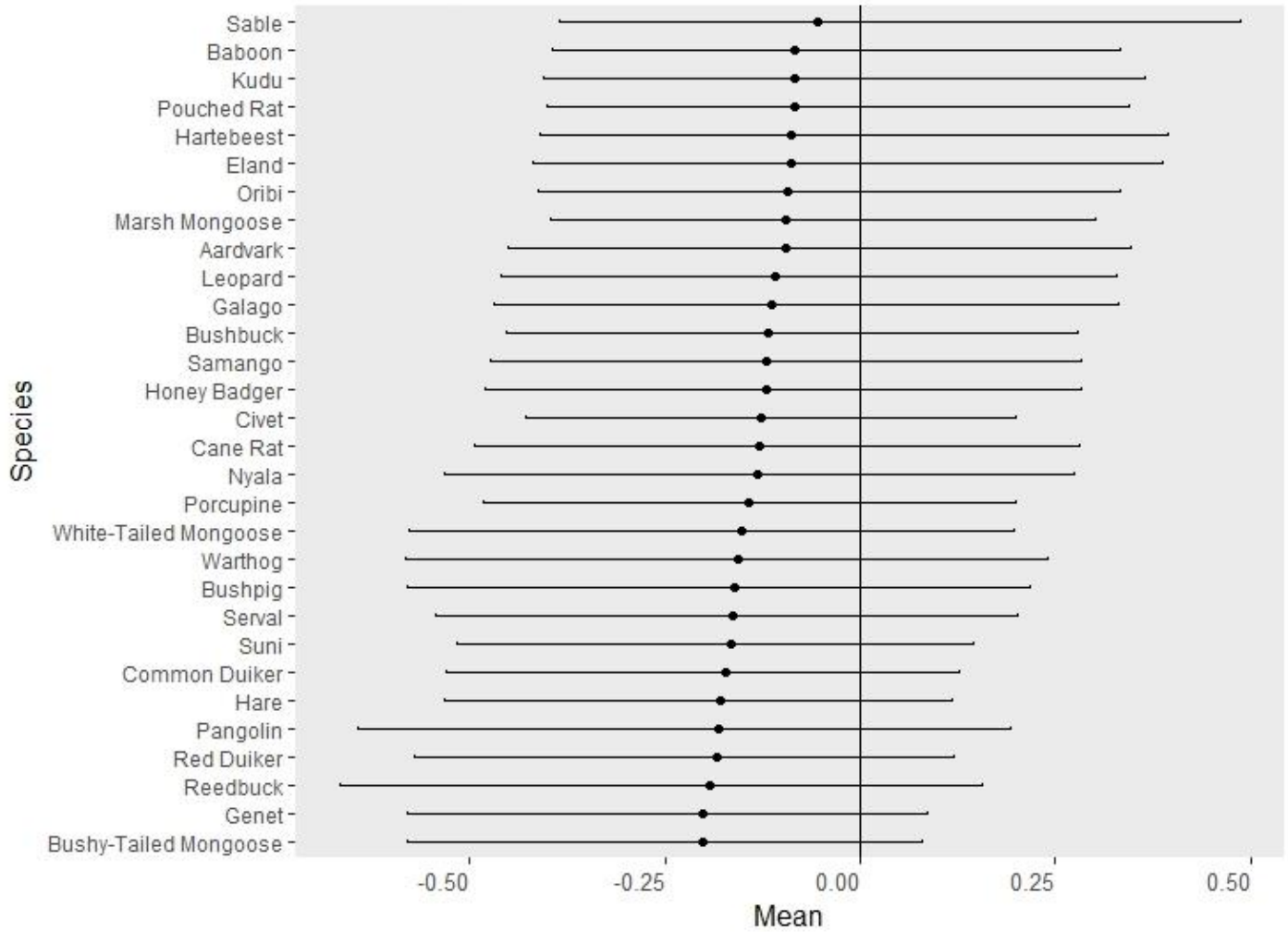

Figure A.4 Mean species-specific coefficient estimates for distance to active roads with $95 \%$ credibility bars. 


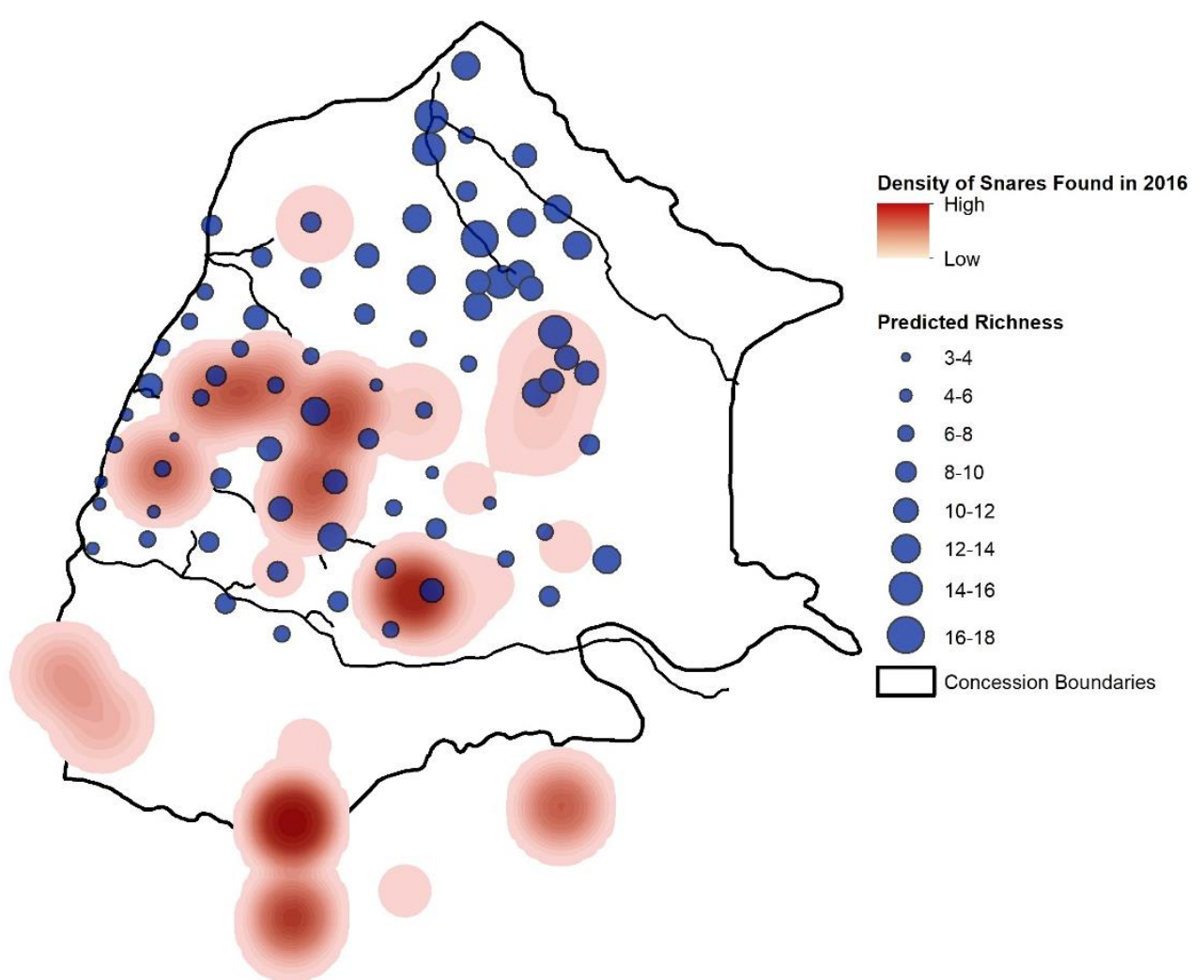

Figure A.5 Kernel density estimates for snares seized $(n=468)$ by concession rangers in 2016. Snares included wire, rope, and gin traps. Patrols were nonsystematic. 
APPENDIX B 


\section{Further explanation of the use of NDVI for land cover and habitat types}

For chapters one and two of this these, we used NDVI to represent habitat types, tree cover, and forage availability. This is not uncommon for occupancy analyses but merits further explanation. At our study site, the habitats are made up of miombo woodlands with various tree densities. More open areas, such as grasslands or bare soils, dry out in the dry season and turn brown. Whereas closed-canopy areas with high tree densities, and relatively little undergrowth occur near rivers, and remain deep green throughout the dry season. Such variations in greenness are apparent when looking at a satellite image, or an NDVI raster (Figure B1).
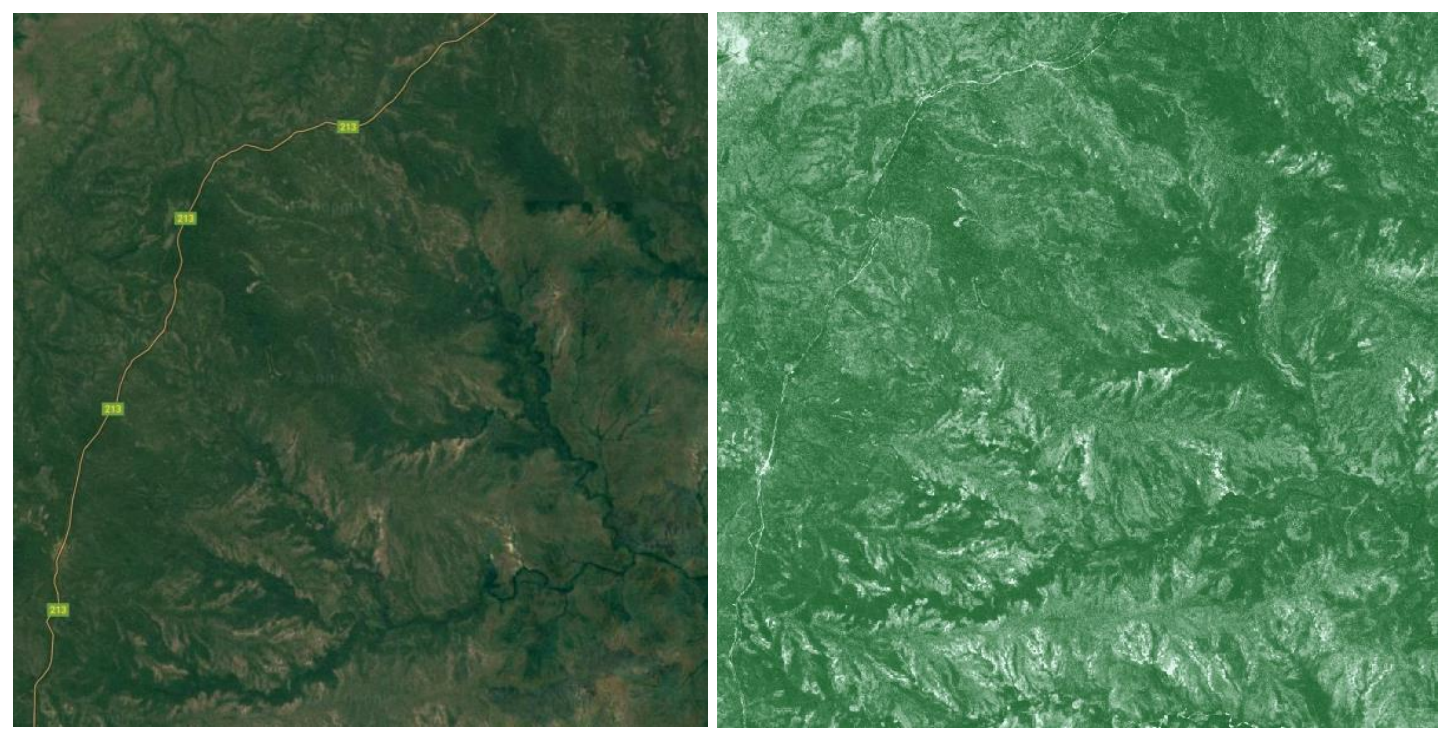

Figure B.1 Satellite image (left) and NDVI raster (right) of our study site.

To be sure, we ran an ANOVA to see how the mean NDVI values compared to the land classes we created using random forest from the same Landsat image. We only had three land classes, given the relative homogeneity of our site, and those were: grasslands and mixed savanna, mixed woodlands, and closed-canopy riparian forests. We expected that areas categorized as savannahs would have low, mean NDVI values, and 
areas categorized as riparian forests would have high, mean NDVI values. Indeed, the means were significantly different $\left(F_{2,72}=45.01, p<0.001\right)$, along the grdient that we expected. We therefore felt comfortable using NDVI as a representation of what we saw on the ground, understanding that this is a coarse measure of habitats and forage variation.

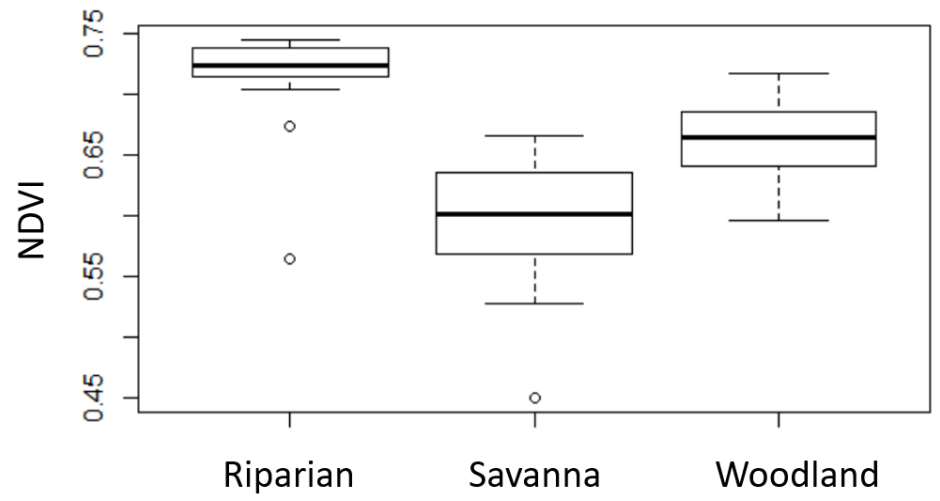

Figure B.2 NDVI values significantly differed between land cover categories $\left(F_{2,72}\right.$ $=45.01, p<0.001)$. 